\title{
MARCELO BELLI
}

Variações da função renal após paratireoidectomias por hiperparatireoidismo primário

Tese apresentada à Faculdade de Medicina da Universidade de São Paulo para obtenção do título de Doutor em Ciências

Programa de Clínica Cirúrgica

Orientador: Prof. Dr. Fábio Luiz de Menezes Montenegro

SÃO PAULO

2018 


\section{MARCELO BELLI}

Variações da função renal após paratireoidectomias por hiperparatireoidismo primário

Tese apresentada à Faculdade de Medicina da Universidade de São Paulo para obtenção do título de Doutor em Ciências

Programa de Clínica Cirúrgica

Orientador: Prof. Dr. Fábio Luiz de Menezes Montenegro

SÃO PAULO

2018 
Dados Internacionais de Catalogação na Publicação (CIP)

Preparada pela Biblioteca da

Faculdade de Medicina da Universidade de São Paulo

Creprodução autorizada pelo autor

Belli, Marcelo

Variações da função renal após paratireoidectomias por hiperparatireoidismo primário / Marcelo Belli. - São Paulo, 2018.

Tese(doutorado)--Faculdade de Medicina da Universidade de São Paulo.

Programa de Clínica Cirúrgica.

Orientador: Fábio Luiz de Menezes Montenegro.

Descritores: 1.Hiperparatireoidismo primário 2.Paratireoidectomia 3. Taxa de filtração glomerular 4. Lesão renal aguda 5. Insuficiência renal crônica 6.Hipercalcemia 7.Hormônio paratireóideo

$\mathrm{USP} / \mathrm{FM} / \mathrm{DBD}-015 / 18$ 


\section{DEDICATÓRIA}

À minha esposa Mariana, com amor, admiração e gratidão por sua compreensão, carinho, e incansável apoio ao longo do período de elaboração deste trabalho. 


\section{AGRADECIMENTOS}

À minha esposa Mariana Vilela Soares Gomes e à minha filha Helena Vilela Belli, pelo amoroso apoio e companheirismo nesta empreitada longa e de superação.

Aos meus pais Márcio e Maria da Graça, por todo amor e educação recebidos, e por me incentivarem a seguir minha vocação como médico.

Ao Prof. Dr. Fábio Luiz de Menezes Montenegro, por ter me confiado a tarefa de continuar a sua linha de pesquisa, assim como de me motivar a cursar o Doutorado. Sua seriedade, honestidade e inteligência ímpares, são admiradas por todos os que o cercam e que usufruem dos seus ensinamentos.

Aos meus sócios e grandes amigos Gustavo Nunes Bento, Kauê Milanez Lopes e Francisco Van de Sande Lee, pela paciência do convívío e pelo trabalho extra nas minhas inúmeras ausências, durante a elaboração deste trabalho.

Ao Prof. Dr. Luiz Roberto Medina dos Santos, pela amizade e pelo prazeroso convívio durante os meus primeiros anos como especialista. Os valiosos ensinamentos e o primor da técnica cirúrgica serão transmitidos às gerações futuras.

Ao Prof. Dr. Lenine Garcia Brandão, e ao Departamento de Cirurgia de Cabeça e Pescoço do HCFMUSP, pela honra de me acolherem como residente da especialidade, e também pela oportunidade concedida à realização da pósgraduação. 
"There is nothing wrong in change, if it is in the right direction. To improve is to change, so to be perfect is to have changed often."

"Não há nada errado em mudar, se for na direção correta. Evoluir é mudar, portanto ser perfeito é ter mudado frequentemente."

Sir Winston Churchill, Junho de 1925.

Churchill: In His Own Words 


\section{NORMATIZAÇÃO ADOTADA}

Esta dissertação está de acordo com as seguintes normas, em vigor no momento desta publicação:

Referências: adaptado de International Committee of Medical Journals Editors (Vancouver)

Universidade de São Paulo. Faculdade de Medicina. Serviço de Biblioteca e Documentação. Guia de apresentação de dissertações, teses e monografias. Elaborado por Anneliese Carneiro da Cunha, Maria Júlia de A. L. Freddi, Maria F. Crestana, Marinalva de Souza Aragão, Suely Campos Cardoso, Valéria Vilhena. 2. ed. Revisada e Ampliada. São Paulo: Serviço de Biblioteca e Documentação; 2009.

Abreviaturas dos títulos dos periódicos de acordo com List of Journals Indexed in Index Medicus

A ortografia da Língua Portuguesa adotada está conforme o Acordo Ortográfico da Língua Portuguesa, assinado em Lisboa, em 16 de dezembro de 1990, por Portugual, Brasil, Angola, São Tomé e Príncipe, Cabo Verde, Guiné-Bissau, Moçambique e, posteriormente, por Timor Leste. Decreto Legislativo Brasileiro $n^{\circ} 54$, aprovado em 18 de abril de 1995 e em vigor desde $1^{\circ}$ de janeiro de 2009. 


\section{RESUMO}

Belli M. Variações da função renal após paratireoidectomias por hiperparatireoidismo primário [tese]. São Paulo: Faculdade de Medicina, Universidade de São Paulo; 2018.

INTRODUÇÃO: Em pacientes transplantados renais, a paratireoidectomia está associada à piora aguda da função renal. Os efeitos agudos e crônicos da paratireoidectomia sobre a filtração glomerular foram pouco estudados em Hiperparatireoidismo Primário (HPTP). MÉTODO E CASUÍSTICA: Neste estudo retrospectivo de coorte, foram estudados 494 pacientes submetidos a paratireoidectomia por HPTP, entre os anos de 2007 e 2016. Variações agudas da creatinina foram aferidas diariamente na internação, até o $4^{\circ}$ pós-operatório, sendo classificados conforme os critérios de KDIGO para IRA. Dados bioquímicos incluíram dosagem sérica de creatinina, cálcio iônico e total, paratormônio (PTH) e 25-OH vitamina D. A taxa de filtração glomerular foi estimada a partir da equação CKD-EPI. Foram comparados dados de função renal pré e pós-operatórios até 5 anos de seguimento. RESULTADOS: Dos 494 pacientes, 391 (79,1\%) eram mulheres e 422 $(85,4 \%)$ de cor branca. A causa mais comum de HPTP foi adenoma de paratireóide (351, 71,1\%) e a mediana de idade foi de 58 anos. As medianas (Q1-Q3) de creatinina, PTH e cálcio total séricos foram de: $0,81 \mathrm{mg} / \mathrm{dL}(0,68-1,01), 154,5 \mathrm{pg} / \mathrm{mL}$ $(106-238,5)$ e $10,9 \mathrm{mg} / \mathrm{dL}(10,3-11,5)$ respectivamente. A mediana de eGFR préoperatória foi de $86 \mathrm{~mL} / \mathrm{min} \times 1,73 \mathrm{~m}^{2}$. No período agudo, houve redução mediana de $26 \mathrm{~mL} / \mathrm{min} \times 1,73 \mathrm{~m}^{2}$ na eGFR $(p<0,0001)$, que representou $-27,44 \%( \pm 19,12 \%)$ de variação aguda da eGFR. De acordo com os critérios de IRA, $41,1 \%$ dos pacientes tiveram IRA estágio $1,5,9 \%$ estágio 2 e $1,8 \%$ estágio 3 . Outros 223 pacientes $(45,1 \%)$ tiveram elevação da creatinina porém não preencheram critérios de IRA. Na análise univariada foram observadas correlações fracas, porém significativas, entre o percentual de variação aguda de eGFR e os seguintes fatores pré-operatórios: idade, PTH, cálcio e creatinina. Uma redução definitiva da eGFR foi observada em 
60,7\% dos pacientes, após 12 meses de seguimento. CONCLUSÃO: Houve significativa redução aguda da função renal após paratireoidectomia por HPTP, sendo que quase metade dos pacientes preencheram critérios de IRA. Observou-se importante recuperação da eGFR no primeiro mês de pós-operatório, podendo ocorrer algum grau de perda definitva de função renal.

Descritores: hiperparatireoidismo primário; paratireoidectomia; taxa de filtração glomerular; lesão renal aguda; insuficiência renal crônica; hipercalcemia; hormônio paratireóideo 


\section{ABSTRACT}

Belli M. Acute and long-term kidney function after parathyroidectomy for primary hyperparathyroidism [thesis]. São Paulo: "Faculdade de Medicina, Universidade de São Paulo"; 2018.

INTRODUCTION: In kidney transplant patients, parathyroidectomy is associated with acute decrease in renal function. Acute and chronic effects of parathyroidectomy on renal function have not been as extensively studied in primary hyperparathyroidism (PHPT). PATIENTS AND METHODS: Retrospective cohort study of 494 patients undergoing parathyroidectomy for PHPT. Acute renal changes were evaluated daily until day 4 post parathyroidectomy, and stratified according to acute kidney injury $(\mathrm{AKI})$ criteria. Biochemical assessment included serum creatinine, total and ionized calcium, PTH, and 25-hydroxyvitamin D (25OHD). EGFR were calculated using the CKD-EPI equation. We compared preoperative and postoperative renal function up to 5 years of follow-up. RESULTS: 391 (79.1\%) patients were female and 422 (85.4\%) were non-African American. Median age was 58 years old. Median (interquartile range) preoperative serum creatinine, $\mathrm{PTH}$ and total calcium were $0.81 \mathrm{mg} / \mathrm{dL}(0.68$ 1.01), $154.5 \mathrm{pg} / \mathrm{mL}$ (106-238.5), and $10.9 \mathrm{mg} / \mathrm{dL}$ (10.3-11.5) respectively. Median (interquartile range) preoperative eGFR was $86 \mathrm{~mL} / \mathrm{min} / 1.73 \mathrm{~m} 2$ (65-101.3). After surgery the median acute decrease in eGFR was $26 \mathrm{~mL} / \mathrm{min} / 1.73 \mathrm{~m} 2(p<0.0001)$. Acutely, 41.1\% patients developed AKI stage 1, 5.9\% AKI stage 2 and $1.8 \% \mathrm{AKI}$ stage 3. Acute eGFR decrease (\%) correlated with age, PTH, calcium and preoperative creatinine, in univariate analysis. Permanent reduction in eGFR occurred in $60.7 \%$ of the patients, after acute episode. CONCLUSION: There is a significant acute impairment in renal function after parathyroidectomy for PHPT and almost half of patients meet the criteria for AKI. Significant eGFR recovery was observed during first month after surgery, but a small permanent reduction may occur. 
Descriptors: hyperparathyroidism, primary; parathyroidectomy; glomerular filtration rate; acute kidney injury; renal insufficiency, chronic; hypercalcemia; parathyroid hormone 


\section{LISTA DE ABREVIATURAS}

250HD Valor medido da 25-hidroxi vitamina $\mathrm{D}$, em $\mathrm{ng} / \mathrm{mL}$

ADQI Acute Dialysis Quality Initiative - Tradução: Iniciativa de Qualidade em Diálise Aguda

AINE Anti-inflamatório não esteroidal

AKI $\quad$ Acute Kidney Injury - Tradução: Injúria Renal Aguda

ANOVA Análise da Variância

Basal Valor medido de qualquer exame laboratorial no período pré-operatório

Cal Valor medido do cálcio iônico sérico, em $\mathrm{mg} / \mathrm{dL}$

CaT Valor medido do cálcio total sérico, em $\mathrm{mg} / \mathrm{dL}$

CaU 24h Valor medido da calciúria de 24 horas, em mg/vol 24h

CKD-EPI Chronic Kidney Disease Epidemiology Collaboration - Tradução:

Colaboração Epidemiológica na Doença Renal Crônica

$\mathrm{Cr} \quad$ Valor medido da creatinina sérica, em $\mathrm{mg} / \mathrm{dL}$

Cr pré $\quad$ Valor medido da creatinina sérica no pré-operatório, em $\mathrm{mg} / \mathrm{dL}$

Cr PO Valor medido da creatinina no pós-operatório até 96 horas, em mg/dL

DP Desvio padrão

DRC Doença renal crônica

eGFR Estimated Glomerular Filtration Rate - Tradução: Taxa de filtração glomerular estimada, em $\mathrm{mL} / \mathrm{min} \times 1,73 \mathrm{~m}^{2}$

eGFR pré Estimated Glomerular Filtration Rate preoperative - Tradução: Taxa de filtração glomerular estimada no pré-operatório, em $\mathrm{mL} / \mathrm{min} \times 1,73 \mathrm{~m}^{2}$

eGFR PO Estimated Glomerular Filtration Rate postoperative - Tradução: Taxa de filtração glomerular estimada no período agudo, em $\mathrm{mL} / \mathrm{min} \mathrm{x}$ $1,73 \mathrm{~m}^{2}$

EPM Erro padrão da média

et al. e outros 
G1 Classificação de DRC grau 1: (função renal normal ou aumentada): se eGFR $\geq 90 \mathrm{~mL} / \mathrm{min} \times 1,73 \mathrm{~m}^{2}$

G2 Classificação de DRC grau 2: (levemente diminuída) se eGFR entre 89 e $60 \mathrm{~mL} / \mathrm{min} \times 1,73 \mathrm{~m}^{2}$

G3 Classificação de DRC grau 3: (moderadamente diminuída) se eGFR entre 59 e $30 \mathrm{~mL} / \mathrm{min} \times 1,73 \mathrm{~m}^{2}$

G4 Classificação de DRC grau 4: (função severamente diminuída) se eGFR $29-15 \mathrm{~mL} / \mathrm{min} \times 1,73 \mathrm{~m}^{2}$

G5 Classificação de DRC grau 5: (falência renal) se eGFR $<15 \mathrm{~mL} / \mathrm{min} x$ $1,73 \mathrm{~m}^{2}$

HCMFUSP Hospital das Clínicas da Faculdade de Medicina da Universidade de São Paulo

HPT Hiperparatireoidismo

HPTP Hiperparatireoidismo primário

IC $95 \%$ Intervalo de Confiança de 95\%

IRA Injúria renal aguda

KDIGO Kidney Disease: Improving Global Outcomes - Tradução: Doença Renal: Melhorando os Resultados Globais

m Mês / meses

MDRD Modification of Diet on Renal Disease - Tradução: Modificações da Dieta em Doença Renal

Min-Max Valores mínimos e máximos observados

N Número de indivíduos

NEM Neoplasia Endrócrina Múltipla

p Nível descritivo calculado

Po Período entre término da cirurgia e o quarto dia de pós-operatório

Pré-op Pré-operatório

Pós-op Pós-operatório

PTH Valor medido do paratormônio, em pg/mL

Q1-Q3 Intervalo interquartil 
RIFLE Acronym of Risk / Injury / Failure / Loss / End stage renal desease Tradução: Acrônimo de Risco / Injúria / Falência / Perda / Doença renal terminal

S+ $\quad$ Grupo de pacientes cuja creatinina reduziu no pós-operatório até 96 horas

So Grupo de pacientes cuja creatinina aumentou no pós-operatório até 96 horas, porém sem preencher critérios para injúria renal aguda

S1 Grupo de pacientes com injúria renal aguda estágio 1

S2 Grupo de pacientes com injúria renal aguda estágio 2

S3 Grupo de pacientes com injúria renal aguda estágio 3

Sem IRA Conjunto de pacientes cuja creatinina reduziu, ficou igual ou aumentou no pós-operatório agudo, porém não preencheram critérios para injúria renal aguda 


\section{LISTA DE SÍMBOLOS}

$\begin{array}{ll}\mathbf{d L} & \text { Decilitro } \\ \mathbf{g} & \text { Grama } \\ \mathbf{L} & \text { Litro } \\ \mathbf{m g} & \text { Miligrama } \\ \mathbf{m L} & \text { Mililitro } \\ \mathbf{n g} & \text { Nanograma } \\ \mathbf{p g} & \text { Picograma } \\ \mathbf{9 9} \mathbf{T c} & \text { Tecnécio-99 } \\ \mathbf{U I} & \text { Unidade internacional }\end{array}$




\section{LISTA DE TABELAS}

Tabela 1 - Distribuição de pacientes conforme a etiologia do HPTP

Tabela 2 - Valores pré-operatórios de PTH, cálcio total, cálcio iônico, fósforo e 25-OH vitamina $\mathrm{D}$

Tabela 3 - Valores de creatinina sérica do pré-operatório até 1 mês de pós-operatório (em $\mathrm{mg} / \mathrm{dL})$.....

Tabela 4 - Valores de creatinina sérica do pré-operatório até 60 meses $(\mathrm{mg} / \mathrm{dL})$.

Tabela 5 - Valores de creatinina sérica $(\mathrm{mg} / \mathrm{dL})$ em pacientes com dados completos de $\mathrm{Cr}$ pré-op, Cr PO, Cr 1m, Cr 12m e Cr $24 \mathrm{~m}$

Tabela 6 - Valores de eGFR $\left(\mathrm{mL} / \mathrm{min} \times 1,73 \mathrm{~m}^{2}\right)$ do pré-operatório até 60 meses

Tabela 7 - Valores de eGFR $\left(\mathrm{mL} / \mathrm{min} \times 1,73 \mathrm{~m}^{2}\right)$ em pacientes com dados completos de eGFR pré-op, PO, 1 mês, 12 meses e 24 meses.

Tabela 8 - Correlações entre variação aguda da eGFR (\%) e variáveis pré operatórias

Tabela 9 - Correlações entre variação crônica (12 meses) da eGFR (\%) e variáveis pré e pós-operatórias

Tabela 10 - Distribuição dos pacientes conforme padrão de variação da creatinina no período pos-operatório agudo

Tabela 11 - Valores de eGFR $\left(\mathrm{mL} / \mathrm{min} \times 1,73 \mathrm{~m}^{2}\right)$ até 36 meses, no grupo IRA estágio 1 (S1).

Tabela 12 - Valores de eGFR $\left(\mathrm{mL} / \mathrm{min} \times 1,73 \mathrm{~m}^{2}\right)$ até 36 meses, no grupo IRA estágio 2 (S2).

Tabela 13 - Valores de eGFR $\left(\mathrm{mL} / \mathrm{min} \times 1,73 \mathrm{~m}^{2}\right)$ até 36 meses, no grupo IRA estágio 3 (S3).....

Tabela 14 - Valores da mediana (Q1-Q3) de dados pré-operatórios nos diversos grupos por IRA

Tabela 15 - Medianas (Q1-Q3) de eGFR ( $\left.\mathrm{mL} / \mathrm{min} \times 1,73 \mathrm{~m}^{2}\right)$ dos grupos Adenoma e NEM 1, até 24 meses.

Tabela 16 - Médias (DP) de eGFR ( $\left.\mathrm{mL} / \mathrm{min} \times 1,73 \mathrm{~m}^{2}\right)$ dos grupos por etiologia, até 24 meses, excluídos grupos Adenoma e NEM 1. 
Tabela 17 - Valores da Mediana (Q1-Q3) de dados pré-operatórios nos diversos grupos por etiologia.

Tabela 18 - Medianas (Q1-Q3) das eGFR (mL/min x 1,73m²) entre grupos G1 a G4, até 24 meses .56

Tabela 19 - Mediana (Q1-Q3) das variáveis pré e pós-operatórias entre grupos por eGFR basal, utilizando corte de $60 \mathrm{~mL} / \mathrm{min} \times 1,73 \mathrm{~m}^{2}$ .58

Tabela 20 - Valores da Mediana (Q1-Q3) de cálcio total $(\mathrm{mg} / \mathrm{dL})$ até 72 horas de pós-operatório 60 


\section{LISTA DE GRÁFICOS}

Gráfico 1 - Valores de mediana e IC 95\% de creatinina sérica $(\mathrm{mg} / \mathrm{dL})$ do pré-operatório até 1 mês

Gráfico 2 - Valores de mediana e IC 95\% de creatinina sérica $(\mathrm{mg} / \mathrm{dL})$ do pré-operatório até 60 meses.

Gráfico 3 - Valores de mediana e IC 95\% da variação de eGFR (\%) no período agudo, até 1 mês de pós-operatório

Gráfico 4 - Valores de mediana e IC 95\% de eGFR $\left(\mathrm{mL} / \mathrm{min} \times 1,73 \mathrm{~m}^{2}\right)$ do pré-operatório até 60 meses.

Gráfico 5 - Valores de mediana e IC 95\% da variação de eGFR (\%) até 60 meses de pós-operatório

Gráfico 6 - Valores de mediana e IC $95 \%$ de eGFR $\left(\mathrm{mL} / \mathrm{min} \times 1,73 \mathrm{~m}^{2}\right)$ do préoperatório até 24 meses, em pacientes com dados completos.

Gráfico 7 - Correlação entre variação aguda da eGFR (\%) e Idade (anos).

Gráfico 8 - Correlação entre variação aguda da eGFR (\%) e PTH pré-operatório $(\mathrm{pg} / \mathrm{mL})$

Gráfico 9 - Médias e EPM de eGFR $\left(\mathrm{mL} / \mathrm{min} \times 1,73 \mathrm{~m}^{2}\right)$ dos grupos $\mathrm{S}+$ e $\mathrm{S} 0$ (Sem IRA), até 36 meses de pós-operatório

Gráfico 10 - Médias e EPM de eGFR $\left(\mathrm{mL} / \mathrm{min} \times 1,73 \mathrm{~m}^{2}\right)$ entre grupos IRA estágios 1 a 3 , até 48 meses.

Gráfico 11 - Médias e EPM da variação de eGFR ( $\left.\mathrm{mL} / \mathrm{min} \times 1,73 \mathrm{~m}^{2}\right)$ comparada aos valores basais, nos pacientes com IRA estágios 1 a 3, até 48 meses

Gráfico 12 - Medianas (Q1-Q3) de PTH pré-operatório por grupos IRA KDIGO

Gráfico 13 - Médias e ERM das eGFR $\left(\mathrm{mL} / \mathrm{min} \times 1,73 \mathrm{~m}^{2}\right)$ entre grupos por etiologia até 36 meses (excluídos pacientes do grupo Outros).

Gráfico 14 - Médias e EPM de eGFR $\left(\mathrm{mL} / \mathrm{min} \times 1,73 \mathrm{~m}^{2}\right)$ dos grupos Adenoma e NEM1 com dados completos, até 24 meses de pós-operatório.

Gráfico 15 - Medianas (Q1-Q3) de eGFR ( $\left.\mathrm{mL} / \mathrm{min} \times 1,73 \mathrm{~m}^{2}\right)$ pré-operatórias entre grupos por etiologia

Gráfico 16 - Médias e EPM da variação de eGFR (\%) nos grupos Adenoma e NEM1, comparados aos valores basais, até 36 meses 
Gráfico 17 - Médias e EPM da variação de eGFR (\%) de acordo com faixas de eGFR pré-operatória (DRC KDIGO), utilizando ponto de corte de $60 \mathrm{~mL} / \mathrm{min} \times 1,73 \mathrm{~m}^{2}$, até 48 meses.

Gráfico 18 - Médias e EPM da variação de eGFR (\%) de acordo com a 25-OH vitamina D pré-operatória, utilizando ponto de corte de $20 \mathrm{ng} / \mathrm{mL}$......59

Gráfico 19 - Médias e EPM da variação de eGFR (\%) de acordo com a 25-OH vitamina D pré-operatória, utilizando ponto de corte de $30 \mathrm{ng} / \mathrm{mL}$......60

Gráfico 20 - Médias e EPM de cácio total $(\mathrm{mg} / \mathrm{dL})$ nas $72 \mathrm{~h}$ de pós-operatório, dos grupos Adenoma e NEM 1 com dados completos 


\section{SUMÁRIO}

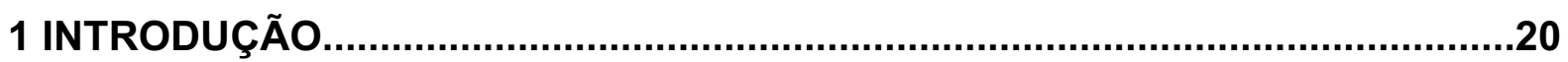

2 OBJETIVOS

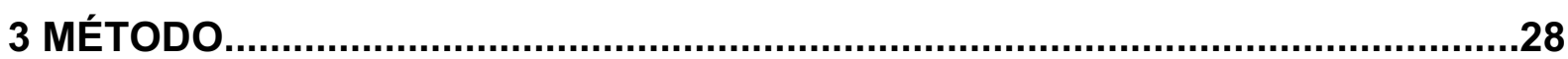

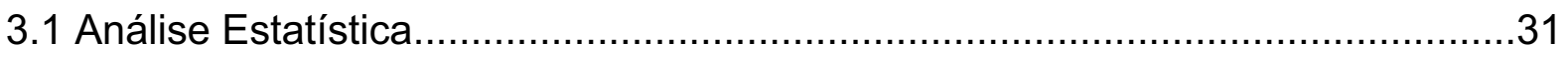

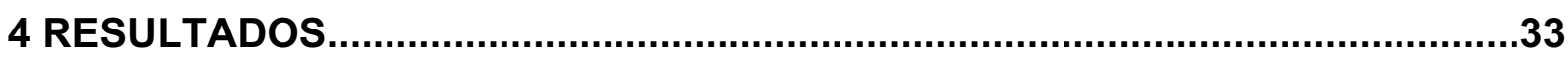

4.1 Classificação quanto à injuria renal aguda.......................................43

4.2 Classificação por grupos conforme a etiologia......................................50

4.3 Classificação conforme faixas de eGFR - DRC KDIGO ….........................56

4.4 Classificação conforme 25-OH vitamina D pré-operatória................................59

4.5 Curvas de cálcio no pós-operatório até 72 horas ............................................60

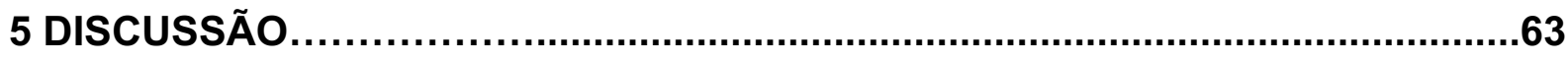

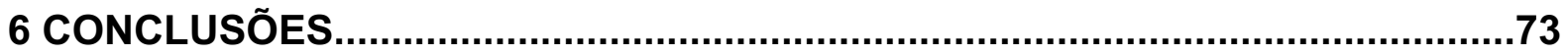

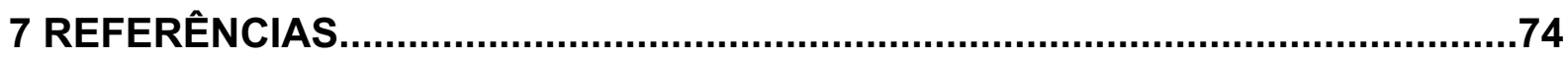

\section{APÊNDICES}




\section{INTRODUÇÃO}

O hiperparatireoidismo (HPT) primário se caracteriza por doença de uma ou mais glândulas paratireóides, que decorre da regulação anormal da secreção do paratormônio (PTH) em resposta às variações da calcemia. Pode ser caracterizado por hipercalcemia na presença de PTH sérico elevado ou inadequado para os níveis de cálcio. $(1,2)$

O HPT primário pode ocorrer em qualquer idade, sendo mais prevalente nas mulheres acima dos 45 anos. A incidência da doença teve seu ápice nos anos 80 , após a popularização dos painéis bioquímicos com a dosagem do cálcio sérico.(1, 3) Estima-se incidência de 66 casos por 100.000 habitantes/ano entre as mulheres, nos Estados Unidos da América, com algumas diferenças entre raças.(4) Já outro estudo estimou prevalência de $0,86 \%$ na população geral.(5)

Alterações sutis na fisiologia regulatória do cálcio podem acarretar alterações renais significativas, já que, em condições normais, o cálcio iônico é mantido numa faixa ótima de concentração sérica, às custas da liberação pulsátil do PTH em resposta à queda da calcemia.(6) A liberação do PTH eleva a calcemia de três maneiras: a) mobilização do cálcio ósseo (reabsorção); b) aumento da absorção intestinal do cálcio (indiretamente); c) aumento da reabsorção do cálcio no túbulo distal do néfron, diminuindo sua excreção na urina.(6)

As complicações mais frequentes do HPT primário, resultantes da exposição perniciosa à hipercalcemia com PTH elevado são: a diminuição da densidade mineral óssea (osteopenia ou osteoporose); nefrolitíase e/ou nefrocalcinose; e distúrbios neurocognitivos e psiquiátricos. $(1,7)$

A principal causa de HPT primário é o adenoma de paratireóide, responsável por cerca de $90 \%$ dos casos.(8) Pode haver duplo adenoma em até $5 \%$ dos pacientes e, outros $5 \%$ podem ser portadores de hiperplasia das paratireóides, que pode ser esporádica ou estar associada à Neoplasia Endócrina Múltipla (NEM) tipos 
1 e 2.(8, 9) Casos de carcinoma de paratireóide são raros e representam menos de $1 \%$ dos pacientes com HPTP. (10)

Conforme consenso publicado em 2014, o tratamento cirúrgico é indicado aos pacientes com HPT primário sintomáticos, independente da idade.(11) Nos pacientes assintomáticos, a paratireoidectomia é indicada nos mais jovens $(<50$ anos) e naqueles com alguma lesão de órgão-alvo (ossos e rins). Outros fatores que indicam cirurgia incluem hipercalcemia severa, a taxa de filtração glomerular inferior a $60 \mathrm{~mL} / \mathrm{min} \times 1,73 \mathrm{~m}^{2}$ e calciúria de $24 \mathrm{~h}$ superior a $400 \mathrm{mg} / \mathrm{vol} 24 \mathrm{~h} .(11)$

A paratireoidectomia representa o único tratamento definitivo disponível e o número de cirurgias realizadas tem aumentado em alguns países.(12) Recentemente, o uso de calcimiméticos como o Cinacalcete, utilizado nos pacientes com DRC e HPT secundário, foi validado também para uso em pacientes com HPTP, quando há contraindicação à paratireoidectomia. $(13,14)$ Esta medicação tem como objetivo reduzir os níveis de PTH e controlar parcialmente a hipercalcemia nos pacientes com HPTP.(15)

O procedimento cirúrgico utilizado no tratamento depende da suspeita diagnóstica, da presença de doença uni ou multiglandular, assim como dos achados dos exames de ultrassonografia cervical e cintilografia das paratireóides com ${ }^{99} \mathrm{Tc}$ Sestamibi.(16) Nos pacientes com adenoma único são indicadas paratireoidectomias com exploração unilateral, procedimentos rápidos e com mínimo trauma, sob anestesia geral. Em casos selecionados, podem ser realizadas sob anestesia local e sedação, numa plataforma de internação aos moldes de hospital-dia. (17)

Nos pacientes com hiperplasia de paratireóides, esporádica ou relacionadas à NEM, são usualmente indicadas paratireoidectomia subtotal, ou paratireoidectomia total com autoenxerto autólogo heterotópico.(16) Alguns grupos defendem a abordagem unilateral, como maneira de reduzir as chances de hipoparatireoidismo. (18) Pode haver prolongamento do tempo cirúrgico em casos de dificuldade na localização de uma ou mais paratireóides, e nos casos de glândula supranumerária ou ectópica. O recurso da aferição do PTH sérico no intraoperatório (PTH rápido) pode ser usado para presumir a chance de sucesso do tratamento, assim como motivar eventual mudança de conduta cirúrgica durante o procedimento.(16) 
No período pós-operatório, durante a internação, podem ser aferidos cálcio iônico, PTH e creatinina séricos, porém não há recomendação formal de monitorização da função renal.(16) Na prática clínica, observa-se como regra geral que há redução abrupta do $\mathrm{PTH}$ e cálcio sérico no $1^{\circ}$ dia pós-operatório. Nos pacientes com as formas mais graves da doença pode haver hipocalcemia prolongada, decorrente do fenômeno de fome óssea. (19)

Recentemente, alterações agudas da função renal após paratireoidectomias, em pacientes transplantados renais com HPT persistente, tem chamado a atenção do nosso grupo.(20) Em alguns estudos, houve redução do débito urinário e elevação da creatinina sérica, com recuperação da função renal, sem afetar a sobrevida do enxerto.(21) Em outras séries, a extensão da paratireoidectomia influenciou a redução da função renal precoce e tardia. $(22,23)$ Nos pacientes com HPT terciário, submetidos a paratireoidectomias, parece haver maior grau de disfunção renal aguda após estas, quando comparadas à outras cirurgias de portes semelhantes.(21)

A Injúria Renal Aguda (IRA) pode ser explicada como uma redução abrupta da função renal, que pode ou não representar lesão estrutural com evolução para insuficiência ou falência renal.(24) Numa definição atual, é melhor compreendida como uma síndrome, uma condição clínica frequente, com alta morbimortalidade e potencialmente evitável. (25)

Nas últimas duas décadas, diversas classificações de gravidade foram validadas para o uso clínico, com objetivo de padronizar as definições e se correlacionar com prognóstico, além de nortear as decisões terapêuticas. A classificação de RIFLE, acrônimo da lingua inglesa proposta pelo grupo ADQI (Acute Dialysis Quality Initiative), se destacou por incluir alterações mais precoces e por considerar pacientes em risco para IRA.(26) Tais alterações se basearam nos estudos que mostraram aumento de mortalidade, mesmo com alterações mais sutis da função renal. (27)

Em 2004, outro grupo de especialistas internacionais propôs a criação do KDIGO (Kidney Diseases: Improving Global Outcomes). As recomendações do KDIGO gradativamente passaram a nortear algumas condutas na nefrologia. Em 
2012 foram publicadas as recomendações com critérios diagnósticos e de gravidade para IRA, divididos em estágios 1, 2 e 3.(25)

No contexto de pacientes graves, internados em Unidades de Terapia Intensiva (UTI), estudo multicêntrico recente observou alta incidência de IRA, presente em mais de $50 \%$ dos pacientes admitidos.(28) Observou-se uma correlação entre critérios de gravidade KDIGO e mortalidade intra-hospitalar. Após análise multivariada, IRA estágios 2 e 3 aumentaram em 2,9 a 6,8 vezes o risco de morte, respectivamente. No mesmo estudo, $23,5 \%$ dos pacientes com IRA necessitaram de Terapia Renal Substitutiva por tempo determinado, denotando possível evolução para doença renal crônica (DRC).

A incidência de IRA após cirurgias eletivas pode variar de acordo com o tipo e porte cirúrgicos, além da presença ou não de algumas comorbidades.(29) Nos pacientes submetidos à cirurgias cardiovasculares, devido ao uso de circulação extra-corpórea, a frequência de IRA pós-operatória pode atingir $22 \%$ e se relaciona com o risco de morte e de complicações.(30) Nesse tipo de cirurgia, pode haver algum grau de piora aguda da função renal em até $62 \%$ dos pacientes. (31) Outro estudo mostrou que em cirurgias eletivas gerais a incidência de IRA pode chegar a 13,4\%, independente da classificação utilizada.(32) Nessa mesma revisão houve perda definitiva de função renal em até $53 \%$ dos pacientes, após o episódio agudo, além do significativo aumento do risco de óbito precoce (30 dias) nos pacientes com IRA.

Alguns trabalhos mostram que pacientes hígidos, que sofrem episódio isolado de IRA, tem $90 \%$ de aumento de risco de desenvolverem DRC, além de apresentarem maior mortalidade a longo prazo.(33) Nos pacientes com disfução renal prévia, os eventos agudos aceleram a progressão da doença de base, especialmente nos que não recuperam as eGFR prévias logo após a resolução da IRA.(34) Tais fatos denotam a importância da prevenção dos eventos, por meio da identificação dos grupos de risco e da implementação de medidas capazes de reduzir as chances de IRA nos pacientes cirúrgicos.

O HPT primário se manifesta bioquimicamente como um distúrbio da homeostase do cálcio.(35) O principal órgão regulador do cálcio sérico é o rim, não 
só pela alta taxa de transporte ativo do íon, mas também pelo papel endócrino exercido através da conversão da 25-OH vitamina D em sua forma ativa.(35) Apesar de haver evidência, em modelo animal, de que o cálcio exerça influência vasomotora, seu efeito sobre a hemodinâmica glomerular parece depender da ação da Angiotensina II, potente vasoconstrictor capaz de promover o influxo de $\mathrm{Ca}^{2+}$ no endotélio das arteríolas aferente e eferente. (36) Em estudo envolvendo pacientes com HPTP, quando estimada filtração glomerular pela dosagem sérica da cistatinaC, houve correlação positiva com cálcio iônico e total, denotando pior função renal nos pacientes com níveis mais elevados de cálcio sérico.(37)

Zaladek et al.(38) buscaram detalhar o papel do PTH na vasorregulação renal, utilizando modelo animal em ratos. Observou-se que a ausência do peptídeo foi acompanhada de declínico significativo da taxa de filtração glomerular, da pressão de perfusão renal, do clearance de inulina e da osmolalidade urinária. Os efeitos moduladores do PTH, assim como sua ação na concentração da urina, não dependeram da influência do cálcio sérico. (39)

Em outro estudo, Massfelder et al.(40) estudaram, em ratos Wistar, os efeitos da infusão intrarenal de PTH recombinante na vasorregulação do néfron. Após infusão do PTH, observou-se um aumento significativo do fluxo sanguíneo renal (10\%), da taxa de filtração glomerular (20\%) e do fluxo urinário (57\%). Outros autores relacionaram a ativação do sistema renina-angiotensina-aldosterona com alterações renais no HPTP, independente da ação do PTH sérico. (41)

Recentemente, questionou-se a existência de hiperfiltração glomerular também no HPTP, pela possível ação sistêmica do PTH sobre a vasculatura renal.(42) A presença de certo grau de hiperfiltração induzida pelo estímulo crônico do PTH, poderia explicar uma piora funcional agudamente, após normalização metabólica que ocorre no tratamento cirúrgico. Além do PTH, outras substâncias presentes nas paratireóides, com ação vasopressora, podem influenciar nesse controle renal da filtração glomerular.(43)

Takenaka et al.(44) publicaram artigo de revisão sobre hiperfiltração glomerular do rim diabético. Segundo os autores, há evidência de que a hiperfiltração se desenvolve simultaneamente à ativação do sistema renina-angiotensina, que por 
sua vez, depende da dilatação da arteríola aferente na presença de concentrações elevadas de angiotensina II. Este modelo é chamado de hipótese tubular e, no diabetes melitus, pode ser explicado pela redução do feedback tubuloglomerular. Além do diabetes, outra causa conhecida de hiperfiltração glomerular é a anemia falciforme.(45)

Num estudo em seres humanos, foram avaliados indivíduos com hipercalcemia decorrentes ou não de HPT primário.(46) O clearance de inulina medido foi $100 \%$ superior nos pacientes com hipercalcemia decorrente do HPT primário, quando comparado aos indivíduos com os mesmos níveis de cálcio sem PTH elevado. Não há, até o momento, evidência suficiente para sustentar a teoria de hiperfiltração glomerular no HPT primário, apesar dos seus efeitos vasomoduladores, nos modelos animais, corroborarem para uma possível ligação.

A intensidade da piora aguda da função renal após paratireoidectomias, em pacientes transplantados renais com HPT persistente, correlaciona-se com a redução do PTH no pós-operatório.(47) Uma vez que a redução abrupta do PTH é comum também após o tratamento cirúrgico do HPT primário, há razão para concluir que o mecanismo semelhante possa cursar com alterações renais agudas neste último grupo.(48)

Peacock relatou elevação aguda da creatinina sérica após paratireoidectomias por HPTP e observou uma maior frequência de disfunção aguda nos pacientes com pior função renal inicial.(49) Entretanto, pouca atenção tem sido dada ao assunto, uma vez que o monitoramento da função renal no pós-operatório agudo não é rotina nos principais centros, tampouco há recomendação formal de vigilância no consenso internacional.(16)

Com ênfase na função renal pós-operatória, Egan et al.(50) conduziram estudo prospectivo observacional, que envolveu 62 pacientes submetidos a paratireoidectomias por HPTP. Observou-se queda significativa da eGFR no $1^{\circ} \mathrm{PO}$ e após 90 dias, quando comparados aos valores basais, sendo que dois pacientes (3\%) preencheram critérios para IRA estágio 1. Dos pacientes com seguimento até três meses, $30,4 \%$ mantiveram creatinina sérica superior a $10 \%$ da medida préoperatória. Este representa o principal artigo específico sobre o tema em HPTP. 
Diante da escassez de estudos sobre o tema e da observação clínica de que os pacientes submetidos a paratireoidectomias por HPTP experimentam deterioração aguda da função renal, da mesma forma que os casos de HPT terciário, desenhou-se este estudo. 


\section{OBJETIVOS}

Avaliar a frequência e a intensidade da disfunção renal aguda no pósoperatório de paratireoidectomias por HPT primário e correlacioná-la com a recuperação da função renal a longo prazo.

Estudar o impacto da reserva funcional renal e a gravidade do HPT primário na piora aguda da função renal e sua recuperação no pós-operatório tardio.

Estabelecer o período mínimo de seguimento pós-operatório capaz de predizer a evolução da função renal tardia em pacientes submetidos a paratireoidectomias por HPT primário. 


\section{MÉTODO}

Estudo retrospectivo de coorte, com pacientes submetidos à paratireoidectomia para tratamento do hiperparatireoidismo primário, realizadas no Hospital das Clínicas da Faculdade de Medicina da Universidade de São Paulo (HCFMUSP), entre janeiro de 2007 e dezembro de 2016.

O projeto de pesquisa foi aprovado pela Comissão de Ética em Pesquisa do Hospital das Clínicas da FMUSP com Certificado de apresentação para Apreciação Ética numero 03532612.4.0000.0068, e aprovado na sessão de 18/07/2012 e registro eletrônico da aprovação em 19/07/2012.

Critérios de inclusão: todos os pacientes com diagnóstico de HPT primário submetidos ao tratamento cirúrgico no período estipulado, independente da etiologia e indicação cirúrgica.

Critérios de exclusão: pacientes menores de 18 anos; pacientes com recidiva do HPTP devido à atividade do autoenxerto; pacientes sem registro de função renal pré-operatória; ausência de dados de função renal durante internação hospitalar no perioperatorio (período agudo); ausência de dados do seguimento ambulatorial após alta hospitalar; doença renal crônica grau 5 (eGFR $<15 \mathrm{~mL} / \mathrm{min} \times 1.73 \mathrm{~m}^{2}$ )

Foram pesquisados os dados demográficos de idade, gênero e raça. Houve registro e estratificação por etiologia: adenoma (AD); duplo adenoma (DA); hiperplasia esporádica (HE); neoplasia endócrina múltipla (NEM) tipos 1 ou 2a; carcinoma de paratireóide; hiperplasia relacionada ao uso do lítio.

Pacientes com doença uniglandular foram submetidos a cirurgia focalizada, sempre sob anestesia geral, com auxilio do exame de PTH rápido intraoperatório. Para os pacientes cuja etiologia do HPT era NEM 1 ou hiperplasia esporádica (doença multiglandular), o procedimento de escolha foi a paratireoidectomia total com autoenxerto autólogo heterotópico, no antebraço não dominante. Alguns casos foram submetidos a paratireoidectomia subtotal por escolha da equipe cirúrgica. 
No pré-operatório foram avaliados dados de creatinina sérica ( $\mathrm{Cr}$ pré), paratormônio $(\mathrm{PTH})$, cálcio iônico (Cal), cálcio total (CaT), fósforo $(\mathrm{P}), 25-\mathrm{OH}$ Vitamina D e calciúria de $24 \mathrm{~h}$ (CaU 24h).

Durante internação pós-operatória foram aferidas creatinina sérica do $1^{\circ}$ ao $4^{\circ}$ dia pós-op ( $\mathrm{Cr} 1^{\circ} \mathrm{PO}$ até $\left.\mathrm{Cr} 4^{\circ} \mathrm{PO}\right)$; PTH no $1^{\circ} \mathrm{PO}$; cálcio iônico e total do $1^{\circ}$ ao $3^{\circ}$ dia pós-op (Cal e CaT $1^{\circ} \mathrm{PO}$ ao $\left.3^{\circ} \mathrm{PO}\right)$.

Os valores de referência para os exames laboratoriais (séricos) foram: cálcio total (8,6 a 10,2 mg/dL); cálcio iônico (4,6 a 5,3 mg/dL); fósforo (2,7 a 4,5 mg/dL); fosfatase alcalina (45 a $122 \mathrm{U} / \mathrm{L}$ para homens e 35 a $104 \mathrm{U} / \mathrm{L}$ para mulheres); creatinina $(0,7$ a $1,2 \mathrm{mg} / \mathrm{dL}$ para homens e 0,5 a $0,9 \mathrm{mg} / \mathrm{dL}$ para mulheres) e $25-\mathrm{OH}$ vitamina D (10 a $30 \mathrm{ng} / \mathrm{mL})$. Os valores do paratormônio (PTH) para exames coletados no HCFMUSP até 21/11/2012 variavam entre 15 e 81 pg/mL (referência). Após este período, passou a ser utilizado ensaio de $2^{a}$ geração, com aferição da molécula intacta do PTH, com referência entre 15 e $65 \mathrm{pg} / \mathrm{mL}$. Os valores de referência da calciúria de $24 \mathrm{~h}$ foram de 100 a $320 \mathrm{mg} / \mathrm{vol} 24 \mathrm{~h}$.

Conforme protocolo assistencial prévio ao estudo, estabelecido entre as equipes do HC-FMUSP envolvidas no tratamento destes pacientes (Grupo de Paratireóides e doenças congênitas da Disciplina de Cirurgia de Cabeça e Pescoço e da Disciplina de Endocrinologia), a internação após paratireoidectomia se prolonga por 3 dias (até o $3^{\circ} \mathrm{PO}$ ), quando é avaliada a possibilidade de alta hospitalar. Este período de internação tem como objetivo corrigir a hipocalcemia e reduzir o risco de reinternações após alta hospitalar. Os exames laboratoriais utilizados para o estudo presente são os mesmos já solicitados na rotina assistencial.

No pós-operatório tardio, período de acompanhamento ambulatorial, foram registrados os dados de creatinina após 1 mês $(\mathrm{Cr} 1 \mathrm{~m}), 3$ meses $(\mathrm{Cr} 3 \mathrm{~m}), 6$ meses (Cr 6m), 12 meses ( $\mathrm{Cr} \mathrm{12m),} 24$ meses ( $\mathrm{Cr} 24 \mathrm{~m}), 36$ meses $(\mathrm{Cr} 36 \mathrm{~m}), 48$ meses $(\mathrm{Cr}$ $48 \mathrm{~m})$ e 60 meses $(\mathrm{Cr} 60 \mathrm{~m})$.

Baseados nos dados de creatinina sérica, idade, gênero e raça dos pacientes, foram calculadas as taxas de filtração glomerular estimadas (eGFR), através de 
calculadora eletrônica disponível na internet (http://mdrd.com), que utiliza a equação do estudo do grupo CKD-EPI (Chronic Kidney Disease Epidemiology Collaboration), publicado em 2009.(51) A fórmula utilizada para $\mathrm{Cr}$ em mg/dL é:

eGFR $\left(\operatorname{mL} / \min \times 1,73 m^{2}\right)=141 X \min (C r / k, 1)^{a} X \max (C r / k, 1)^{-1,209} X 0,993^{\text {idade }}$ $X 1,018$ (se feminino) $X 1,159$ (se afrodescendente)

Foram calculadas as eGFR para cada dado de creatinina disponível: eGFR pré, eGFR $1^{\circ}$ ao $4^{\circ} \mathrm{PO}$, eGFR $1 \mathrm{~m}$, eGFR 3m, eGFR $6 \mathrm{~m}$, eGFR $12 \mathrm{~m}$, eGFR $24 \mathrm{~m}$, eGFR 36m, eGFR 48m e eGFR $60 \mathrm{~m}$.

A intensidade da disfunção renal aguda no pós-operatório foi quantificada em termos absolutos e relativos (percentual de elevação ou queda) de creatinina e eGFR. Os pacientes que preencheram critérios diagnósticos para Injúria Renal Aguda (IRA) foram estratificados em estágios, conforme a classificação de KDIGO. (25) No presente estudo não foram utilizados os parâmetros de débito urinário para classificação da IRA (dados indisponíveis).

Na classificação do KDIGO, os estágios da IRA, para alterações de creatinina, estão organizados da seguinte maneira:

- IRA estágio 1: aumento de creatinina de 1,5 a 1,9 vezes o valor basal ou elevação igual ou superior a $\mathbf{0 , 3} \mathrm{mg} / \mathrm{dL}$.

- IRA estágio 2: aumento de creatinina de 2 a 2,9 vezes o valor basal

- IRA estágio 3: aumento de creatinina de 3,0 vezes o valor basal ou $\mathrm{Cr} \geq 4,0$ $\mathrm{mg} / \mathbf{d L}$ ou necessidade de terapia substitutiva (ex: hemodiálise).

Os pacientes que tiveram redução da creatinina no período agudo foram designados como grupo S+. Já os pacientes que tiveram elevação da creatinina, porém sem preencher critérios de IRA, foram designados como grupo $\mathbf{S 0}$ e os grupos S1, S2 e S3 representam IRA estágios 1, 2 e 3 respectivamente.

Para cálculo da intensidade da variação aguda da função renal, empregou-se a seguinte fórmula:

Variação Aguda da Função Renal (\%) $=100$ x (eGFR PO - eGFR pré) $/$ 
Foram utilizados como parâmetros para comparação pré e pós-operatórios, os maiores valores de creatinina entre o $1^{\circ}$ e $4^{\circ} \mathrm{PO}$ (chamado $\mathrm{Cr}$ PO), e os menores valores da eGFR entre $01^{\circ}$ e $4^{\circ} \mathrm{PO}$ (chamado eGFR PO).

Para cálculo da intensidade da variação crônica (definitiva) da função renal, empregou-se a seguinte fórmula:

Variação Crônica da Função Renal (\%)=100 x (eGFR 12 meses - eGFR pré)/eGFR pré

Em algumas análises de grupos foi utilizada classificação da função renal préoperatória (eGFR pré) por faixas, conforme recomendação da KDIGO para DRC:

- $\mathbf{G 1}$ (função renal normal ou aumentada): se eGFR $\geq 90 \mathrm{~mL} / \mathrm{min} \times 1,73 \mathrm{~m}^{2}$

- $\mathbf{G 2}$ (levemente diminuída): se eGFR entre 89 e $60 \mathrm{~mL} / \mathrm{min} \times 1,73 \mathrm{~m}^{2}$

- $\mathbf{G} 3$ (moderadamente diminuída): se eGFR entre 59 e $30 \mathrm{~mL} / \mathrm{min} \times 1,73 \mathrm{~m}^{2}$

- $\mathbf{G 4}$ (função severamente diminuída): se eGFR 29-15 $\mathrm{mL} / \mathrm{min} \times 1,73 \mathrm{~m}^{2}$

* OBS: os pacientes com eGFR pré-operatória inferior a $15 \mathrm{~mL} / \mathrm{min} \times 1,73 \mathrm{~m}^{2}$, classificados como falência renal ou DRC grau 5 (G5) pela KDIGO, foram excluídos do estudo.

\subsection{ANÁLISE ESTATÍSTICA}

Os dados coletados foram organizados em planilhas do programa Microsoft $₫$ Excel versão 15. As variáveis quantitativas contínuas foram analisadas pelo teste de Kolmogorov-Smirnov para verificar perfil de distribuição, sendo descritas em média e desvio padrão (DP) quando a distribuição foi paramétrica (normal). Quando a distribuição foi não paramétrica, elas foram apresentadas em mediana e intervalo interquartil (Q1-Q3). O valor máximo e o valor mínimo também foram apresentados (Min-Max). 
Os testes de inferência empregados em distribuições normais foram o teste $T$, teste T pareado, análise de variância (ANOVA), ANOVA para amostras repetidas e, para comparação de diversos grupos, utilizou-se o teste de Turkey.

Em distribuições não normais, foi utilizado o teste de Mann-Whitney; o teste de Friedman, para comparações pareadas e o teste de comparações múltiplas de Dunn, quando adequado.

A pesquisa de correlações foi feita por meio do coeficiente de correlação de Pearson ou Spearman, conforme as características das distribuições testadas.

Para análise estatística univariada foi utilizado programa de estatística Graphpad Prism® versão 7.0. Utilizado também programa Minipad® para análise das variáveis categóricas. 


\section{$4 \quad$ RESULTADOS}

No período de janeiro de 2007 a dezembro de 2016 foram identificados 521 pacientes operados com diagnóstico de HPT primário no HCFMUSP. Desses, 27 casos foram excluídos e as análises foram realizadas nos 494 restantes.

Os motivos da exclusão dos 27 pacientes foram: 11 casos $(40,7 \%)$ sem dados de função renal tardia; 5 casos (18,5\%) com idade < 18 anos; 4 casos $(14,8 \%)$ com recidiva relacionada ao implante de paratireóide; 4 casos $(14,8 \%)$ com eGFR préoperatória < $15 \mathrm{~mL} / \mathrm{min} \times 1,73 \mathrm{~m}^{2}$ (falência renal); 3 casos $(11,1 \%$ ) sem dados de função renal durante a internação.

Dos 494 pacientes estudados, 391 (79,1\%) eram mulheres e $103(20,9 \%)$ eram homens. Do total, $422(85,4 \%)$ pacientes eram brancos e $72(14,6 \%)$ negros. A distribuição conforme diagnóstico (tipo do HPT primário), está exposta na Tabela 1.

Tabela 1 - Distribuição de pacientes conforme a etiologia do HPTP

\begin{tabular}{l|cc}
\hline & $\mathbf{n}$ & $\%$ \\
\hline Adenoma & 351 & 71,1 \\
NEM 1 & 91 & 18,4 \\
Hiperplasia Esporádica & 25 & 4,0 \\
Duplo Adenoma & 20 & 5,1 \\
Carcinoma & 3 & 0,6 \\
NEM 2A & 2 & 0,4 \\
HPT associado ao uso de Lítio & 2 & 0,4 \\
Total & $\mathbf{4 9 4}$ & $\mathbf{1 0 0}$ \\
\hline
\end{tabular}

Para fins de análise estatística: os pacientes com diagnóstico de carcinoma de paratireóide $(n=3)$; Neoplasia Endócrina Múltipla tipo 2a $(n=2)$ e HPT relacionado ao uso de Lítio $(n=2)$ foram agrupados em grupo Outros. 
Foram registrados 3 óbitos nos primeiros 30 dias de pós-operatório, do total de 521 pacientes iniciais, representando $0,58 \%$ de taxa de mortalidade. Um paciente foi a óbito 6 dias após a cirurgia, por sepse de causa abdominal; outro faleceu 14 dias após a cirurgia, com reinternação por falência renal e hipocalcemia severa; já o terceiro foi por causa desconhecida, 20 dias após o procedimento. Dos pacientes operados por carcinoma de paratireóide (3 pacientes), dois deles estão sem evidência de doença após 5 anos e o terceiro está em seguimento oncológico por metástases pulmonares estáveis, com PTH e cálcio controlados.

A idade dos pacientes no momento da cirurgia variou de 18 a 86 anos, com mediana de 58 anos e Q1-Q3 de 49 - 67,2 anos. A Tabela 2 elenca os valores préoperatórios de PTH, CaT, Cal, P e 25-OH vitamina D.

Tabela 2 - Valores pré-operatórios de PTH, cálcio total, cálcio iônico, fósforo e 25$\mathrm{OH}$ vitamina $\mathrm{D}$

\begin{tabular}{c|ccccc}
\hline & PTH $(\mathbf{p g} / \mathbf{m L})$ & $\mathbf{C a T}(\mathbf{m g} / \mathbf{d L})$ & Cal $(\mathbf{m g} / \mathbf{d L})$ & $\mathbf{P}(\mathbf{m g} / \mathbf{d L})$ & $\begin{array}{c}25-\text { OH vit D } \\
(\mathbf{n g} / \mathbf{m L})\end{array}$ \\
\hline n & 494 & 494 & 494 & 480 & 440 \\
Mediana & $\mathbf{1 5 4 , 5}$ & $\mathbf{1 0 , 9}$ & $\mathbf{5 , 9 4}$ & $\mathbf{2 , 7}$ & $\mathbf{1 9}$ \\
Q1 - Q3 & $106-238,5$ & $10,3-11,5$ & $5,6-6,4$ & $2,3-3,1$ & $14-24$ \\
Min - Max & $42-6556$ & $8,6-17,8$ & $4,38-9,8$ & $0,8-5,7$ & $4-79,6$ \\
\hline
\end{tabular}

Os valores de calciúria de $24 \mathrm{~h}$ no pré-operatório foram registrados em 383 (77,5\%) pacientes e variaram de 8 a 956,9 mg/vol 24h, com mediana de 224,8 mg/vol 24h, e Q1-Q3 de 128,2 - 347,1. Dos 383 pacientes que possuíam dados de CaU24h, $61(15,9 \%)$ deles apresentava valores superiores a $\mathbf{4 0 0} \mathbf{~ m g} / \mathbf{v o l} \mathbf{2 4 h}$, enquanto em $322(84,07 \%)$ deles era $\leq 400 \mathrm{mg} / \mathrm{vol} 24 \mathrm{~h}$.

A creatinina pré-operatória variou entre 0,28 a $3,76 \mathrm{mg} / \mathrm{dL}$. A mediana foi de 0,81 mg/dL, com Q1-Q3 de 0,68 -1,01 mg/dL. Os valores medidos de creatinina, do pré-operatório até 1 mês de seguimento, estão expostos na Tabela 3. 
Tabela 3 - Valores de creatinina sérica do pré-operatório até 1 mês de pósoperatório (em $\mathrm{mg} / \mathrm{dL})$

\begin{tabular}{|c|c|c|c|c|c|c|}
\hline & Cr pré-op & $\mathrm{Cr} 1^{\circ} \mathrm{PO}$ & $\mathrm{Cr} 2^{\circ} \mathrm{PO}$ & $\mathrm{Cr} 3^{\circ} \mathrm{PO}$ & $\mathrm{Cr} 4^{\circ} \mathrm{PO}$ & $\mathrm{Cr} 1 \mathrm{~m}$ \\
\hline$n$ & 494 & 470 & 425 & 334 & 227 & 395 \\
\hline Min & 0,28 & 0,45 & 0,43 & 0,33 & 0,49 & 0,35 \\
\hline Q1 & 0,68 & 0,84 & 0,83 & 0,77 & 0,76 & 0,72 \\
\hline Mediana & 0,81 & 1,05 & 1,04 & 1,005 & 0,96 & 0,87 \\
\hline Q3 & 1,01 & 1,39 & 1,425 & 1,353 & 1,33 & 1,13 \\
\hline Max & 3,76 & 4,77 & 5,15 & 5,03 & 4,94 & 4,23 \\
\hline
\end{tabular}

Durante a internação hospitalar, a creatinina sérica medida diariamente mostrou redução em $30(6,1 \%)$ pacientes, permanecendo estável em $6(1,21 \%)$ e com elevação em 458 (92,71\%) pacientes.

No teste de Kruskal-Wallis houve diferença entre as medianas de Cr pré-op vs. todas as medidas até $4^{\circ} \mathrm{PO}(\mathrm{p}<0,0001)$, inclusive entre $\mathrm{Cr}$ pré-op e $\mathrm{Cr} \mathbf{1 m}$ $(p=0,0019)$. Houve diferença estatística entre as medianas de $1^{\circ} \mathrm{PO}$ a $4^{\circ} \mathrm{PO}$ comparadas à $\mathrm{Cr} 1$ mês, utilizando teste de comparações múltiplas de Dunn. Não houve diferença entre as medidas de $1^{\circ}$ até $4^{\circ} \mathrm{PO}$ entre si. O Gráfico 1 mostra a curva de variação aguda da creatinina até 1 mês de pós-operatório.

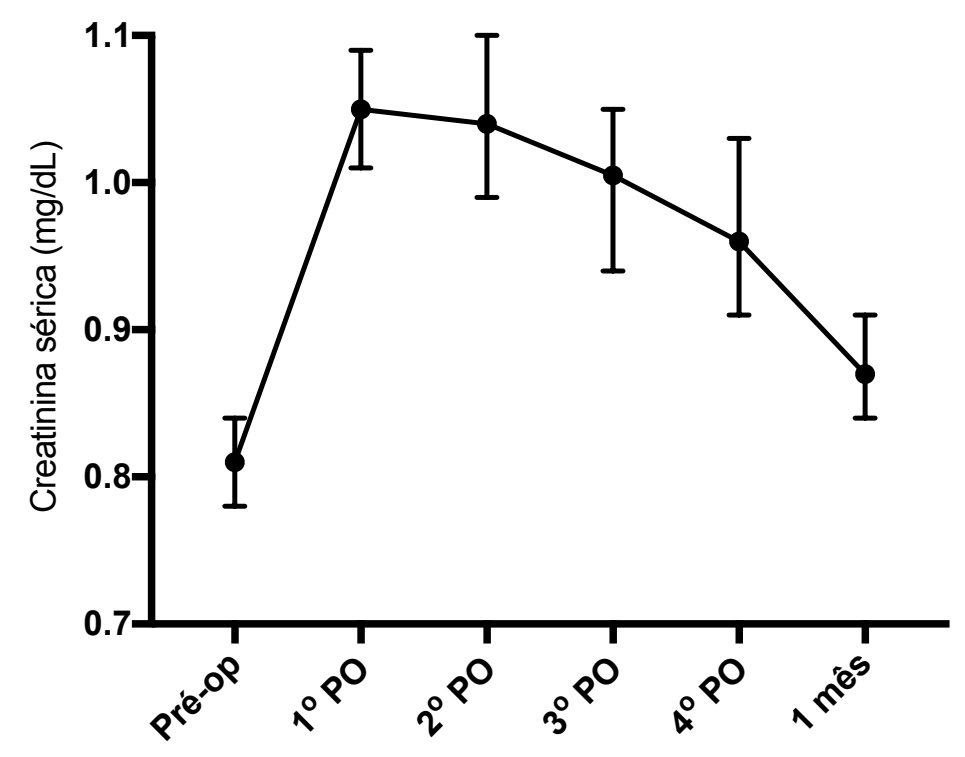

Gráfico 1 - Valores de mediana e IC 95\% de creatinina sérica ( $\mathrm{mg} / \mathrm{dL}$ ) do préoperatório até 1 mês 
Quando selecionados os pacientes com todos os valores de creatinina na internação até 1 mês $\left(\mathrm{Cr}\right.$ pré, $1^{\circ} \mathrm{PO}, 2^{\circ} \mathrm{PO}, 3^{\circ} \mathrm{PO}, 4^{\circ} \mathrm{PO}$ e $\left.1 \mathrm{~m}\right)$, que totalizam 161 pacientes, foi possível aplicar teste de Friedman com medidas pareadas. Nessa análise a mediana de $\mathrm{Cr}$ pré foi inferior a todas até 1 mês $(p<0,0001)$. Houve diferença estatística entre todas as medianas de $\mathrm{Cr}$ pós-op entre si até 1 mês, com curva de queda a partir do $1^{\circ} \mathrm{PO}$. Entre o $4^{\circ} \mathrm{PO}$ e $\mathrm{Cr} 1 \mathrm{mês}$, a diferença se manteve significativa $(p=0,0142)$ com o teste de Wilcoxson.

Em relação ao momento do pico de creatinina sérica no pós-operatório recente (Cr PO), observou-se que em 220 pacientes (44,5\%) ocorreu no $1^{\circ} \mathrm{PO}$; em 193 pacientes $(39,1 \%)$ no $2^{\circ} \mathrm{PO}$; em $54(10,9 \%)$ no $3^{\circ} \mathrm{PO}$; e em $27(5,5 \%)$ no $4^{\circ} \mathrm{PO}$.

Os valores medidos de creatinina sérica, do pré-operatório até 60 meses de seguimento, estão expostos na Tabela 4.

Tabela 4 - Valores de creatinina sérica do pré-operatório até 60 meses (mg/dL)

\begin{tabular}{|c|c|c|c|c|c|c|c|c|c|c|}
\hline & $\begin{array}{l}\text { Cr } \\
\text { pré- } \\
\text { op }\end{array}$ & $\begin{array}{c}\mathrm{Cr} \\
\text { PO* }^{*}\end{array}$ & $\begin{array}{l}\mathrm{Cr} \\
1 \mathrm{~m}\end{array}$ & $\begin{array}{l}\mathrm{Cr} \\
3 \mathrm{~m}\end{array}$ & $\begin{array}{c}\mathrm{Cr} \\
6 \mathrm{~m}\end{array}$ & $\begin{array}{c}\mathrm{Cr} \\
12 \mathrm{~m}\end{array}$ & $\begin{array}{c}\mathrm{Cr} \\
24 \mathrm{~m}\end{array}$ & $\begin{array}{c}\mathrm{Cr} \\
36 \mathrm{~m}\end{array}$ & $\begin{array}{c}\mathrm{Cr} \\
48 \mathrm{~m}\end{array}$ & $\begin{array}{c}\mathrm{Cr} \\
60 \mathrm{~m}\end{array}$ \\
\hline$n$ & 494 & 494 & 395 & 347 & 409 & 450 & 362 & 323 & 255 & 193 \\
\hline Min & 0,28 & 0,45 & 0,35 & 0,40 & 0,32 & 0,38 & 0,43 & 0,52 & 0,38 & 0,40 \\
\hline & 0,68 & 0,88 & 0,72 & 0,73 & 0,74 & 0,72 & 0,72 & 0,71 & 0,71 & 0,73 \\
\hline $\begin{array}{l}\text { Median } \\
\text { a }\end{array}$ & 0,81 & 1,10 & 0,87 & 0,89 & 0,89 & 0,86 & 0,86 & 0,87 & 0,86 & 0,86 \\
\hline Q3 & 1,01 & 1,48 & 1,13 & 1,17 & 1,15 & 1,10 & 1,12 & 1,10 & 1,09 & 1,09 \\
\hline Max & 3,76 & 5,15 & 4,23 & 4,38 & 4,74 & 6,07 & 4,66 & 4,52 & 4,03 & 4,95 \\
\hline
\end{tabular}

No teste de Kruskal-Wallis, as medianas de $\mathrm{Cr}$ pré-op foram inferiores às medianas de $\mathrm{Cr}$ até 36 meses. Entre $\mathrm{Cr}$ pré-op e as medidas tardias de 48 e 60 meses, a diferença foi menos expressiva, com $p=0,0283$ e $p=0,0165$, respectivamente (Mann-Whitney). Os valores de $\mathrm{Cr}$ PO foram superiores às demais medidas de $\mathrm{Cr}$ até 60 meses $(p<0,0001)$. Não houve diferença entre $\mathrm{Cr} 1 \mathrm{~m}$ e as demais medidas tardias até 60 meses. O Gráfico 2 mostra a curva de creatinina sérica até 60 meses: 


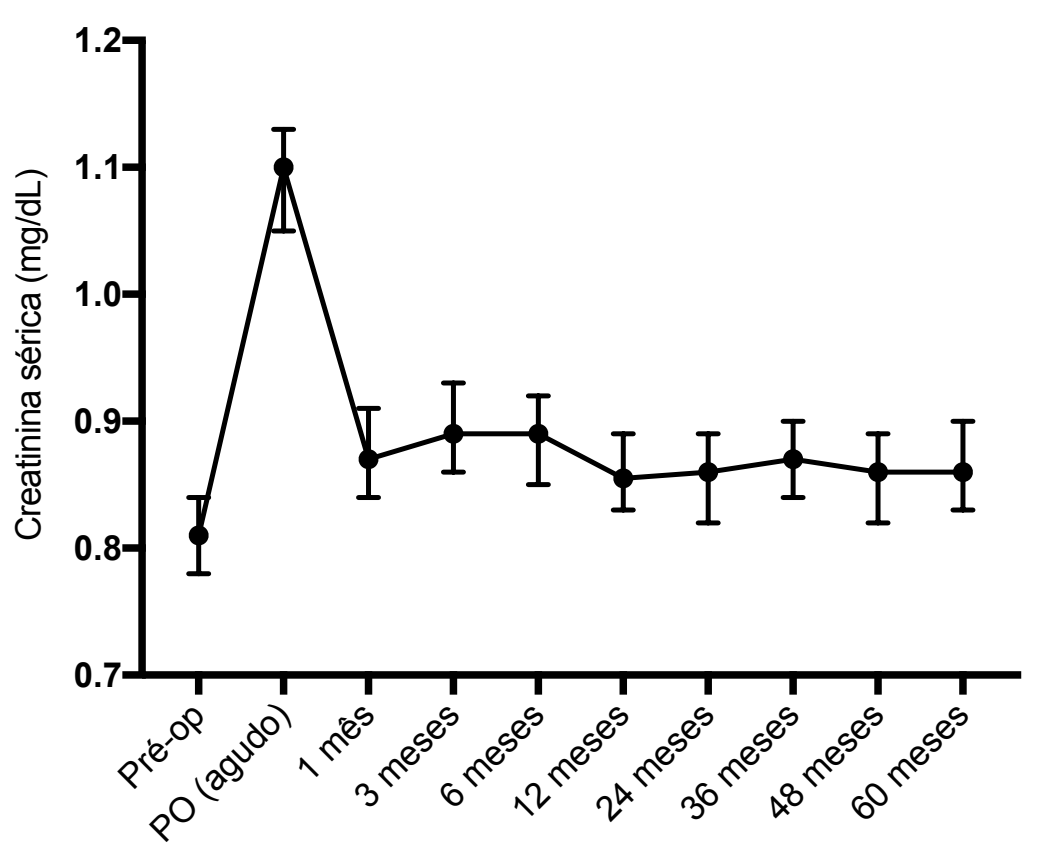

Gráfico 2 - Valores de mediana e IC $95 \%$ de creatinina sérica $(\mathrm{mg} / \mathrm{dL})$ do préoperatório até 60 meses

Quando selecionados os pacientes com valores completos de $\mathrm{Cr}$ até 24 meses ( $\mathrm{Cr}$ pré, PO, 1m, 12m e $24 \mathrm{~m}$ ), foi possível aplicar teste de Friedman com medidas pareadas. Neste cenário, observa-se padrão de elevação aguda ( $\mathrm{Cr}$ pré vs. $\mathrm{PO}$ ), com redução parcial da creatinina até 1 mês e posterior estabilização. Houve diferença entre $\mathrm{Cr}$ pré-op e todas as demais até $24 \mathrm{~m}$ ( $p<0,0001)$, assim como entre $\mathrm{Cr} \mathrm{PO}$ e todas as demais até $24 \mathrm{~m}$ ( $p<0,0001)$. Não houve diferença entre a $\mathrm{Cr} 1$ mês e as demais (12 e $24 \mathrm{~m})$. A Tabela 5 elenca os valores de creatinina com dados completos até 24 meses.

Tabela 5 - Valores de creatinina sérica $(\mathrm{mg} / \mathrm{dL})$ em pacientes com dados completos de Cr pré-op, Cr PO, Cr 1m, Cr 12m e Cr 24m

\begin{tabular}{l|ccccc}
\hline & Cr pré-op & Cr PO & Cr 1m & Cr 12m & Cr 24m \\
\hline $\mathrm{n}$ & $\mathbf{2 8 4}$ & $\mathbf{2 8 4}$ & $\mathbf{2 8 4}$ & $\mathbf{2 8 4}$ & $\mathbf{2 8 4}$ \\
Min & 0,28 & 0,57 & 0,35 & 0,51 & 0,47 \\
Q1 & 0,7 & 0,9125 & 0,73 & 0,74 & 0,75 \\
Mediana & $\mathbf{0 , 8 4}$ & $\mathbf{1 , 1 3}$ & $\mathbf{0 , 9}$ & $\mathbf{0 , 9}$ & $\mathbf{0 , 8 9}$ \\
Q3 & 1,048 & 1,565 & 1,16 & 1,138 & 1,178 \\
Max & 3,76 & 5,15 & 3,49 & 4,23 & 4,66 \\
\hline
\end{tabular}


A taxa de filtração glomerular estimada (eGFR) pré-operatória variou de 16 a $150 \mathrm{~mL} / \mathrm{min} \times 1,73 \mathrm{~m}^{2}$, com mediana de $86 \mathrm{~mL} / \mathrm{min} \times \mathbf{1 , 7 3 \mathrm { m } ^ { 2 }}$ e Q1-Q3 de 65-101,3. No período agudo após a paratireoidectomia, a eGFR pré-operatória foi superior às eGFR dos dias 1, 2, 3 e 4 ( $p<0,0001)$. Entre os valores diários de eGFR, a mediana do $1^{\circ} \mathrm{PO}$ foi similar a $2^{\circ} \mathrm{PO}(\mathrm{p}=0,8529)$ e $3^{\circ} \mathrm{PO}(\mathrm{p}=0,1406)$, porém diferente do $4^{\circ}$ PO $(p=0,0281)$. O Gráfico 3 mostra a variação percentual de eGFR no período agudo (internação), comparada à eGFR basal (pré-operatória).

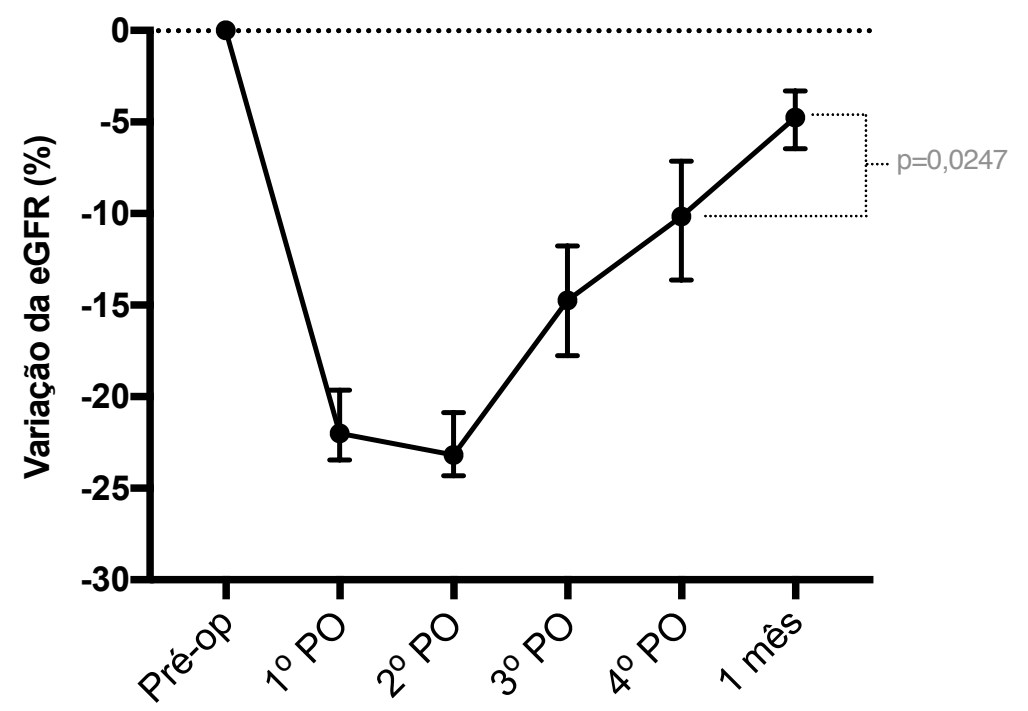

Gráfico 3 - Valores de mediana e IC 95\% da variação de eGFR (\%) no período agudo, até 1 mês de pós-operatório

O Gráfico 4 ilustra as curvas de eGFR até 60 meses de seguimento pósoperatório. Os valores eGFR do pré-operatório até 60 meses de seguimento estão expostos na Tabela 6. 


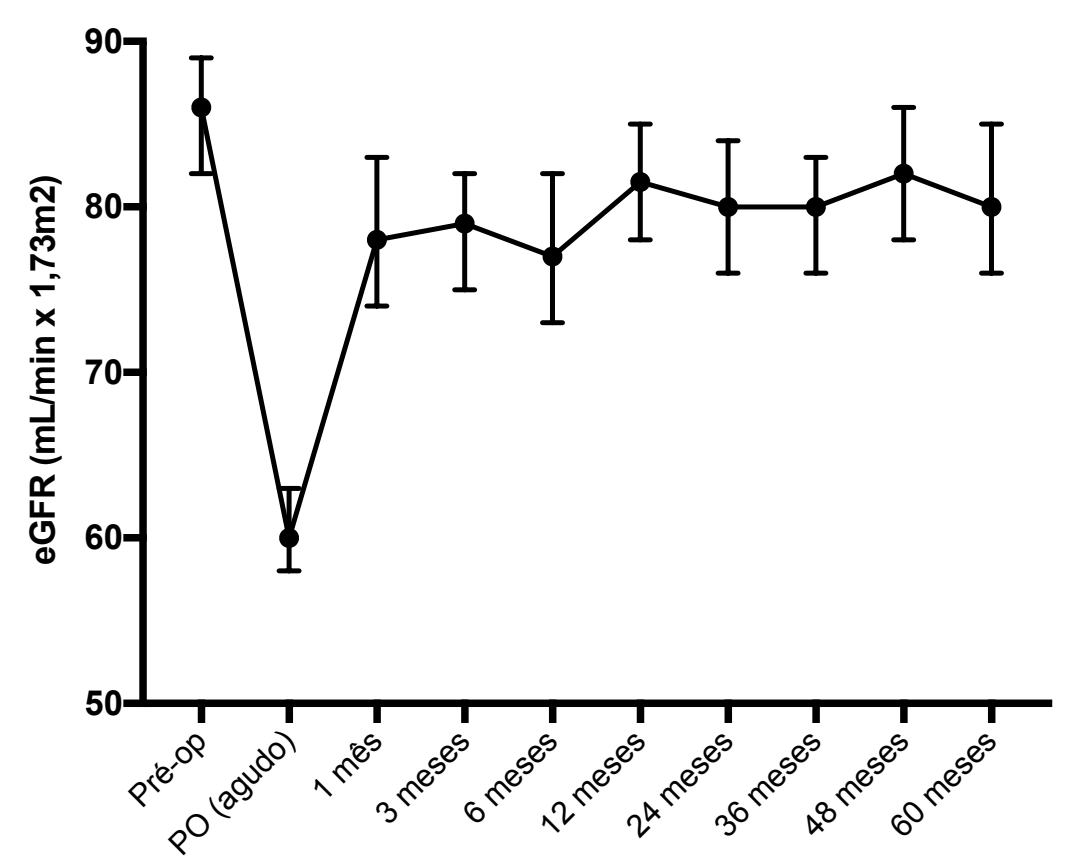

Gráfico 4 - Valores de mediana e IC 95\% de eGFR $\left(\mathrm{mL} / \mathrm{min} \times 1,73 \mathrm{~m}^{2}\right)$ do préoperatório até 60 meses

Tabela 6 - Valores de eGFR $\left(\mathrm{mL} / \mathrm{min} \times 1,73 \mathrm{~m}^{2}\right)$ do pré-operatório até 60 meses

\begin{tabular}{|c|c|c|c|c|c|c|c|c|c|c|}
\hline & $\begin{array}{c}\text { eGFR } \\
\text { pré }\end{array}$ & $\begin{array}{c}\text { eGFR } \\
\text { PO }\end{array}$ & $\begin{array}{c}\text { eGFR } \\
1 \mathrm{~m} \\
\end{array}$ & $\begin{array}{c}\text { eGFR } \\
3 \mathrm{~m}\end{array}$ & $\begin{array}{c}\text { eGFR } \\
6 \mathrm{~m}\end{array}$ & $\begin{array}{c}\text { eGFR } \\
12 \mathrm{~m}\end{array}$ & $\begin{array}{c}\text { eGFR } \\
24 \mathrm{~m}\end{array}$ & $\begin{array}{c}\text { eGFR } \\
36 \mathrm{~m}\end{array}$ & $\begin{array}{c}\text { eGFR } \\
48 \mathrm{~m} \\
\end{array}$ & $\begin{array}{c}\text { eGFR } \\
60 \mathrm{~m}\end{array}$ \\
\hline$n$ & 494 & 494 & 395 & 347 & 409 & 450 & 362 & 323 & 255 & 193 \\
\hline Min & 16 & 10 & 14 & 10 & 5 & 7 & 12 & 13 & 10 & 8 \\
\hline Q1 & 65 & 41 & 59 & 56 & 56 & 59 & 60 & 61 & 61 & 63,5 \\
\hline $\begin{array}{l}\text { Media } \\
\text { na }\end{array}$ & 86 & 60 & 78 & 79 & 77 & 81,5 & 80 & 80 & 82 & 80 \\
\hline Q3 & 101,3 & 80,3 & 96 & 96 & 95,5 & 96 & 97 & 97 & 97 & 96 \\
\hline Max & 150 & 135 & 150 & 147 & 138 & 148 & 136 & 145 & 137 & 139 \\
\hline
\end{tabular}

* eGFR PO: eGFR mais baixa entre o $1^{\circ}$ e $4^{\circ}$ dias de pós-operatório.

Observou-se que houve queda da eGFR agudamente (pré-op vs. PO) com diferença entre as medianas de $-26 \mathrm{~mL} / \mathrm{min} \times 1,73 \mathrm{~m}^{2}(p<0,0001)$. Verificou-se recuperação parcial da eGFR entre PO e 1 mês, com diferença de $+18 \mathrm{~mL} / \mathrm{min} x$ $1,73 m^{2}(p<0,0001)$. Houve diferença entre as medianas de eGFR pré-op e todas as eGFR até 60 meses. Após eGFR 1 mês, não houve diferença entre as eGFR tardias até 60 meses. O Gráfico 5 ilustra a variação percentual de eGFR comparada aos valores basais pré-operatórios. 


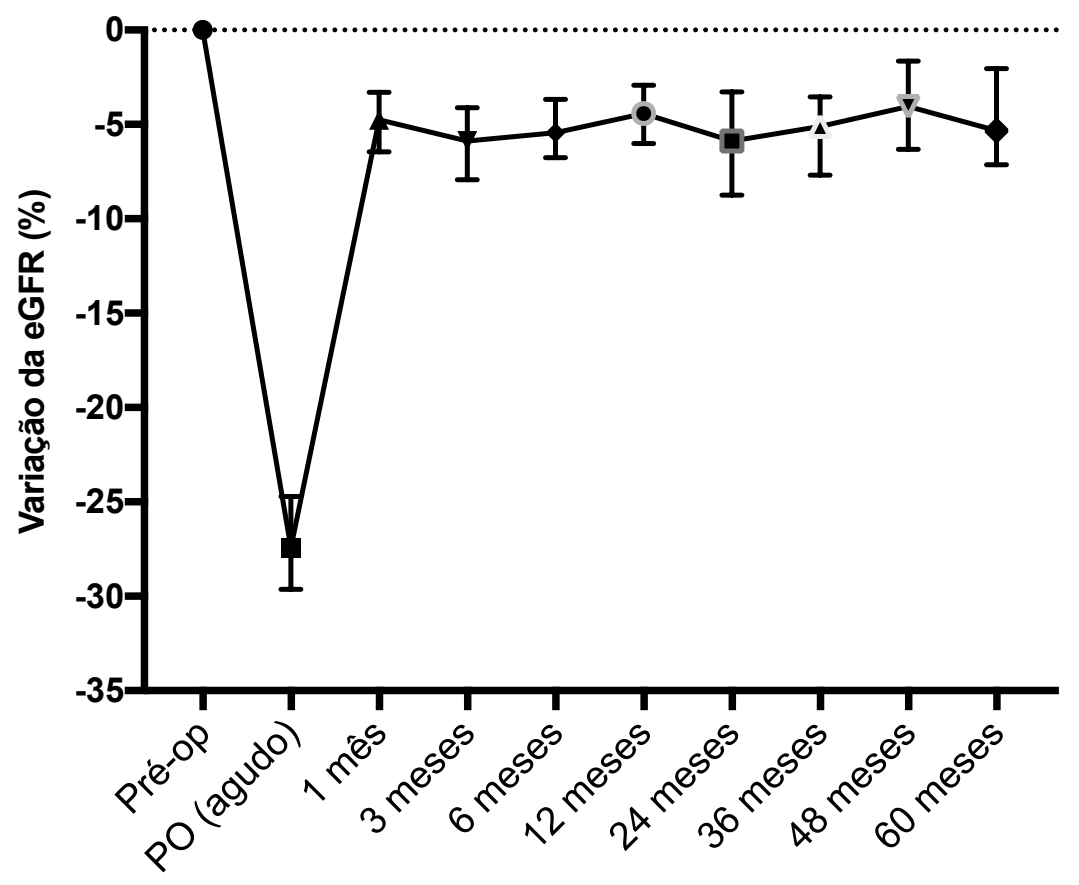

Gráfico 5 - Valores de mediana e IC 95\% da variação de eGFR (\%) até 60 meses de pós-operatório

Quando selecionados os pacientes com todas as medidas de eGFR até 24 meses (pré-op, PO, 1m, 12m e 24m), foi possível aplicar teste de Friedman de amostras repetidas, com diferença significante $(p<0,0001)$. Houve diferença entre as medianas de eGFR pré-op e PO entre si $(p<0,0001)$ e em relação às demais eGFR até 24 meses $(p<0,0001)$. As medianas de eGFR $1 \mathrm{~m}$ foram semelhantes às demais tardias (12 e 24 meses). Nessa amostra, a diferença entre a mediana de eGFR préop e eGFR $1 \mathrm{~m}$ foi de $-5,5 \mathrm{~mL} / \mathrm{min} \times 1,73 \mathrm{~m}^{2}$ ( $\left.\mathrm{p}<0,0001\right)$. A Tabela 7 mostra os valores de eGFR dos pacientes com dados completos até 24 meses. O Grafico 6 ilustra as medianas de eGFR dos 284 pacientes com dados completos até 24 meses.

Tabela 7 - Valores de eGFR (mL/min x 1,73m²) em pacientes com dados completos de eGFR pré-op, PO, 1 mês, 12 meses e 24 meses

\begin{tabular}{l|ccccc}
\hline & eGFR pré-op & eGFR PO & eGFR 1m & eGFR 12m & eGFR 24m \\
\hline $\mathrm{n}$ & $\mathbf{2 8 4}$ & $\mathbf{2 8 4}$ & $\mathbf{2 8 4}$ & $\mathbf{2 8 4}$ & $\mathbf{2 8 4}$ \\
Min & 16 & 11 & 14 & 14 & 12 \\
Q1 & 62 & 40 & 57 & 57 & 55 \\
Mediana & $\mathbf{8 2}$ & $\mathbf{5 8}$ & $\mathbf{7 6 , 5}$ & $\mathbf{7 8}$ & $\mathbf{7 8}$ \\
Q3 & 98,8 & 76 & 94,8 & 93 & 93,8 \\
Max & 149 & 129 & 150 & 148 & 136 \\
\hline
\end{tabular}




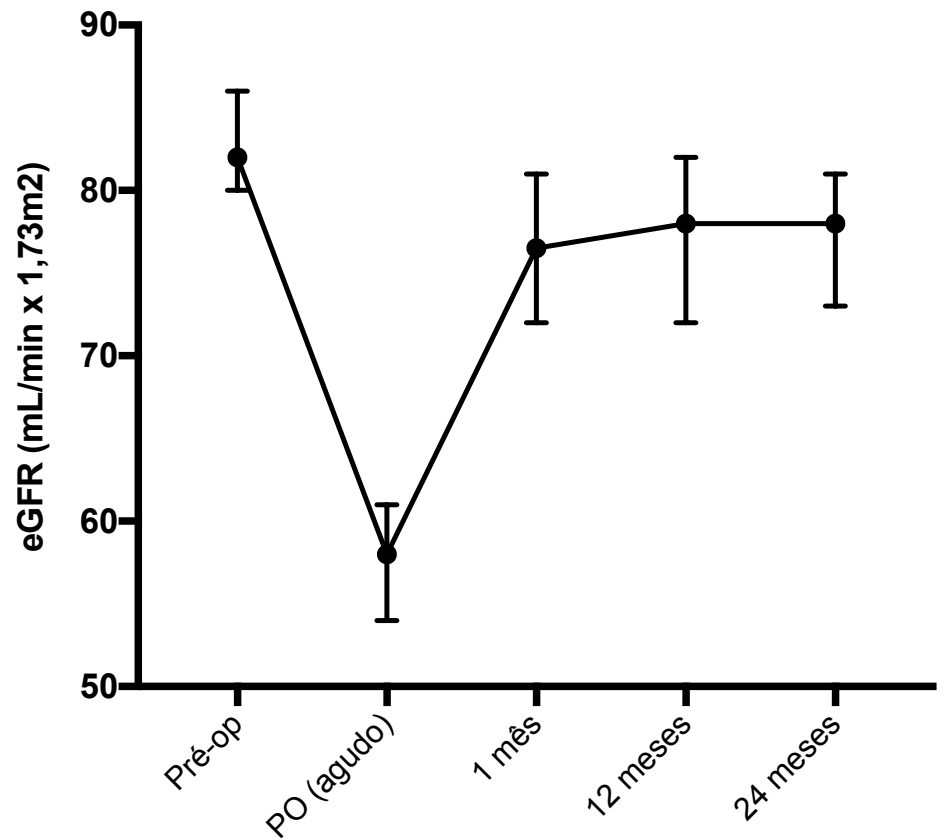

Gráfico 6 - Valores de mediana e IC 95\% de eGFR ( $\left.\mathrm{mL} / \mathrm{min} \times 1,73 \mathrm{~m}^{2}\right)$ do préoperatório até 24 meses, em pacientes com dados completos

Cronicamente, uma redução permanente da eGFR foi observada em $60,7 \%$ dos pacientes após 12 meses da paratireoidectomia, com diferença mediana (Q1Q3) entre os valores basais de $\mathbf{- 4 , 4 2 \%}(-15$ a 4,48$)$. Além desses, outros $5,8 \%$ voltaram aos valores basais de eGFR e outros 33,6\% tiveram melhora da função renal após 1 ano da cirurgia.

A variação aguda da eGFR teve média de $-27,44 \%$ e DP $\pm 19,12 \%$. Quando se comparou a variação aguda da eGFR com os outros dados pré-operatórios, por meio do teste de correlação de Spearman, algumas correlações foram feitas e estão resumidas na Tabela 8 .

Tabela 8 - Correlações entre variação aguda da eGFR (\%) e variáveis préoperatórias

Variação aguda da eGFR (\%) vs.

\begin{tabular}{c|cccccc}
\cline { 2 - 7 } & Idade & PTH & CaT & Cal & Cr & eGFR \\
\hline $\begin{array}{c}\text { Spearman } \\
r\end{array}$ & $-0,196$ & $-0,235$ & $-0,158$ & $-0,181$ & $-0,145$ & 0,213 \\
IC $95 \%$ & $-0,282 a-$ & $-0,319 a-$ & $-0,245 a-$ & $-0,267 a-$ & $-0,233 a-$ & $0,124 a$ \\
& 0,107 & 0,148 & 0,068 & 0,091 & 0,055 & 0,298 \\
$p$ & $<0,0001$ & $<0,0001$ & 0,0004 & $<0,0001$ & 0,0012 & $<0,0001$ \\
\hline
\end{tabular}


Houve correlação negativa entre a variação aguda da eGFR e os níveis préoperatórios de PTH, cálcio total e iônico, creatinina e idade. Verificou-se correlação positiva significativa entre variação aguda e calciúria de $24 h(r=0,158 / p=0,0019)$, fósforo sérico $(r=0,159 / p=0,0004)$ e eGFR pré-operatória. Os Gráficos 7 e 8 ilustram estas correlações com Idade e PTH, respectivamente.

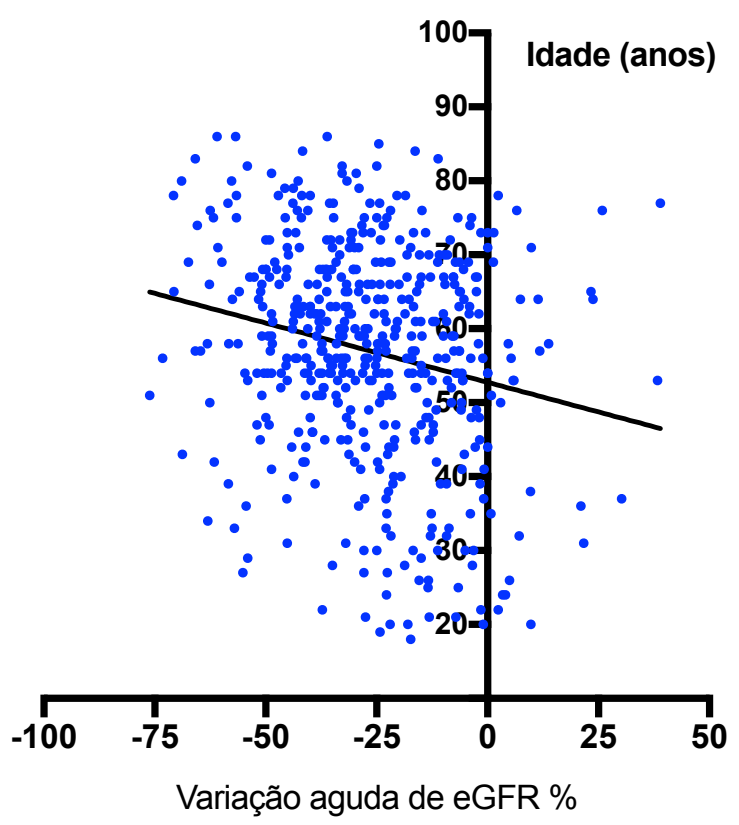

Gráfico 7 - Correlação entre variação aguda da eGFR (\%) e Idade (anos)

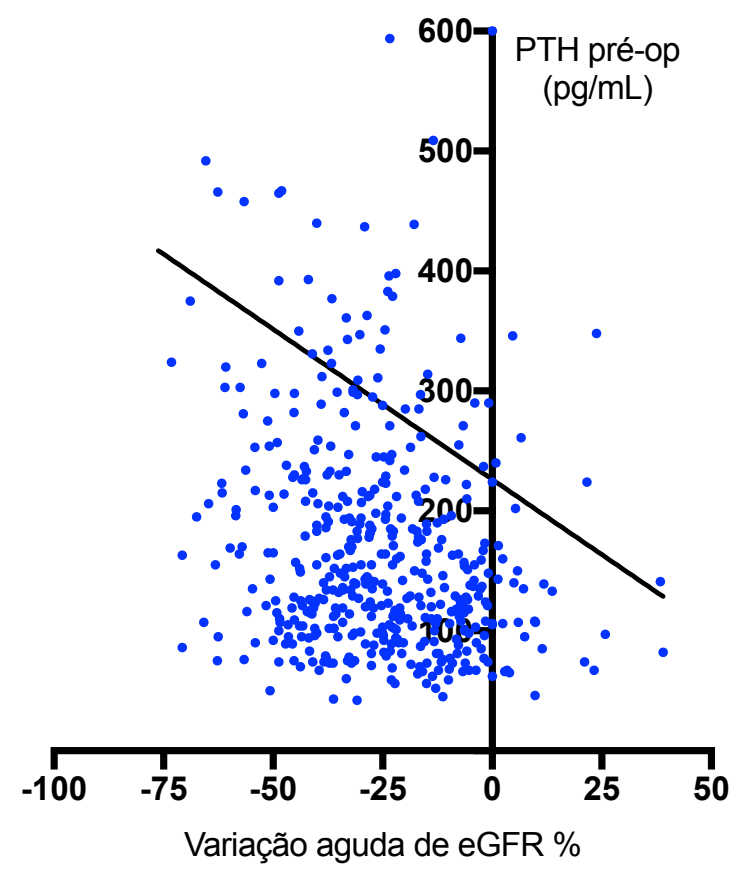

Gráfico 8 - Correlação entre variação aguda da eGFR (\%) e PTH pré-operatório (pg/mL) 
O percentual de variação crônica da eGFR (12 meses) teve mediana (Q1Q3) de $-4,421 \%$ (-15 a 4,484). A Tabela 9 ilustra as correlações entre variação crônica e as demais variáveis.

Tabela 9 - Correlações entre variação crônica (12 meses) da eGFR (\%) e variáveis pré e pós-operatórias

\begin{tabular}{|c|c|c|c|c|c|c|}
\hline & \multicolumn{6}{|c|}{ Variação crônica da eGFR (\%) vs. } \\
\hline & $\begin{array}{l}\text { Var. aguda } \\
\text { (\%) eGFR }\end{array}$ & $\begin{array}{l}\text { 25OHD } \\
\text { pré-op }\end{array}$ & $\begin{array}{c}\mathbf{P} \\
\text { pré-op }\end{array}$ & $\begin{array}{c}\text { Cal } \\
\text { pré-op }\end{array}$ & $\begin{array}{l}\text { PTH } \\
\text { pré-op }\end{array}$ & $\begin{array}{r}\text { eGFR } \\
\text { pré-op }\end{array}$ \\
\hline $\begin{array}{c}\text { Spearman } \\
r\end{array}$ & 0,4308 & 0,2087 & 0,1622 & $-0,1931$ & $-0,2027$ & $-0,1282$ \\
\hline IC 95\% & $\begin{array}{l}0,35 a \\
0,5052\end{array}$ & $\begin{array}{c}0,1104 a \\
0,3029\end{array}$ & $\begin{array}{c}0,0669 a \\
0,2546\end{array}$ & $\begin{array}{c}-0,283 a- \\
0,0997\end{array}$ & $\begin{array}{c}-0,2922 \mathrm{a}- \\
0,1096\end{array}$ & $\begin{array}{c}-0,2207 \mathrm{a}- \\
0,03347\end{array}$ \\
\hline $\mathrm{p}$ & $<0,0001$ & $<0,0001$ & 0,0006 & $<0,0001$ & $<0,0001$ & 0,0065 \\
\hline
\end{tabular}

Verificou-se correlação positiva da variação crônica de eGFR com 25-OH vitamina $\mathrm{D}$ e fósforo pré-operatórios, assim como o percentual de variação da eGFR no período agudo. Por outro lado, houve correlação negativa significante entre a variação crônica da eGFR as medidas pré-operatórias de PTH, cálcio iônico e eGFR.

\subsection{CLASSIFICAÇÃO QUANTO À INJÚRIA RENAL AGUDA}

Foi estudada a incidência de injúria renal aguda (IRA) entre os pacientes operados e realizada estratificação por gravidade (estágios), utilizando a classificação do KDIGO. A Tabela 10 ilustra a distribuição conforme o padrão de variação aguda da creatinina. 
Tabela 10 - Distribuição dos pacientes conforme padrão de variação da creatinina no período pos-operatório agudo

\begin{tabular}{l|cc}
\hline & $\mathbf{n}$ & $\%$ \\
\hline Grupo S+ ( $\downarrow$ Cr PO) & 30 & 6,1 \\
Grupo S0 ( $\uparrow$ Cr PO sem IRA) & 223 & 45,1 \\
IRA estágio 1 (S1) & 203 & 41,1 \\
IRA estágio 2 (S2) & 29 & 5,9 \\
IRA estágio 3 (S3) & 9 & 1,8 \\
Total & $\mathbf{4 9 4}$ & $\mathbf{1 0 0}$ \\
\hline
\end{tabular}

O padrão de elevação da eGFR $(\downarrow C r)$ no pós-operatório do grupo S+ está representado no Gráfico 9 , juntamente com o grupo S0, que não preencheu critérios para IRA, apesar da queda na eGFR.

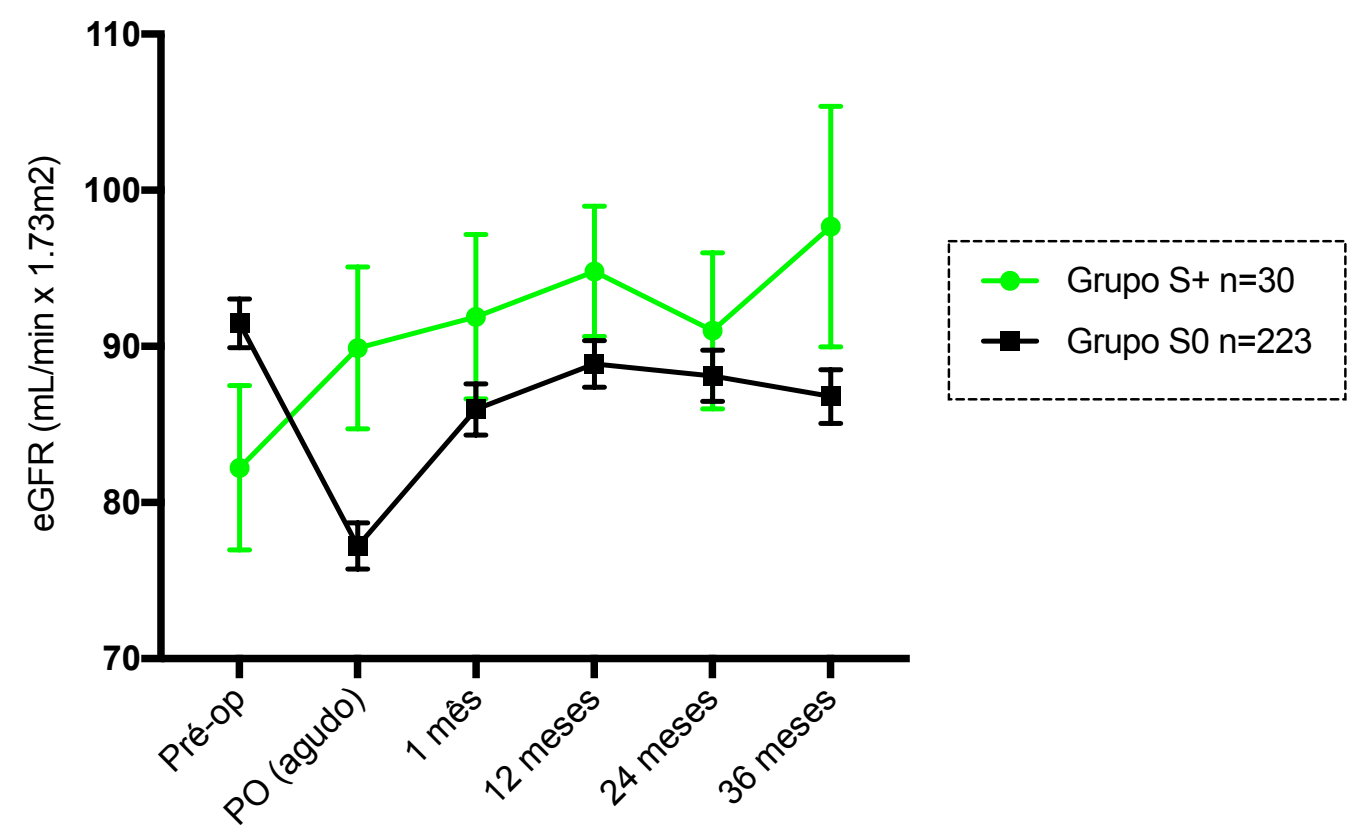

Gráfico 9 - Médias e EPM de eGFR $\left(\mathrm{mL} / \mathrm{min} \times 1,73 \mathrm{~m}^{2}\right)$ dos grupos $\mathrm{S}+$ e S0 (Sem IRA), até 36 meses de pós-operatório

A comparação das medianas de eGFR, entre todos os períodos do grupo S+, não mostrou diferença estatisticamente significante, apesar da tendência de elevação a longo prazo. Quando selecionados os pacientes com dados completos até 12 meses $(n=17)$, utilizando teste de medidas pareadas, houve diferença entre 
eGFR pré-op e eGFR PO ( $p=0,0003)$ e entre eGFR pré-op e eGFR 1m ( $p=0,048)$. Entre eGFR pré-op e 12 meses a diferença não foi significativa $(p=0,068)$.

A curva de eGFR do grupo $\mathbf{S 0}$ mostrou diferença entre as medianas de -18 $\mathrm{mL} / \mathrm{min} \times 1,73 \mathrm{~m}^{2}$ do pré-operatório para eGFR PO $(p<0,0001)$. O teste MannWhitney mostrou diferença também entre eGFR pré-op e eGFR $1 \mathrm{~m}(\mathrm{p}=0,0112)$. Não houve diferença entre eGFR pré-op e eGFR 12m ( $p=0,149)$ e 24 meses $(p=0,106)$.

Quando selecionados apenas os pacientes do grupo SO com dados completos até 24 meses (eGFR pré-op, PO, 1m, 12m e 24m), houve diferença entre eGFR pré-op e todas as demais até 24 meses, utilizando teste ANOVA com medidas repetidas. A eGFR PO foi inferior à todas as demais eGFR até 24 meses $(p<0,0001)$. A diferença média da eGFR no período agudo (pré-op - PO), nesse grupo, foi de $14,3 \mathrm{~mL} / \mathrm{min} \times 1,73 \mathrm{~m}^{2}$. Não houve diferença entre as demais eGFR após 1 mês.

Os pacientes que preencheram critérios de IRA (qualquer estágio) representaram $48,8 \%$ da amostra ( $n=241)$. O Gráfico 10 ilustra as curvas de eGFR entre os grupos.

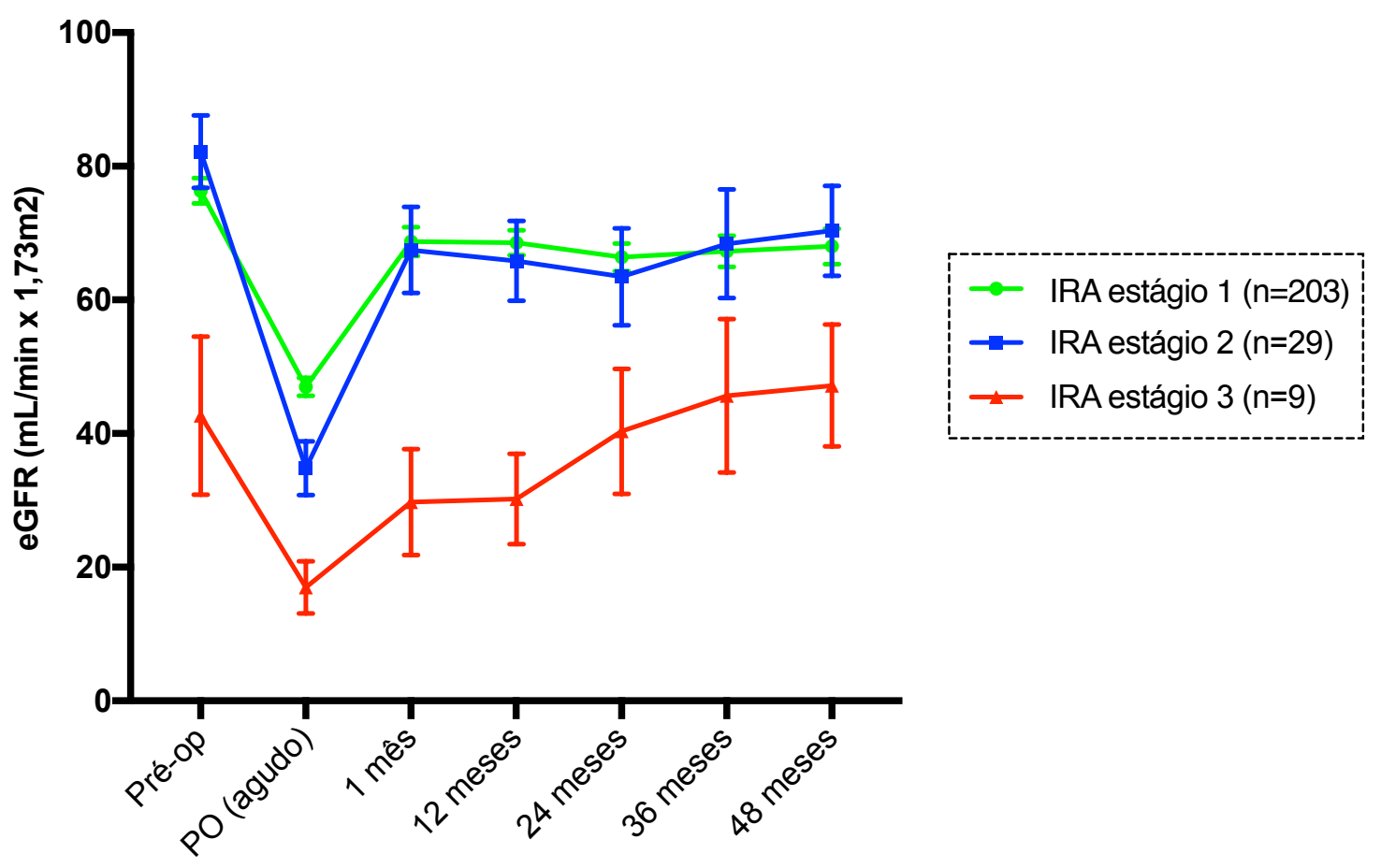

Gráfico 10 - Médias e EPM de eGFR $\left(\mathrm{mL} / \mathrm{min} \times 1,73 \mathrm{~m}^{2}\right)$ entre grupos IRA estágios 1 a 3 , até 48 meses 
Nos pacientes com critérios para IRA estágio 1, observou-se queda aguda da eGFR com recuperação parcial até 1 mês, porém sem retornar aos valores basais. Houve diferença entre eGFR PO e todas as outras eGFR $(p<0,0001)$. A eGFR préop foi significativamente superior a todas as eGFR pós-op até 60 meses, sendo a diferença das medianas de $-8 \mathrm{~mL} / \mathrm{min} \times 1,73 \mathrm{~m}^{2}$ entre eGFR pré-op e 1 mês $(p=0,0108)$. Não houve diferença estatística entre eGFR $1 \mathrm{~m}$ e as demais eGFR tardias. A Tabela 11 resume os valores de eGFR do grupo S1 até 36 meses.

Tabela 11 - Valores de eGFR $\left(\mathrm{mL} / \mathrm{min} \times 1,73 \mathrm{~m}^{2}\right)$ até 36 meses no grupo IRA estágio 1 (S1)

\begin{tabular}{l|cccccc}
\hline & eGFR pré-op & eGFR PO & eGFR 1m & eGFR 12m & eGFR 24m & eGFR 36m \\
\hline $\mathrm{n}$ & $\mathbf{2 0 3}$ & $\mathbf{2 0 3}$ & $\mathbf{1 6 9}$ & $\mathbf{1 8 4}$ & $\mathbf{1 4 6}$ & $\mathbf{1 2 6}$ \\
Min & 17 & 11 & 14 & 14 & 12 & 13 \\
Q1 & 56 & 33 & 46 & 50 & 46 & 48 \\
Mediana & $\mathbf{8 0}$ & $\mathbf{4 6}$ & $\mathbf{7 2}$ & $\mathbf{7 1}$ & $\mathbf{7 0}$ & $\mathbf{7 0 , 5}$ \\
Q3 & 96 & 58 & 90,5 & 88,75 & 87 & 88 \\
Max & 150 & 130 & 150 & 129 & 115 & 134 \\
\hline
\end{tabular}

Os 29 pacientes com IRA estágio 2 tiveram redução aguda da eGFR mais acentuada, cuja diferença entre as medianas de eGFR pré-op e PO foi de -49 $\mathrm{mL} / \min \times 1,73 \mathrm{~m}^{2}(\mathrm{p}<0,0001)$. Observou-se recuperação parcial, semelhante ao grupo S1, com diferença entre eGFR pré-op e eGFR 1m ( $p=0,0662)$, eGFR 12m $(p=0,0319)$ e eGFR 24m ( $p=0,0336)$. Não houve diferença estatística entre eGFR $1 \mathrm{~m}$ e as demais eGFR tardias. Os dados de eGFR do grupo IRA estágio 2 são elencados na Tabela 12.

Tabela 12 - Valores de eGFR $\left(\mathrm{mL} / \mathrm{min} \times 1,73 \mathrm{~m}^{2}\right)$ até 36 meses, no grupo IRA estágio 2 (S2)

\begin{tabular}{l|cccccc}
\hline & eGFR pré-op & eGFR PO & eGFR 1m & eGFR 12m & eGFR 24m & eGFR 36m \\
\hline $\mathrm{n}$ & $\mathbf{2 9}$ & $\mathbf{2 9}$ & $\mathbf{2 5}$ & $\mathbf{2 7}$ & $\mathbf{1 9}$ & $\mathbf{1 7}$ \\
Min & 34 & 12 & 17 & 22 & 16 & 18 \\
Q1 & 56,5 & 22 & 41,5 & 42 & 34 & 42,5 \\
Mediana & $\mathbf{7 8}$ & $\mathbf{2 9}$ & $\mathbf{6 2}$ & $\mathbf{5 6}$ & $\mathbf{6 1}$ & $\mathbf{6 4}$ \\
Q3 & 102,5 & 41,5 & 88,5 & 89 & 93 & 97,5 \\
Max & 148 & 111 & 150 & 148 & 134 & 133 \\
\hline
\end{tabular}


No grupo IRA estágio $3(n=9)$ se repete o padrão de queda aguda com diferença entre eGFR pré-op vs. PO ( $p=0,0003)$. Não houve diferença estatística entre eGFR préop e as demais eGFR, com exceção da eGFR PO. Também não houve diferença estatística entre eGFR $1 \mathrm{~m}$ e as demais medidas tardias. Os dados de eGFR do grupo IRA estágio 3 são demonstrados na Tabela 13.

Tabela 13 - Valores de eGFR $\left(\mathrm{mL} / \mathrm{min} \times 1,73 \mathrm{~m}^{2}\right)$ até 36 meses, no grupo IRA estágio 3 (S3)

\begin{tabular}{l|cccccc}
\hline & eGFR pré-op & eGFR PO & eGFR 1m & eGFR 12m & eGFR 24m & eGFR 36m \\
\hline $\mathrm{n}$ & $\mathbf{9}$ & $\mathbf{9}$ & $\mathbf{8}$ & $\mathbf{9}$ & $\mathbf{6}$ & $\mathbf{6}$ \\
Min & 16 & 10 & 17 & 7 & 12 & 13 \\
Q1 & 20,5 & 11,5 & 17,25 & 14,5 & 23,25 & 19,75 \\
Mediana & $\mathbf{2 5}$ & $\mathbf{1 2}$ & $\mathbf{1 9 , 5}$ & $\mathbf{2 6}$ & $\mathbf{3 5}$ & $\mathbf{4 2 , 5}$ \\
Q3 & 64,5 & 17,5 & 32,5 & 49 & 62,75 & 70,5 \\
Max & 117 & 47 & 83 & 64 & 74 & 90 \\
\hline
\end{tabular}

O Gráfico 11 ilustra a variação absoluta de eGFR em relação aos valores basais, nos 3 grupos com critérios de IRA.

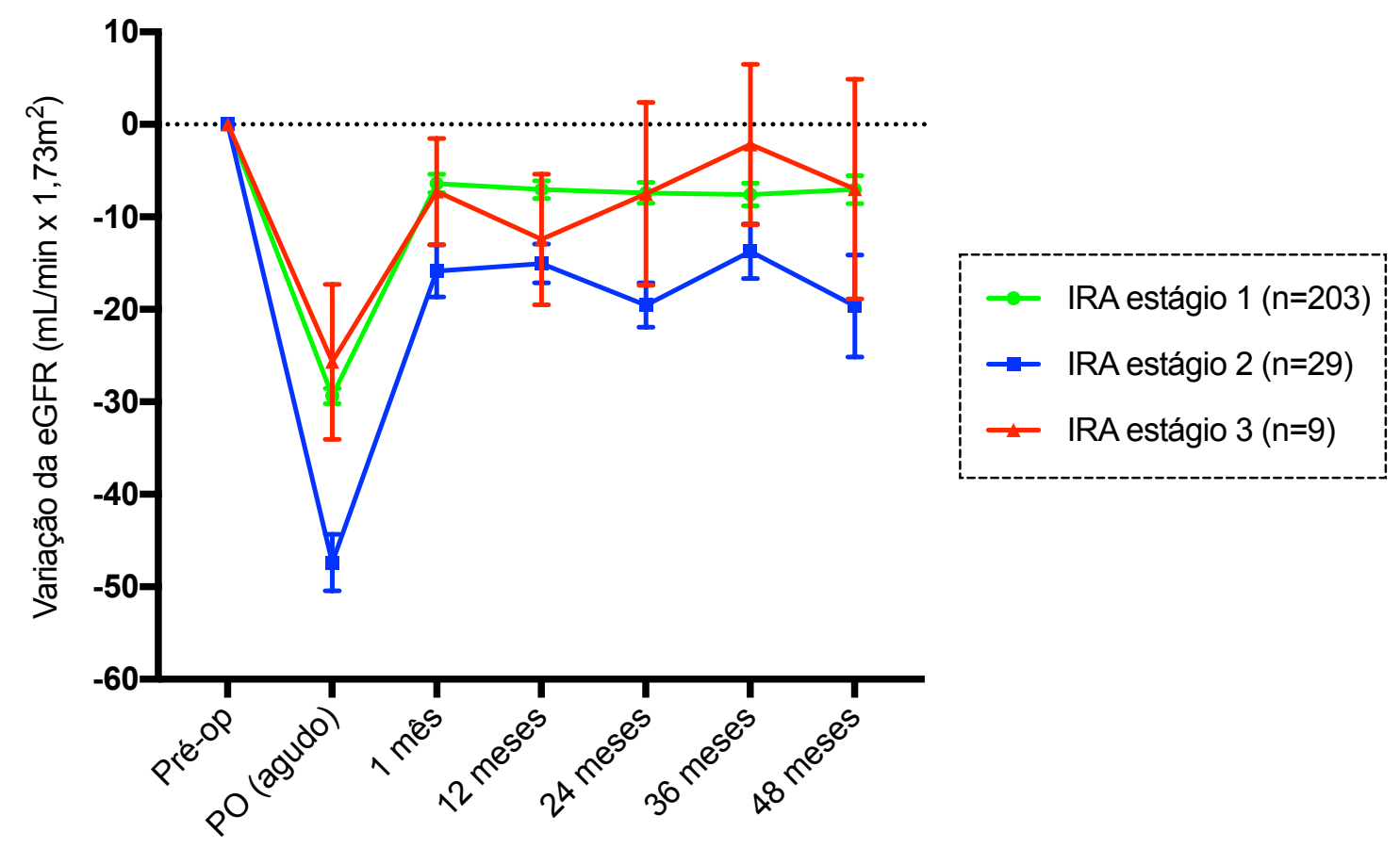

Gráfico 11 - Médias e EPM da variação de eGFR ( $\left.\mathrm{mL} / \mathrm{min} \times 1,73 \mathrm{~m}^{2}\right)$ comparada aos valores basais, nos pacientes com IRA estágios 1 a 3, até 48 meses 
$\mathrm{Na}$ análise dos grupos com apenas pacientes com dados completos até 24 meses (eGFR pré-op, PO, 1m, 12m e 24m), foram utilizados testes com medidas pareadas. $O$ grupo IRA estágio 1 mostrou diferenças entre as eGFR pré-op e todas as eGFR tardias até 24 meses $(p=0,0001)$, utilizando teste ANOVA de medidas repetidas.

Agrupados, IRA estágios 2 e 3, somaram 22 pacientes com dados completos até 24 meses. Nesta análise foram significativas as diferenças entre medianas de eGFR pré-op e todas as demais eGFR até 24 meses, utilizando teste de Friedman Entre eGFR pré-op e eGFR $1 \mathrm{~m}$ a diferença entre as medianas foi de $-31,5 \mathrm{~mL} / \mathrm{min} \mathrm{x}$ $1,73 m^{2}(p=0,0003)$ pelo teste de Wilcoxon.

Além das curvas de eGFR, foram exploradas possíveis diferenças entre os grupos, em relação aos dados dos pacientes no pré-operatório, conforme mostra a Tabela 14.

Tabela 14 - Valores da mediana (Q1-Q3) de dados pré-operatórios nos diversos grupos por IRA

\begin{tabular}{|c|c|c|c|c|}
\hline & Sem IRA* & S1 & S2 & S3 \\
\hline $\mathbf{n}$ & 253 & 203 & 29 & 9 \\
\hline Idade & $56(44,5-65)$ & $62(53-68)$ & $65(45-76,5)$ & $57(51,5-60)$ \\
\hline Creatinina & $\mathbf{0 , 7 8}(0,65-0,92)$ & $\mathbf{0 , 8 6}(0,72-1,17)$ & $\mathbf{0 , 7 6}(0,69-1,08)$ & $2,2(1,50-2,72)$ \\
\hline eGFR & $94(74,5-106)$ & $80 \quad(56-96)$ & $78 \quad(56,5-102,5)$ & $25(20,5-64,5)$ \\
\hline PTH & $133(96-191,5)$ & $183(117-298)$ & $215(159-349,5)$ & $\begin{array}{c}1038(244- \\
1397)\end{array}$ \\
\hline CaT & $10,7(10,2-11,3)$ & $11(10,3-11,8)$ & $11(10,45-12,3)$ & $10,9(10,1-12,7)$ \\
\hline Cal & $\mathbf{5 , 8 5}(5,4-6,2)$ & $6,07(5,7-6,6)$ & $6,27(5,82-6,75)$ & $6,4(5,7-6,8)$ \\
\hline Fósforo & $2,7 \quad(2,4-3,1)$ & $2,6(2,2-3)$ & $2,4 \quad(2,12-2,9)$ & $3,4 \quad(2,7-4)$ \\
\hline $\begin{array}{l}\text { 25-OH vitamina } \\
\text { D }\end{array}$ & $19,3(15-24,9)$ & $19(14-24)$ & $16,3 \quad(9,6-26)$ & $11,6(9,5-13,5)$ \\
\hline $\mathrm{CaU} 24 \mathrm{~h}$ & $252(160,2-364)$ & $\begin{array}{c}193,5(96,4- \\
332,8)\end{array}$ & $\begin{array}{c}162,2(41,7- \\
293,3)\end{array}$ & $\begin{array}{c}154,4(42,8- \\
255,6)\end{array}$ \\
\hline
\end{tabular}

* Sem IRA compreende pacientes dos grupos $S+(n=30)$ e SO $(n=223)$. 
Houve diferença de idade entre o grupo Sem IRA e o grupo $S 1(p<0,0001)$ e S2 ( $p=0,038)$. Entre os grupos $S 1$, S2 e S3 não houve diferença estatística.

As medianas de creatinina pré-operatória foram superiores no grupo S3 comparadas às demais. Entre S3 e Sem IRA a diferença pré-operatória foi de 1,42 $\mathrm{mg} / \mathrm{dL}(\mathrm{p}<0,0001)$. Houve diferença também entre Sem IRA e S1 $(p<0,0001)$, porém sem diferença entre S1 e S2 $(p=0,132)$. Da mesma forma que a $\mathrm{Cr}$, houve diferença estatística entre eGFR pré-op do grupo $S 3$ e os demais, apesar da amostra restrita $(n=9)$. Teste de múltiplas comparações mostrou diferença significante entre S3 e Sem IRA ( $p=0,0002)$; S3 e S1 $(p=0,037)$; e S3 e S2 $(p=0,030)$. O grupo Sem IRA teve eGFR basal superior à $S 1(p<0,0001)$ e à $S 2(p=0,059)$. Entre os grupos $S 1$ e S2 não houve diferença significativa.

As medianas de PTH foram inferiores no grupo Sem IRA em comparação aos demais. O teste de Kruskal-Wallis mostrou diferença entre PTH pré-operatório do grupo Sem IRA vs. S1 ( $p<0,0001)$, S2 $(p=0,0003)$ e S3 $(p<0,0001)$. Houve discrepância também entre a mediana do grupo $S 3$ (mais elevada) e as demais $(p<0,0001)$, sem diferença entre S1 e S2 $(p=0,134)$. O Gráfico 12 ilustra os valores de PTH entre os grupos.

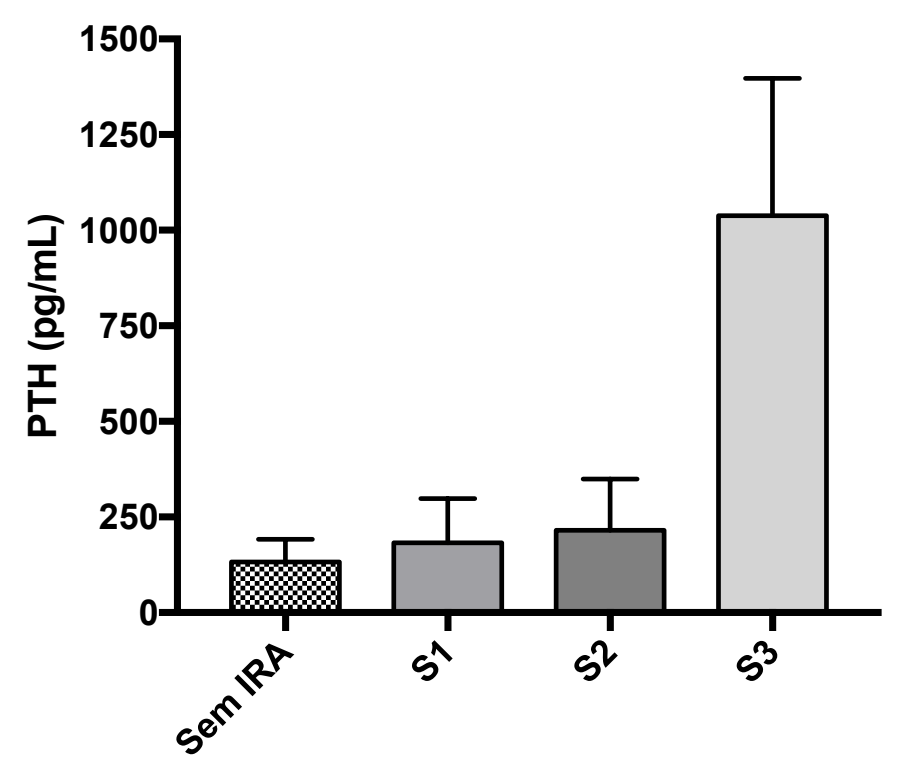

Gráfico 12 - Medianas (Q1-Q3) de PTH pré-operatório por grupos IRA KDIGO 
Houve diferença entre as medianas de cálcio total apenas entre os grupos Sem IRA e S1 $(p=0,0056)$. As observações para cálcio total também foram encontradas para o cálcio iônico.

Os valores de fósforo sérico foram diferentes no grupo S3, com mediana mais elevada, comparados aos grupos $S 1(p=0,011)$, $S 2(p=0,0052)$ e Sem IRA $(p=0,0186)$. Não houve diferença estatística entre e os demais grupos.

Os dados de calciúria de $24 \mathrm{~h}$ mostraram diferença do grupo Sem IRA, que teve mediana superior às dos demais grupos $S 1(p=0,0041), S 2(p=0,0118)$ e S3 $(p=0,030)$. Entre os grupos com IRA não houve diferença estatística.

Foi possível demonstrar diferença entre os valores de $25-\mathrm{OH}$ vitamina $\mathbf{D}$ do grupo S3, cuja mediana foi inferior às demais, comparada aos grupos Sem IRA $(p=0,0169)$ e $S 1$ ( $p=0,0337)$. Entre S2 e S3 não houve diferença significativa.

O resumo da análise por grupos, conforme ocorrência ou não de IRA no pós-operatório, mostrou um perfil de risco aumentado para IRA estágio 3 (severa) nos pacientes com pior função renal de base, com PTH e fósforo elevados, assim como $25-\mathrm{OH}$ vitamina $\mathrm{D}$ baixa. Por outro lado, os pacientes sem ocorrência de injúria renal tenderam à idade mais jovem, com maior eGFR basal, valores inferiores de PTH e calciúria de $24 \mathrm{~h}$ mais elevada que os demais.

\subsection{CLASSIFICAÇÃO POR GRUPOS CONFORME ETIOLOGIA}

Foi realizada estratificação em grupos por etiologia (causas do HPT primário) e algumas diferenças foram encontradas entre eles, como ilustrado no Gráfico 13, com as curvas de eGFR. 


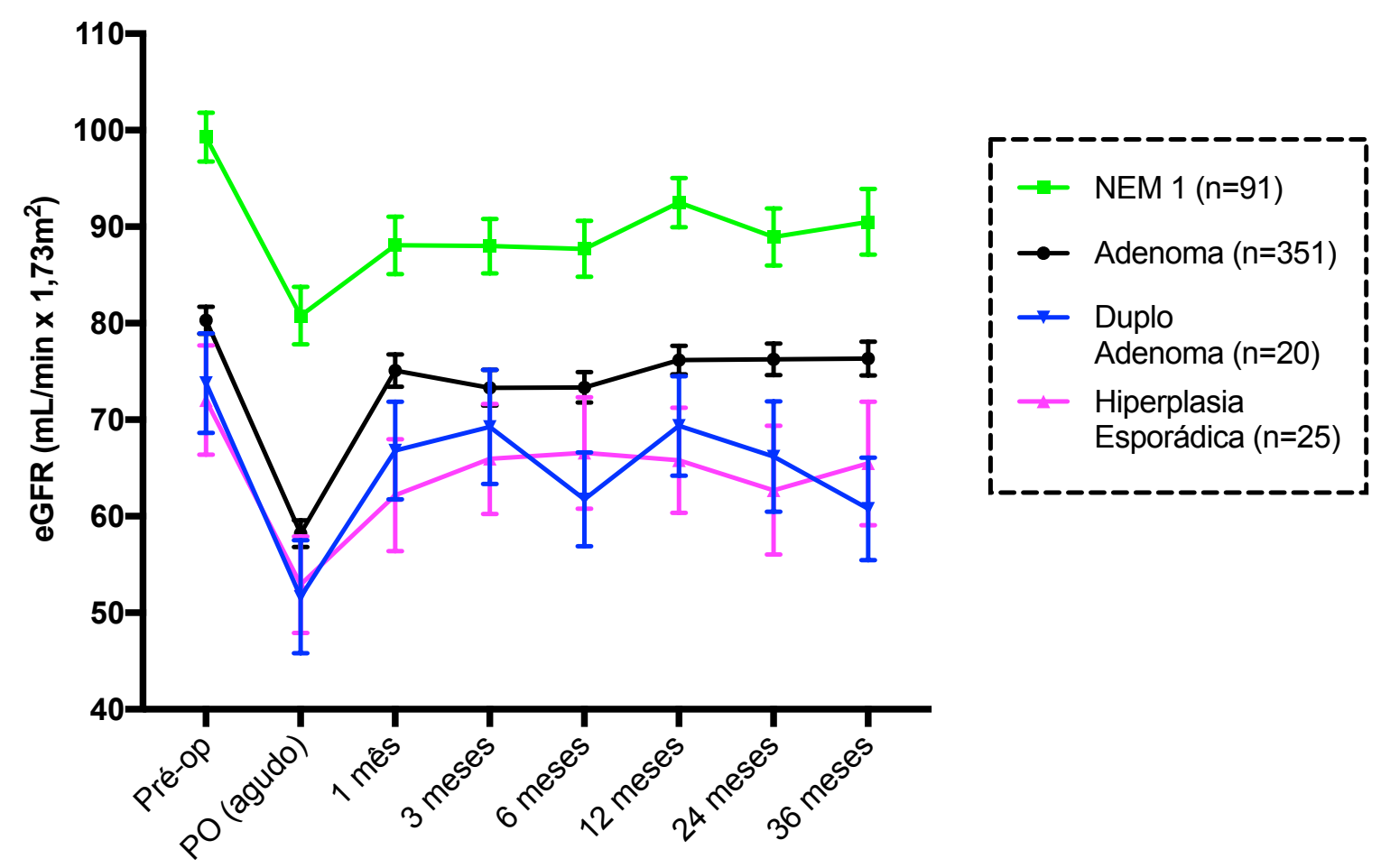

Gráfico 13 - Médias e ERM das eGFR $\left(\mathrm{mL} / \mathrm{min} \times 1,73 \mathrm{~m}^{2}\right)$ entre grupos por etiologia até 36 meses (excluídos pacientes do grupo Outros)

Nota-se que nos 4 grupos principais houve piora aguda da função renal (eGFR pré-op vs. PO) estatisticamente significante, independente da etiologia. No grupo Adenoma a diferença entre as medianas foi de $-25 \mathrm{~mL} / \mathrm{min} \times 1,73 \mathrm{~m}^{2}$ $(p<0,0001)$ no período agudo. Esta diferença não teve significância nos 7 pacientes do grupo Outros $(p=0,235)$.

Após a queda aguda da eGFR, houve recuperação parcial em todos os grupos (eGFR PO vs. 1 mês), com intensidades diferentes. Os pacientes com NEM1 mostraram curva de recuperação mais achatada, com diferença entre as medianas de eGFR PO e 1 mês de $+12 \mathrm{~mL} / \mathrm{min} \times 1,73 \mathrm{~m}^{2} \quad(p=0,0586)$. A eGFR $1 \mathrm{~m}$ foi estatisticamente inferior à eGFR pré-op nos grupos Adenoma $(p=0,0216)$ e NEM1 $(p=0,0031)$ utilizando teste de Mann-Whitney, porém sem diferença nos outros grupos. As eGFR 1 mês foram semelhantes estatisticamente às demais medidas tardias até 60 meses, em todos os grupos. As Tabelas 15 e 16 elencam os dados de eGFR dos grupos por etiologia, até 24 meses. 
Tabela 15 - Medianas (Q1-Q3) de eGFR $\left(\mathrm{mL} / \mathrm{min} \times 1,73 \mathrm{~m}^{2}\right)$ dos grupos Adenoma e NEM 1, até 24 meses

\begin{tabular}{lc|ccccc} 
& $\mathbf{n}$ & $\begin{array}{c}\text { eGFR } \\
\text { pré-op }\end{array}$ & eGFR PO & eGFR 1m & eGFR 12m & eGFR 24m \\
\hline Adenoma & 351 & $\mathbf{8 3 ( 6 1 - 9 8 )}$ & $\mathbf{5 8 ( 3 9 - 7 5 )}$ & $\mathbf{7 7 , 5 ( 5 5 - 9 5 )}$ & $\mathbf{7 9}(59-95)$ & $\mathbf{7 9}(58-95)$ \\
NEM1 & 91 & $\mathbf{1 0 2 ( 8 3 - 1 1 9 )}$ & $\mathbf{8 0 ( 5 8 - 1 0 3 )}$ & $\mathbf{9 2 ( 7 2 - 1 0 7 )}$ & $\mathbf{9 4}(75-110)$ & $\begin{array}{c}\mathbf{9 0 , 5} \\
(71-106)\end{array}$
\end{tabular}

Tabela 16 - Médias (DP) de eGFR $\left(\mathrm{mL} / \mathrm{min} \times 1,73 \mathrm{~m}^{2}\right)$ dos grupos por etiologia, até 24 meses, excluídos grupos Adenoma e NEM 1

\begin{tabular}{lc|ccccc}
\hline & $\mathbf{n}$ & $\begin{array}{c}\text { eGFR } \\
\text { pré-op }\end{array}$ & eGFR PO & eGFR 1m & eGFR 12m & eGFR 24m \\
\hline Hiperplasia & 25 & $\mathbf{7 2 , 0 4 ( 2 8 )}$ & $\mathbf{5 2 , 9}(24,9)$ & $\mathbf{6 2 , 2}(26,5)$ & $\mathbf{6 5 , 8}(27,3)$ & $\mathbf{6 2 , 7}(30,5)$ \\
Esporádica & & $\mathbf{7 3 , 8}(23)$ & $\mathbf{5 1 , 6}(26,2)$ & $\mathbf{6 6 , 8}(20,8)$ & $\mathbf{6 9 , 3}(22,4)$ & $\mathbf{6 6 , 2}(22,9)$ \\
Duplo Adenoma & 20 & $\mathbf{8 9 , 8}(35)$ & $\mathbf{6 7 , 9}(30,6)$ & $\mathbf{8 0 , 6}(34,5)$ & $\mathbf{7 5 , 8}(30,8)$ & $\mathbf{8 6 , 6}(15,8)$ \\
Outros & 7 & $\mathbf{8 9}$ & & &
\end{tabular}

$\mathrm{Na}$ análise do subgrupo de pacientes com todas as medidas de eGFR até 24 meses (eGFR pré-op, PO, 1m, 12m e $24 \mathrm{~m}$ ), houve diferença estatística entre eGFR pré-op e todos as demais eGFR até 24 meses, tanto nos 199 pacientes do grupo Adenoma $(p<0,0001)$, quanto nos 48 do grupo NEM1 $(p<0,0001)$, utilizando teste pareado com medidas repetidas.

No grupo Adenoma a queda aguda média foi de $-22,45 \mathrm{~mL} / \mathrm{min} \times 1,73 \mathrm{~m}^{2}$ $(p<0,0001)$ e a diferença entre a eGFR basal e 1 mês foi de $-5,47 \mathrm{~mL} / \mathrm{min} \times \mathbf{1 , 7 3 \mathrm { m } ^ { 2 }}$ $(p<0,0001)$. Após o $1^{\circ}$ mês, não houve diferença estatística entre as médias.

No grupo NEM1 com dados completos, a redução aguda de eGFR teve média de $-\mathbf{2 0 , 8 1} \mathrm{mL} / \mathrm{min} \times 1,73 \mathrm{~m}^{2}(p<0,0001)$ e a diferença entre a eGFR basal e 1 mês foi de $-10,04 \mathrm{~mL} / \mathrm{min} \times 1,73 \mathrm{~m}^{2}(\mathrm{p}=0,0004)$. Após eGFR $1 \mathrm{~m}$, também não houve diferença entre as médias até 24 meses. O Gráfico 14 compara as curvas de eGFR nos grupos Adenoma e NEM1, com dados completos até 24 meses. 


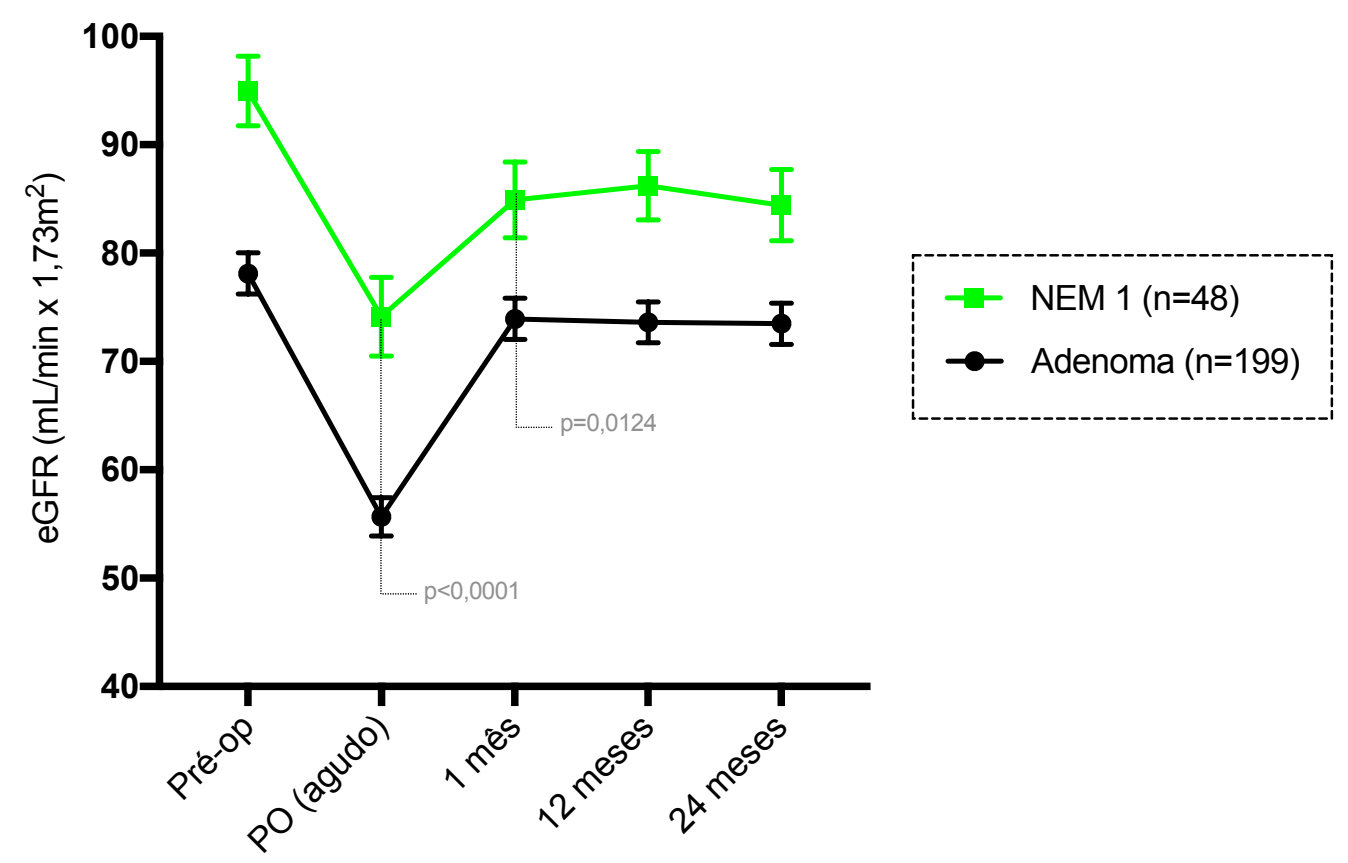

Gráfico 14 - Médias e EPM de eGFR $\left(\mathrm{mL} / \mathrm{min} \times 1,73 \mathrm{~m}^{2}\right)$ dos grupos Adenoma e NEM1 com dados completos, até 24 meses de pós-operatório

$\mathrm{Na}$ comparação entre os grupos, as medianas de creatinina pré-operatória foram diferentes apenas entre NEM1 e Adenoma $(p=0,0307)$, entre NEM1 e Hiperplasia Esporádica $(p=0,0120)$ e sem diferença com Duplo Adenoma $(p=0,0649)$. Os pacientes do grupo NEM 1 tiveram creatinina pré-operatória inferior à dos grupos citados.

As medianas de eGFR pré-operatórias do grupo NEM 1 foram estatisticamente superiores às demais ( $p<0,0001)$, com exceção do grupo OUTROS $(p=0,425)$. Não houve diferença dos demais grupos entre si. O Gráfico 15 ilustra as medianas de eGFR pré-operatórias, divididos por grupos. 


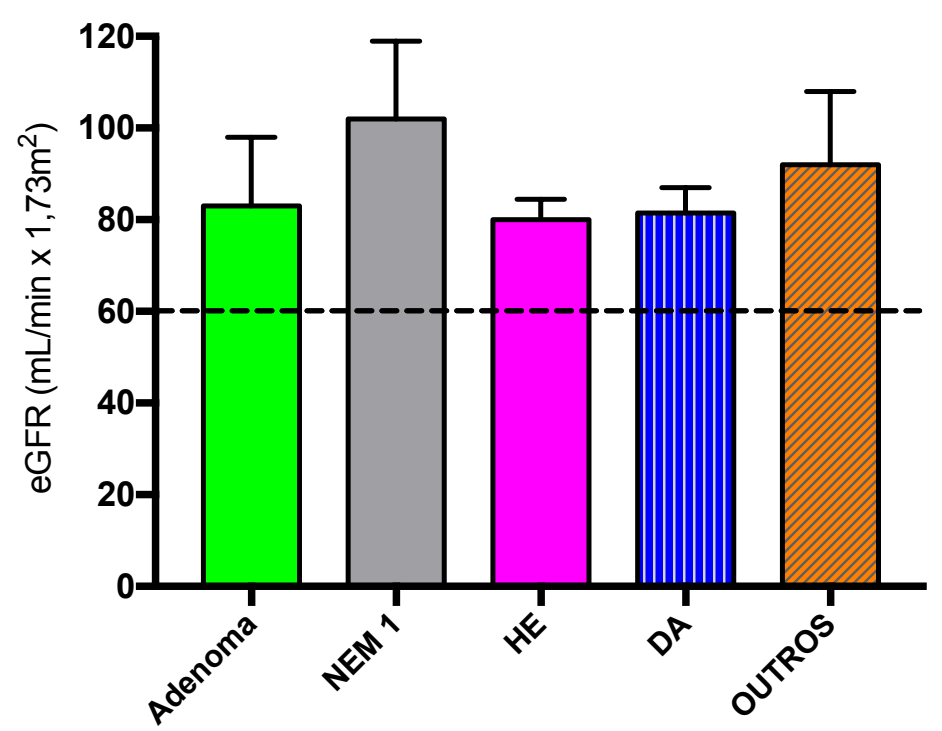

Gráfico 15 - Medianas (Q1-Q3) de eGFR ( $\left.\mathrm{mL} / \mathrm{min} \times 1,73 \mathrm{~m}^{2}\right)$ pré-operatórias entre grupos por etiologia

Quando comparadas as medianas do percentual de variação aguda da eGFR, o grupo NEM 1 variou menos que os grupos Adenoma $(p<0,0001)$, Hiperplasia Esporádica $(p=0,0326)$ e Duplo Adenoma $(p=0,0213)$. Não foi possível estabelecer tal relação com grupo Outros ( $p=0,3207)$. O Grafico 16 mostra as diferenças entre as variações de eGFR nos dois principais grupos, em diferentes momentos.

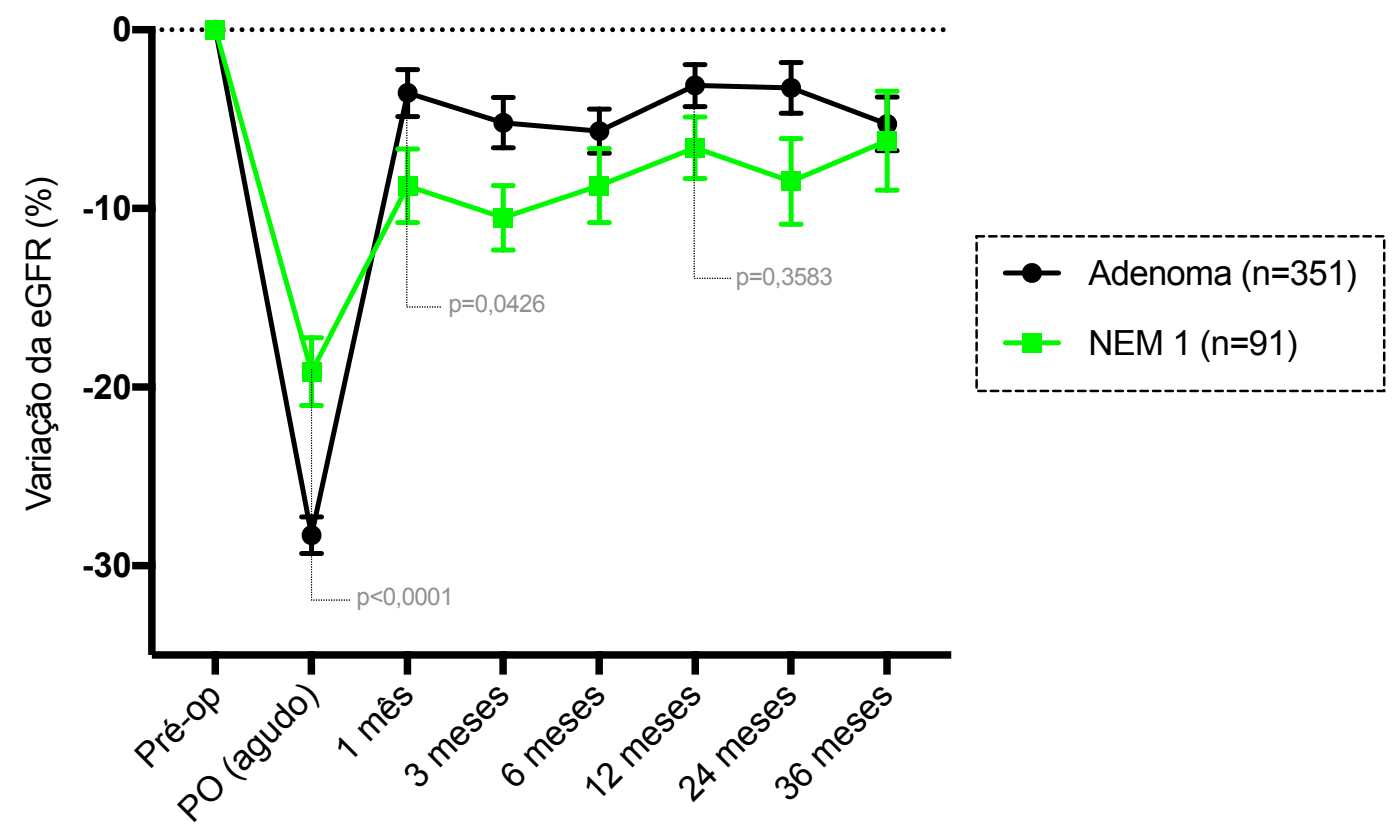

Gráfico 16 - Médias e EPM da variação de eGFR (\%) nos grupos Adenoma e NEM1, comparados aos valores basais, até 36 meses 
Observou-se que, após 1 mês, ainda há diferença entre a recuperação percentual de eGFR nos grupos Adenoma e NEM 1 ( $p=0,0426)$, o que não ocorreu após 12 meses de pós-operatório, quando a variação crônica foi semelhante entre os dois grupos $(p=0,3583)$.

Quanto à idade, os pacientes com diagnóstico de NEM 1 eram mais jovens que os dos grupos Adenoma $(p<0,0001)$, Hiperplasia Esporádica $(p<0,0001)$, Duplo Adenoma $(p<0,0001)$ e do grupo OUTROS $(p=0,019)$. Houve diferença também entre Adenoma e Duplo adenoma ( $p=0,0227)$, sendo o primeiro grupo mais jovem que o segundo. Na comparação dos níveis de PTH pré-operatório, não houve diferença estatística entre os grupos, apesar da mediana mais elevada do grupo Outros $(226 \mathrm{pg} / \mathrm{mL})$. Sobre os valores pré-operatórios de 25-OH vitamina D, também não houve diferença estatística entre os grupos.

Em relação aos níveis de cálcio total, houve diferença estatisticamente significante do grupo Hiperplasia Esporádica com os grupos Adenoma $(p=0,0343)$ e NEM 1 ( $p=0,0218)$. Tais achados, em relação ao cálcio total, não ocorreram com o cálcio iônico, cujas medianas entre os grupos foram semelhantes. A Tabela 17 representa os principais dados pré-operatórios dos grupos por etiologia.

Tabela 17 - Valores da Mediana (Q1-Q3) de dados pré-operatórios nos diversos grupos por etiologia

\begin{tabular}{|c|c|c|c|c|}
\hline & Adenoma & NEM1 & $\begin{array}{l}\text { Hiperplasia } \\
\text { esporádica }\end{array}$ & $\begin{array}{c}\text { Duplo } \\
\text { adenoma }\end{array}$ \\
\hline$n$ & 351 & 91 & 25 & 20 \\
\hline Idade (anos) & $60(53-68)$ & $44(31-56)$ & $67(53,5-75,5)$ & $64,5(59-71,8)$ \\
\hline Cr pré-op (mg/dL) & $\mathbf{0 , 8 2}(0,68-1,03)$ & $\mathbf{0 , 7 8}(0,64-0,9)$ & $\mathbf{0 , 8 4}(0,75-1,21)$ & $\mathbf{0 , 8 2}(0,73-1,09)$ \\
\hline $\begin{array}{l}\text { eGFR pré-op } \\
\left(\mathrm{mL} / \mathrm{min} \times 1,73 \mathrm{~m}^{2}\right)\end{array}$ & $83(61-98)$ & $102(83-119)$ & $80(52,5-84,5)$ & $81,5(53-87)$ \\
\hline $\begin{array}{l}\text { Var. aguda eGFR } \\
(\%)\end{array}$ & $-29,6(-41$ a -14$)$ & $17,2(-31$ a -5$)$ & $-29,0(-36$ a -15$)$ & $-32,2(-48 a-16)$ \\
\hline $\begin{array}{l}\text { PTH pré-op } \\
(\mathrm{pg} / \mathrm{mL})\end{array}$ & $149(106-254)$ & $171(108-224)$ & $152(96-196)$ & $158,5(119-280)$ \\
\hline $\begin{array}{l}\text { CaT pré-op } \\
(\mathrm{mg} / \mathrm{dL})\end{array}$ & $10,9(10,3-11,6)$ & $10,9(10,5-11,5)$ & $10,5(9,8-11,1)$ & $10,75(10,2-12)$ \\
\hline
\end{tabular}


$\mathrm{Na}$ comparação dos valores de calciúria de 24h, o grupo Hiperplasia Esporádica teve a menor mediana (136,6 mg/vol 24h), em comparação com a dos grupos Adenoma ( $p=0,0040)$, NEM1 $(p=0,003)$ e OUTROS $(p=0,0141)$. A diferença entre os demais grupos não foi significante.

Entre as medianas de fósforo sérico, o grupo Hiperplasia Esporádica teve valor mais alto, comparado ao dos grupos Adenoma $(p=0,0266)$ e NEM 1 $(p=0,0054)$, aplicando teste de Mann-Whitney.

\subsection{CLASSIFICAÇÃO CONFORME FAIXAS DE EGFR - DRC KDIGO}

De acordo com a classificação de KDIGO para doença renal crônica, foi conduzida análise por grupos, conforme os dados de eGFR pré-operatórios. A Tabela 18 mostra os valores de eGFR para cada grupo, até 24 meses.

Tabela 18 - Medianas (Q1-Q3) das eGFR ( $\left.\mathrm{mL} / \mathrm{min} \times 1,73 \mathrm{~m}^{2}\right)$ entre grupos $\mathrm{G} 1$ a $\mathrm{G} 4$, até 24 meses

\begin{tabular}{ccc|cccc}
\hline & $\mathbf{n}$ & $\%$ & eGFR pré-op & eGFR PO & eGFR 1m & eGFR 24m \\
\hline G1 & $\mathbf{2 2 3}$ & 45,1 & $\mathbf{1 0 3}(96-116)$ & $\mathbf{8 1}(66-97)$ & $\mathbf{9 7}(88-110)$ & $\mathbf{9 7}(87-107)$ \\
$\mathbf{G 2}$ & $\mathbf{1 6 9}$ & 34,2 & $\mathbf{7 8}(69-83)$ & $\mathbf{5 3}(42,5-64)$ & $\mathbf{7 2 , 5}(63-81)$ & $\mathbf{7 4}(64-84,5)$ \\
$\mathbf{G 3}$ & $\mathbf{8 4}$ & 17,0 & $\mathbf{5 1}(41-55)$ & $\mathbf{3 1 , 5 ( 2 3 - 4 1 )}$ & $\mathbf{4 2}(31-60)$ & $\mathbf{4 3}(33-54,7)$ \\
$\mathbf{G 4}$ & $\mathbf{1 8}$ & 3,6 & $\mathbf{2 2 , 5 ( 1 8 , 7 - 2 5 )}$ & $\mathbf{1 2 , 5 ( 1 2 - 1 8 )}$ & $\mathbf{2 2 , 5}(17,8-33)$ & $\mathbf{2 7 , 5}(18,8-41)$ \\
Total & $\mathbf{4 9 4}$ & 100 & & & & \\
\hline
\end{tabular}

Foram observadas curvas de queda aguda da eGFR, com diferença entre eGFR pré-op e PO, em todos os 4 grupos $(p<0,0001)$, independente da faixa de eGFR basal. No grupo G1, ocorreu recuperação parcial da função renal até 1 mês, porém a eGFR pré-op foi superior às medianas de eGFR pós-operatórias até 60 meses, com diferença entre as medianas de eGFR pré-op e 1 mês de $-6 \mathrm{~mL} / \mathrm{min} x$ $1,73 m^{2}(p<0,0001)$. Não houve diferença entre eGFR 1 mês e as demais medidas tardias. 
No grupo $\mathbf{G 2}$ houve repetição do padrão de curva de $\mathrm{G} 1$, sendo que entre eGFR pré-op e 1 mês a diferença foi de $-5,5 \mathrm{~mL} / \mathrm{min} \times 1,73 \mathrm{~m}^{2}(\mathrm{p}=0,0025)$. Houve diferença estatística entre eGFR pré-op e as demais tardias até 36 meses $(p=0,0063)$, com exceção de eGFR $24 m(p=0,107)$. Também neste grupo a eGFR $1 \mathrm{~m}$ foi semelhante às eGFR tardias.

Entre os pacientes com eGFR basal de $59-30 \mathrm{~mL} / \mathrm{min} \times 1,73 \mathrm{~m}^{2}$ (grupo G3), apesar da piora aguda de função, não houve diferença estatística entre eGFR pré-op e eGFR $1 \mathrm{~m}(\mathrm{p}=0,321)$. Já nos pacientes do grupo $\mathbf{G} 4$, a mediana de eGFR pré-op foi semelhante à eGFR 1 mês $(p=0,428)$. Não houve diferença entre a eGFR basal e as demais eGFR tardias, em ambos os grupos nessa amostra.

Foram agrupados os pacientes de acordo com eGFR basal, utilizando $60 \mathrm{~mL} / \mathrm{min}$

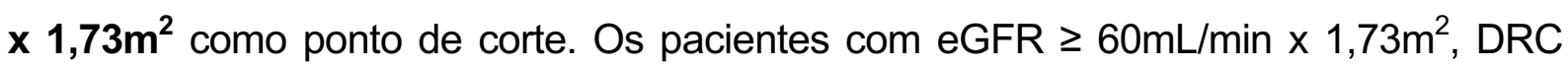
KDIGO grupos $G 1$ e $G 2$, totalizaram $n=392$. Os que tinham eGFR $<60 \mathrm{~mL} / \mathrm{min} x$ $1,73 \mathrm{~m}^{2}$, DRC KDIGO grupos G3 e G4, totalizaram $n=102$. O Gráfico 17 mostra a variação de eGFR comparada aos valores basais, nos dois grupos.

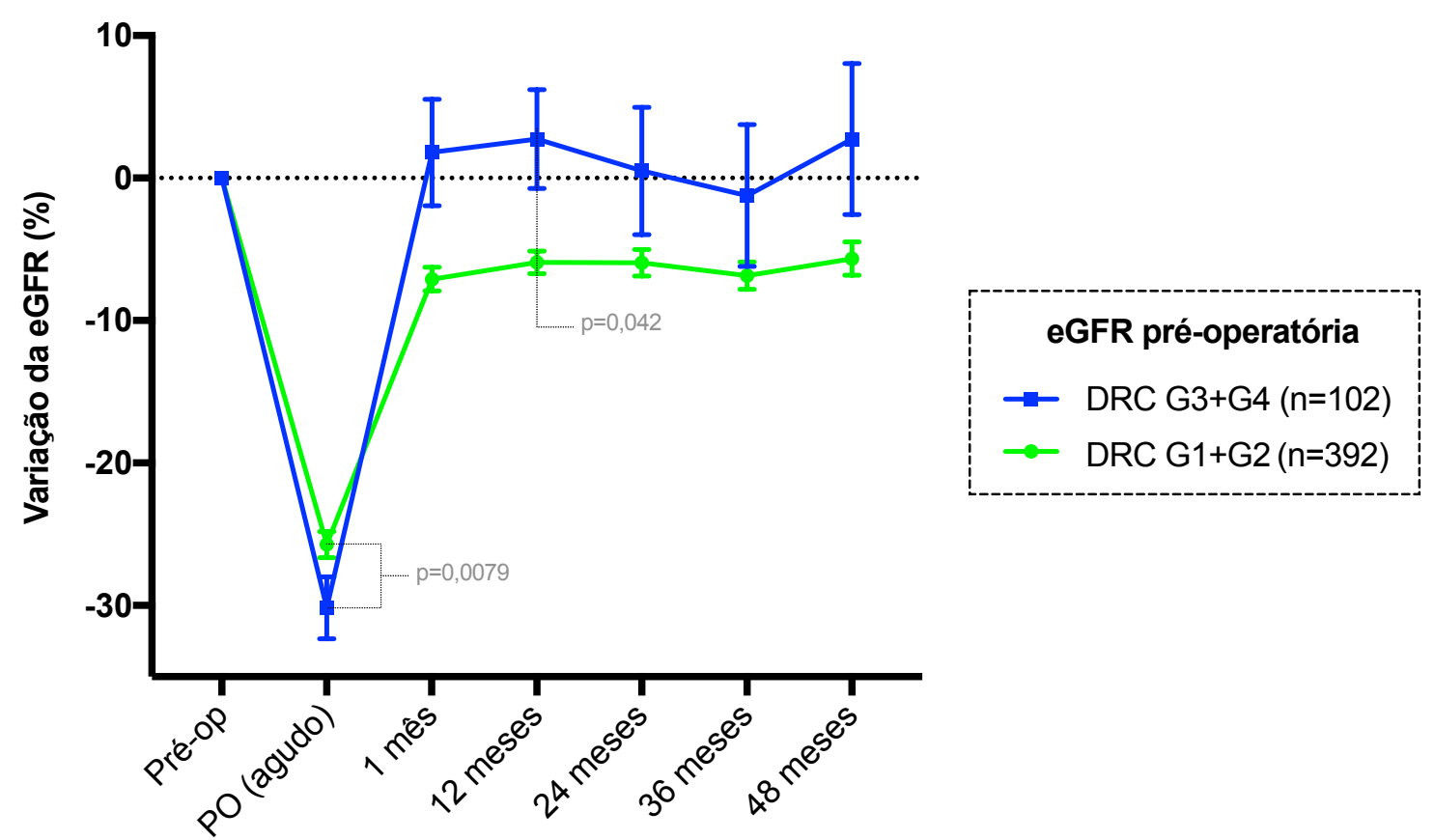

Gráfico 17 - Médias e EPM da variação de eGFR (\%) de acordo com faixas de eGFR pré-operatória (DRC KDIGO), utilizando ponto de corte de 60 $\mathrm{mL} / \mathrm{min} \times 1,73 \mathrm{~m}^{2}$, até 48 meses 
Nos $392(79,3 \%)$ pacientes com eGFR $\geq 60 \mathrm{~mL} / \mathrm{min} \times 1,73 \mathrm{~m}^{2}$, a queda aguda de eGFR teve mediana de $24 \mathrm{~mL} / \mathrm{min} \times 1,73 \mathrm{~m}^{2}(\mathrm{p}<0,0001)$, com recuperação de +19 $\mathrm{mL} / \mathrm{min} \times 1,73 \mathrm{~m}^{2}$ após 1 mês de pós-operatório $(p<0,0001)$. Após 12 meses, a mediana de eGFR foi $-5 \mathrm{~mL} / \mathrm{min} \times 1,73 \mathrm{~m}^{2}$, comparada aos valores basais pré-operatórios $(p<0,0001)$, diferença que se manteve até 5 anos de seguimento.

No grupo de $102(20,6 \%)$ pacientes com eGFR $<60 \mathrm{~mL} / \mathrm{min} \times 1,73 \mathrm{~m}^{2}$, a queda aguda absoluta foi de $13 \mathrm{~mL} / \mathrm{min} \times 1,73 \mathrm{~m}^{2}(\mathrm{p}<0,0001)$, com retorno à mediana basal em 1 mês de pós-operatório $(p=0,3076)$. Não houve mudanças significativas da eGFR até 60 meses de seguimento. As diferenças entre os grupos estão resumidas na Tabela 19.

Tabela 19 - Mediana (Q1-Q3) das variáveis pré e pós-operatórias entre grupos por eGFR basal, utilizando corte de $60 \mathrm{~mL} / \mathrm{min} \times 1,73 \mathrm{~m}^{2}$

\begin{tabular}{|c|c|c|c|}
\hline & $\begin{array}{c}\mathbf{G 1 + G 2} \\
\mathrm{eGFR} \geq 60 \mathrm{~mL} / \mathrm{min} \mathrm{x} \\
1,73 \mathrm{~m}^{2} \\
\end{array}$ & $\begin{array}{c}\text { G3+G4 } \\
\text { eGFR }<60 \mathrm{~mL} / \mathrm{min} \mathrm{x} \\
1,73 \mathrm{~m}^{2} \\
\end{array}$ & $\begin{array}{c}\text { Teste Mann- } \\
\text { Whitney } \\
(\mathbf{p})\end{array}$ \\
\hline $\mathbf{n}$ & 392 & 102 & \\
\hline Idade (anos) & $56(46,2-66)$ & $66(57-73)$ & $<0,0001$ \\
\hline Cr pré-op (mg/dL) & $\mathbf{0 , 7 5}(0,64-0,87)$ & $1,35(1,09-1,66)$ & $<0,0001$ \\
\hline $\begin{array}{l}\text { eGFR pré-op } \\
\left(\mathrm{mL} / \mathrm{min} \times 1,73 \mathrm{~m}^{2}\right)\end{array}$ & $93(80-106,8)$ & $46(33-53,2)$ & $<0,0001$ \\
\hline $\begin{array}{l}\text { Var aguda } \\
\text { eGFR (\%) }\end{array}$ & $-25(-38,2$ a $-12,2)$ & $-31,9(-45,2$ a $-18,1)$ & 0,0079 \\
\hline $\begin{array}{l}\text { Var crônica }(12 \mathrm{~m}) \\
\text { eGFR }(\%)\end{array}$ & $-5,1(-14,2$ a 3,09$)$ & $0(-17,9$ a 18,35$)$ & 0,0420 \\
\hline $\begin{array}{l}\text { PTH pré-op } \\
\text { (pg/mL) }\end{array}$ & $143(104-218)$ & $212,5(125-443,8)$ & $<0,0001$ \\
\hline $\begin{array}{l}\text { CaT pré-op } \\
(\mathrm{mg} / \mathrm{dL})\end{array}$ & $10,9(10,3-11,5)$ & $10,9(10,3-11,7)$ & 0,5522 \\
\hline Cal pré-op (mg/dL) & $5,91 \quad(5,6-6,3)$ & $\mathbf{6 , 0 2}(5,7-6,56)$ & 0,0261 \\
\hline
\end{tabular}

O grupo com pior função renal pré-operatória $(G 3+G 4)$ teve idade superior, valores de PTH e cálcio iônico mais elevados quando comparado ao grupo com eGFR basal $\geq 60 \mathrm{~mL} / \mathrm{min} \times 1,73 \mathrm{~m}^{2}(\mathrm{G} 1+\mathrm{G} 2)$, além de maior variação percentual da eGFR agudamente. Após 12 meses, o grupo G3+G4 retornou aos valores basais de eGFR, enquanto o grupo $\mathrm{G} 1+\mathrm{G} 2$ teve perda definitiva de $5,1 \%$. 


\subsection{CLASSIFICAÇÃO CONFORME 25-OH VITAMINA D PRÉ-OPERATÓRIA}

Dos 440 pacientes que possuíam dados de 25-OH vitamina D, $235(53,41 \%)$ apresentavam valores inferiores a $20 \mathrm{ng} / \mathrm{mL}$, enquanto $205(46,59 \%)$ tinham valores maiores ou iguais a $20 \mathrm{ng} / \mathrm{mL}$. A mediana (Q1-Q3) de 25OHD pré-operatória foi de 19 (14-24) $\mathrm{ng} / \mathrm{mL}$. O percentual de variação aguda da eGFR entre os grupos foi semelhante $(p=0,2628)$, usando $20 \mathrm{ng} / \mathrm{mL}$ como ponto de corte. Já na variação crônica de eGFR (\%), os pacientes com $250 \mathrm{HD}<20 \mathrm{ng} / \mathrm{mL}$ tiveram perda mediana de $6,77 \%$ comparada com a eGFR basal, enquanto a mediana das diferenças, no grupo $\geq 20 \mathrm{ng} / \mathrm{mL}$, foi zero ( $p<0,0001)$. Os Gráficos 18 e 19 mostram as curvas de eGFR, em pacientes agrupados pelos valores de 25OHD pré-operatória, com pontos de corte de 20 e $30 \mathrm{ng} / \mathrm{mL}$, respectivamente.

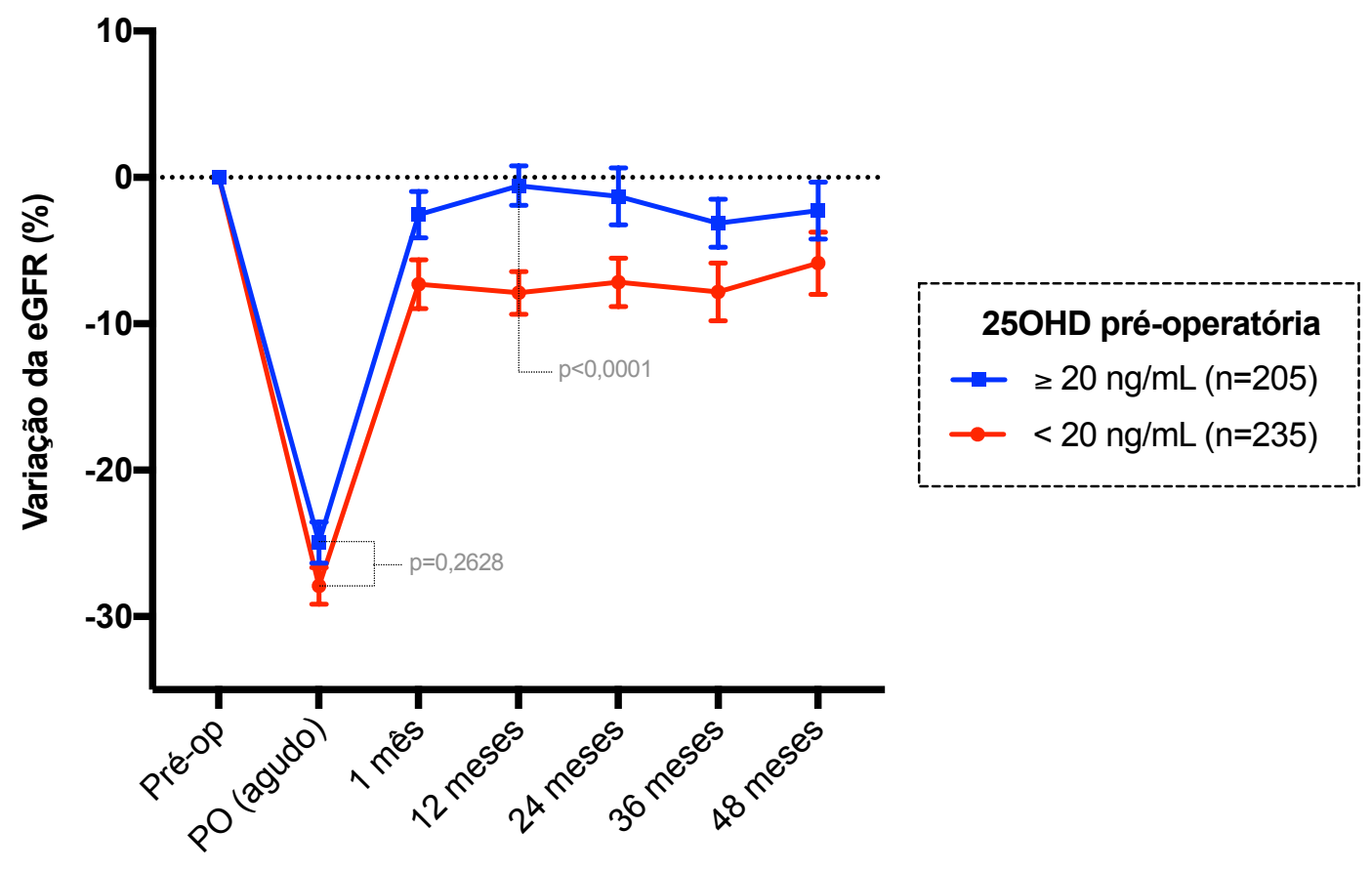

Gráfico 18 - Médias e EPM da variação de eGFR (\%) de acordo com a 25-OH vitamina D pré-operatória, utilizando ponto de corte de $20 \mathrm{ng} / \mathrm{mL}$ 


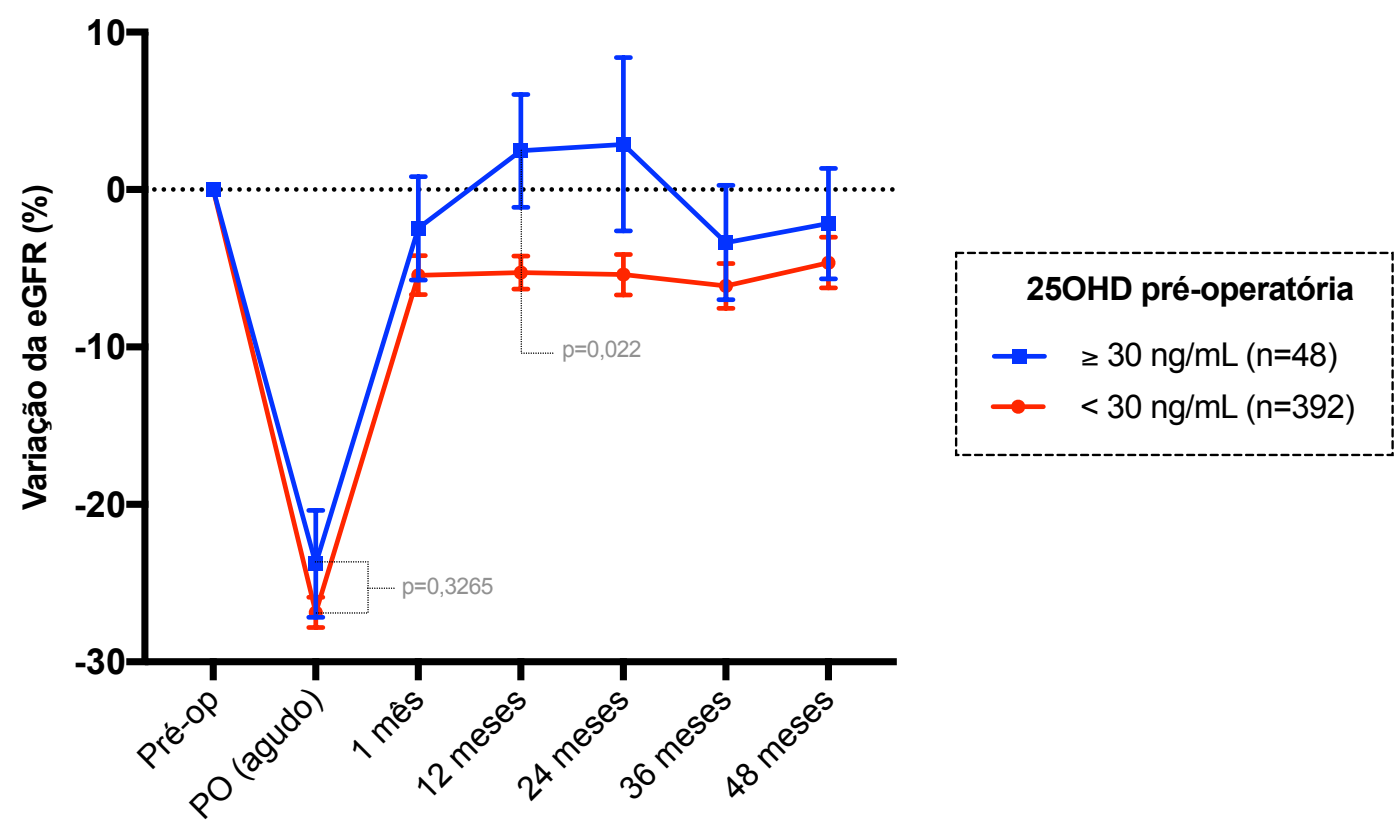

Gráfico 19 - Médias e EPM da variação de eGFR (\%) de acordo com a 25-OH vitamina D pré-operatória, utilizando ponto de corte de $30 \mathrm{ng} / \mathrm{mL}$

Nessa análise, é possível observar que ambos os grupos tiveram redução aguda da eGFR ( $p<0,0001)$, porém os pacientes com valores mais elevados de 250HD no pré-operatório, tiveram melhor evolução da função renal tardia até 12 e 24 meses.

\subsection{CURVAS DE CÁLCIO NO PÓS-OPERATÓRIO ATÉ 72 HORAS}

As medidas de variação diária do cálcio sérico até 72 horas de pós-operatório são apresentadas na Tabela 20.

Tabela 20 - Valores da Mediana $(\mathrm{Q} 1-\mathrm{Q} 3)$ de cálcio total $(\mathrm{mg} / \mathrm{dL})$ até 72 horas de pós-operatório

\begin{tabular}{l|cccc}
\hline & CaT pré-op & CaT ${ }^{\circ}$ PO & CaT ${ }^{\circ}$ PO & CaT 3 ${ }^{\circ}$ PO \\
\hline $\mathrm{n}$ & $\mathbf{4 9 4}$ & $\mathbf{4 8 2}$ & $\mathbf{4 7 4}$ & $\mathbf{3 9 3}$ \\
Q1 & 10,3 & 8,7 & 8,4 & 8,3 \\
Mediana & $\mathbf{1 0 , 9}$ & $\mathbf{9 , 1}$ & $\mathbf{8 , 8}$ & $\mathbf{8 , 9}$ \\
Q3 & 11,5 & 9,7 & 9,3 & 9,3
\end{tabular}


$\mathrm{Na}$ análise geral, houve diferença entre as medianas do CaT pré-op e $1^{\circ} \mathrm{PO}$ de $-\mathbf{1 , 8} \mathbf{m g} / \mathrm{dL}(\mathbf{p}<\mathbf{0 , 0 0 0 1})$ e mediana (Q1-Q3) da variação percentual de $\mathbf{- 1 5 , 9 7 \%}$ ($20,45$ a $-11,04)$. Entre $1^{\circ}$ e $2^{\circ} \mathrm{PO}$, a redução do CaT foi $\mathbf{- 0 , 3} \mathbf{~ m g / d L}(\mathbf{p}<\mathbf{0 , 0 0 0 1})$. Houve discreta elevação do calcio entre $2^{\circ}$ e $3^{\circ} \mathrm{PO}(+0,1 \mathrm{mg} / \mathrm{dL})$, sem significância estatística $(p=0,646)$.

Na comparação entre a variação aguda do cálcio total (\%) e a variação aguda da eGFR (\%), houve correlação positiva no teste de Spearman, com r=0,1511 / IC $95 \% 0,2403-0,0594(p=0.0009)$. Mesmo teste realizado com variação do cálcio iônico teve $r=0,1243$ / IC 95\% 0,2138 - 0,0328 ( $p=0.0062)$.

Foram analizados subgrupos de pacientes com dados completos de cálcio até $3^{\circ} \mathrm{PO}$ (medidas pré-op, $1^{\circ}, 2^{\circ}$ e $3^{\circ} \mathrm{PO}$ ), nos grupos Adenoma ( $\left.n=249\right)$ e NEM1 $(n=86)$, utilizando testes pareados de Friedman. O padrão de queda do CaT entre o pré-operatório e cada um dos dias de pós-operatório, foi diferente entre os dois grupos.

Nos pacientes com Adenoma ocorreu queda mediana do CaT de -1,8 mg/dL no $1^{\circ} \mathrm{PO}(\mathrm{p}<0,0001)$, com desaceleração da queda até $2^{\circ} \mathrm{PO}$, cuja diferença foi de $0,3 \mathrm{mg} / \mathrm{dL}(p<0,0001)$. Houve retomada sutil do CaT no $3^{\circ} \mathrm{PO}(+0,1 \mathrm{mg} / \mathrm{dL})$, com significância estatística $(p=0,0363)$. As mesmas relações foram observadas para $o$ cálcio iônico no grupo Adenoma, até o $2^{\circ} \mathrm{PO}(\mathrm{p}<0,0001)$, porém não houve elevação do Cal entre o $2^{\circ}$ e $3^{\circ} \mathrm{PO}$.

Nos pacientes do grupo NEM1 com dados completos de cálcio até $\mathbf{7 2 h}$, ocorreu queda sustentada do CaT entre pré-op, $1^{\circ}, 2^{\circ}$ e $3^{\circ} \mathrm{PO}(p=0,0001)$, diferentemente da curva do grupo Adenoma. Nos pacientes com NEM1, a queda inicial mediana foi de $-\mathbf{1 , 7 5} \mathrm{mg} / \mathrm{dL}$ ( $\mathbf{p}<0,0001$ ). O comportamento do cálcio iônico seguiu o mesmo padrão do cálcio total para o grupo NEM1. O Gráfico 20 ilustra a diferença entre as curvas do cálcio total nos grupos Adenoma e NEM1 com dados completos. 


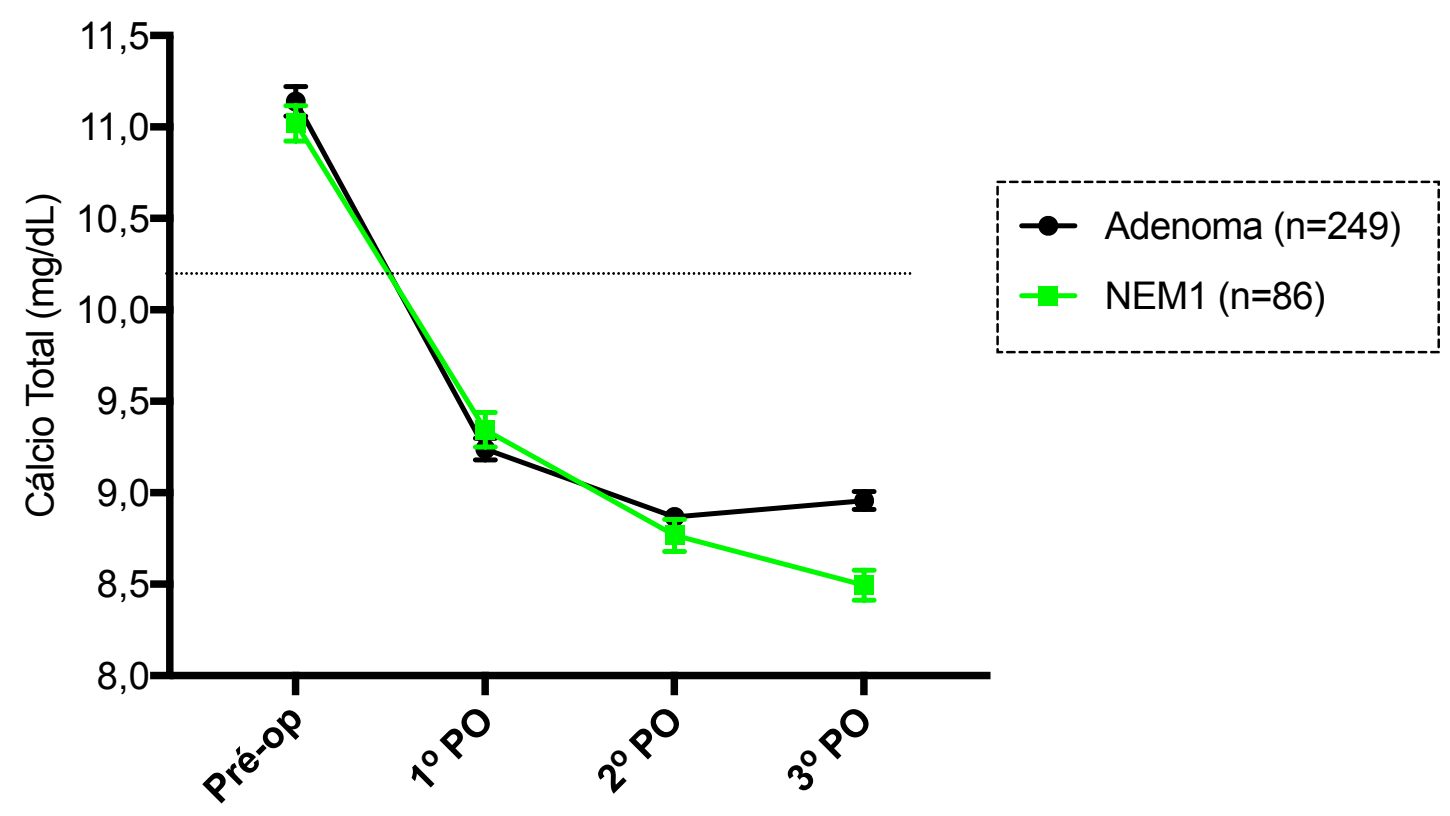

Gráfico 20 - Médias e EPM de cácio total $(\mathrm{mg} / \mathrm{dL})$ nas 72h de pós-operatório, dos grupos Adenoma e NEM 1 com dados completos

Quando avaliados os valores pós-operatórios do PTH ( $\left.1^{\circ} \mathrm{PO}\right)$, observou-se queda abrupta em todos os grupos. Apesar de partirem de valores de PTH semelhantes, houve diferença entre grupo Adenoma e os demais. Pacientes com diagnóstico de NEM1 tiveram queda aguda do PTH mais acentuada que os pacientes com Adenoma (mediana 3 vs. $14 \mathrm{pg} / \mathrm{mL}-\mathrm{p}<0,0001$ ). 


\section{DISCUSSÃO}

Neste estudo foi possível demonstrar que uma proporção significativa de pacientes submetidos à paratireoidectomia por HPT primário, independente do tipo e extensão do procedimento, sofreu algum grau de deterioração aguda da função renal. Dos 494 pacientes estudados, 92,7\% tiveram redução da filtração glomerular nos primeiros 4 dias de pós-operatório, sendo que 241 indivíduos $(48,8 \%)$ preencheram critérios de injúria renal aguda (IRA), pela classificação KDIGO.(25) Importante ressaltar que, apesar de alguns dados clínicos e do débito urinário não terem sido controlados, a elevação aguda da creatinina teve curso indolente e assintomático, sendo que apenas um paciente necessitou de hemodiálise durante a internação. Albright e Refeistein haviam notado, ainda na década de 50, que alguns pacientes apresentavam oligúria severa no pós-operatório de paratireoidectomia por adenoma.(48)

Apesar da elevada frequência de IRA encontrada, 203 (84,2\%) pacientes tiveram IRA estágio 1, enquanto 38 (15,8\%) preencheram critérios para IRA estágios 2 e 3 . A incidência de injúria renal, no pós-operatório de cirurgias eletivas nas diversas especialidades e portes, tende a ser inferior à encontrada nessa coorte. Estudos sobre IRA após cirurgias cardíacas com circulação extra-corpórea, consideradas de alto risco, relatam taxas de 10 a $22 \% .(30,31)$ Grams et. al(53) acompanharam 161.185 pacientes submetidos a cirurgias diversas, divididos por tipo e especialidade. Neste estudo, $12 \%$ do total de pacientes evoluíram com IRA, sendo $76 \%$ estágio $1,14 \%$ estágio 2 e $7 \%$ estágio 3 . A incidência variou conforme o tipo de cirurgia: cardíaca $(18,7 \%)$, cirurgia geral $(13,2 \%)$, torácica $(12 \%)$, ortopédica $(10,2 \%)$, vascular $(9,2 \%)$ e urológica $(8,6 \%)$. As cirurgias otorrinolaringológicas, em que estavam incluídas algumas cirurgias do pescoço, evoluíram com IRA em apenas $4,1 \%$ dos pacientes. Após análise multivariada, foram identificadas correlações entre presença ou ausência de IRA e mortalidade intra-hospitalar ( 8,2 vs. $1,1 \%)$, tempo de internação (15,8 vs. 8,6 dias), readmissão após alta ( 21,1 vs. $13,3 \%)$ e mortalidade 
em até 1 ano (18,9 vs. $8 \%$ ). Essas correlações foram proporcionais ao grau de disfunção renal, por estágios KDIGO.

Uma revisão sistemática sobre IRA em pós-operatório de cirurgias abdominais, que englobou mais de 80 mil pacientes, selecionou estudos a partir de 2004 que já utilizaram classificações RIFLE, AKIN ou KDIGO. (32) A incidência geral de IRA foi de $13,4 \%$, sendo $72 \%$ estágio $1,17 \%$ estágio 2 e $11 \%$ estágio 3 . A taxa de recuperação da função renal para o valor de base, quando informada, variou de 47 a $79 \%$. Nessa mesma revisão, quando selecionados estudos com dados de mortalidade precoce (30 dias), houve risco relativo 12,6 vezes maior nos pacientes com algum grau de IRA. As taxas de mortalidade se correlacionaram com os estágios da IRA de maneira progressiva, independente das diversas classificações utilizadas nos últimos anos. $(28,29,54)$

Em nossa coorte, dos 521 pacientes iniciais, foram contabilizados 3 óbitos no perioperatório, representando $0,58 \%$ de mortalidade após paratireoidectomia. Recentemente, um estudo restrospectivo com 14500 pacientes submetidos a paratireoidectomia por HPTP, avaliou dados de morbimortalidade precoce (30 dias), em que foram relatados $20(0,14 \%)$ óbitos e $173(1,3 \%)$ reinternações. (55) Kravietz et al.(56) realizaram estudo transversal sobre readmissões precoces, após alta hospitalar pós-paratireoidectomias por HPT primário e secundário. Dentre os 4295 pacientes tratados por HPT primário, houve 241 (5,6\%) reinternações, índice mais alto que o relatado em estudos anteriores. Após estratificação das causas dessas reinternações, a falência renal representou 9,54\% do total, assim como hipocalcemia $(12,86 \%)$ e septicemia $(13,69 \%)$. Após regressão logística, a falência renal teve o maior impacto no risco de reinternação após alta (OR 2,22 IC: 1,57-3,12). Em nossa coorte, houve apenas uma reinternação $(0,19 \%)$ em 30 dias, devido a injúria renal e hipocalcemia severa, complicações que levaram o paciente ao óbito.

O protocolo cirúrgico em nossa Instituição sugere internação mínima de três dias, período em que é possível corrigir a hipocalcemia e realizar controle laboratorial diário. Nesse sentido, nossa casuística diferiu dos demais estudos em HPTP que tendiam a realizar o pós-operatório de paratireoidectomia com internação de 1 dia ou em regime ambulatorial. $(17,55)$ A rotina estabelecida pelo departamento há cerca de 20 anos permitiu, em última análise, que as observações dos autores, 
sobre a elevação aguda da creatinina após as paratireoidectomias, fossem estudadas consistentemente.

Além de representar aumento do risco de morte pós-operatória, a ocorrência de IRA também ocasiona aumento da morbidade e do risco de progressão para doença renal crônica.(32) D'Horre et al.(34) realizaram estudo de coorte prospectivo que envolveu 311 pacientes com DRC pré-existente, seguidos por 5 anos. O estudo avaliou a influência dos episódios de IRA na progressão da DRC, além de avaliar a velocidade da perda funcional renal. Os dados indicaram que episódios isolados de IRA provocaram significativa elevação do risco (razão de chances de 5,9) de progressão rápida da DRC pré-existente. Em consequência disso, uma recuperação apenas parcial da função, após episódio isolado de IRA, foi o principal determinante de perda da função renal durante os 5 anos de seguimento.

A discrepância entre o porte cirúrgico e a alteração de função renal, após paratireoidectomia, já foi estudada anteriormente nos pacientes transplantados renais com HPT persistente (terciário).(21) Nesse grupo de pacientes, há maior vigilância da função renal pós-operatória, devido à preocupação com o rim transplantado. No HPT terciário, há estudos que mostraram redução aguda da filtração glomerular pós-operatória, alguns com perda funcional a longo prazo.(22, 42, 47, 57) Montenegro et al. (58) estudou a disfunção renal aguda em 76 pacientes após paratireoidectomias por HPT terciário e observou IRA em $60 \%$ dos pacientes, pelos critérios RIFLE. Verificou-se ainda que, quanto mais severo o estágio da IRA, maior o risco de redução definitiva na eGFR após 12 e 24 meses, comparada aos valores basais. Em outro estudo semelhante, com 19 pacientes submetidos a paratireoidectomia por HPT terciário, os autores compararam a eGFR basal com a eGFR 12 meses após a cirurgia e verificaram diferença média de $-5,8 \mathrm{~mL} / \mathrm{min} x$ $1,73 m^{2}(p=0,010)$, porém sem diferença após 24 meses $(p=0,276)$.(59) Há razões para se concluir que tais alterações renais, agudas e tardias, ocorram também nos pacientes com HPT primário, apesar de não haver, nos guidelines de tratamento, recomendação de monitorização da função renal e/ou diurese no pós-operatório de paratireoidectomia.(16)

Recentemente, Egan et al.(50) conduziram um estudo de coorte envolvendo 62 pacientes submetidos a paratireoidectomias por HPTP. A creatinina foi utilizada 
como biomarcador da função renal e a eGFR foi calculada pela equação CKD-EPI. Foram realizadas aferições uma vez no $1^{\circ} \mathrm{PO}$, após 60 e após 90 dias de pósoperatório. Houve redução aguda média da eGFR de $-3 \mathrm{~mL} / \mathrm{min} \times 1,73 \mathrm{~m}^{2}$ no $1^{\circ} \mathrm{PO}$ $(p<0,01)$ e $-5 \mathrm{~mL} / \mathrm{min} \times 1,73 \mathrm{~m}^{2}$ após 90 dias $(p<0,05)$, comparadas aos valores basais. Cerca de $42 \%$ dos pacientes tiveram elevação aguda da creatinina igual ou superior a $10 \%$ do valor pré-operatório. Dos 45 pacientes com seguimento completo (62 iniciais), 41,4\% mantiveram valores de eGFR inferiores aos iniciais após 90 dias de pós-operatório. Os autores atribuem a queda da filtração glomerular a fatores clínicos, organizados em escore de comorbidades. Outros fatores como cálcio ou PTH não foram informados. Os resultados obtidos confirmaram os do presente estudo, de que houve redução aguda da função renal, persistente em alguns casos. $\mathrm{O}$ fato de a creatinina ter sido aferida apenas uma vez no $1^{\circ} \mathrm{PO}$ pode ter reduzido a sensibilidade da análise, uma vez que, em nossa coorte, observou-se que $55,5 \%$ dos pacientes tiveram a pior medida de creatinina entre o $2^{\circ}$ e $\circ 4^{\circ}$ dias de pósoperatório.

Além da disfunção renal do período agudo, houve recuperação apenas parcial da eGFR no seguimento pós-operatório, com redução estatisticamente significante da mediana de eGFR após 1 mês, comparada aos valores basais $(p<0,0001)$. Durante os primeiros dois dias de pós-operatório, houve redução da eGFR, com recuperação gradual no $3^{\circ}$ e $4^{\circ}$ dias, ainda com diferença estatística em relação à eGFR 1 mês ( $p=0,0241)$. A curva de eGFR sugeriu que a recuperação da função renal, após o episódio agudo, deva se estabilizar ainda antes de 1 mês, por volta de uma semana. Após 1 mês de pós-operatório, não houve recuperação estatística da eGFR em nenhuma das análises até 5 anos de seguimento, indicando o prognóstico da função renal a longo prazo.

No presente estudo, pacientes com alterações mais discretas da função renal aguda eram, em média, mais jovens, com valores de PTH e cálcio mais baixos, além de apresentarem melhor eGFR no pré-operatório. Por outro lado, pacientes com IRA estágio 3 eram mais velhos, com PTH elevado e pior eGFR basal. A análise univariada mostrou que o percentual de variação aguda da eGFR se correlacionou com idade, PTH, cálcio iônico e total, fósforo e eGFR pré-operatória. Apesar de significativas, as correlações foram fracas e as váriaveis foram interrelacionadas, 
além de terem distribuições não paramétricas. Pelos motivos anteriores, os autores optaram por não realizar análise multivariada, nessa amostra.

$\mathrm{Na}$ literatura, os resultados da função renal tardia após o tratamento cirúrgico do HPTP, são conflitantes. Alguns autores acreditam que a paratireoidectomia pode causar redução adicional da eGFR.(35) Em estudo prospectivo com 19 pacientes, não foram detectadas diferenças entre a função renal pré e pós-operatória (12 meses), em contraste com nossos resultados.(60) Outro estudo, publicado em 1980, com casuística de 139 pacientes, sugeriu que a piora de função renal tardia pósopearatória estaria condicionada à presença de fatores adversos, como infecção urinária ou a presença de hipertensão arterial.(61) Em nossa coorte, $60.7 \%$ dos pacientes tiveram algum grau de perda definitiva da eGFR após 12 meses, comparados aos valores pré-operatórios, enquanto 33,6\% tiveram melhora da função renal. O percentual geral de variação da eGFR basal vs. 12 meses (variação crônica) teve mediana de $-4,42 \%$. Já a perda definitva da eGFR nos pacientes que experimentaram episódio de IRA estágio 1 foi de $-7,65 \%$, enquanto que os indivíduos com IRA estágio 2 tiveram redução de $-24,42 \%$ da eGFR. Tais achados indicaram que a intensidade do evento agudo se correlacionaria com o prognóstico renal a longo prazo e, com isso, deveria-se motivar ações preventivas e de vigilância da função renal nos pacientes em risco para IRA pós-operatória.

Tassone et al. (62) realizaram estudo de coorte com foco nas alterações tardias de função renal após paratireoidectomias. Foram encontradas correlações entre a faixa de eGFR pré-operatória e o prognóstico renal. A amostra de 109 pacientes foi dividida em dois grupos, de acordo com a eGFR basal, sendo 95 casos (grupo 1) com eGFR $\geq 60 \mathrm{~mL} / \mathrm{min} \times 1,73 \mathrm{~m}^{2}$ e 14 casos (grupo 2) com eGFR < $60 \mathrm{~mL} / \mathrm{min} \times 1,73 \mathrm{~m}^{2}$. O grupo 1 , com eGFR basal superior, teve perda definitva média de $-5,2 \mathrm{~mL} / \mathrm{min} \times 1.73 \mathrm{~m}^{2}(\mathrm{p}=0.0017)$ após a cirurgia, enquanto que o grupo 2 teve perda de $-2,4 \mathrm{~mL} / \mathrm{min} / 1.73 \mathrm{~m}^{2}$ ( $\left.p=0.509\right)$. Infelizmente, este estudo não possuía dados da função renal aguda e o seguimento médio foi de apenas 2,15 anos. Os autores concluíram que a paratireoidectomia seria capaz de, por si só, impedir a piora da função renal pós-operatória nos pacientes com DRC grau 3 ou superior (< $60 \mathrm{~mL} / \mathrm{min} \times 1,73 \mathrm{~m}^{2}$ ), pela classificação de KDIGO. Tal conclusão, possivelmente, subestimaria o papel das alterações renais agudas encontradas em nossos 
resultados. Por questões metodológicas, nosso estudo e o de Tassone et al.(62) não possuem grupo controle, de pacientes com HPTP e que não foram submetidos ao tratamento cirúrgico, com o objetivo de avaliar o curso natural da função renal nos pacientes não tratados. Por razões éticas, um estudo com esse desenho em pacientes com HPTP sintomáticos, não seria permitido. Por outro lado, um estudo com pacientes assintomáticos, comparados prospectivamente por 2 anos, não verificou diferenças entre valores de creatinina dos indivíduos seguidos clinicamente, em relação aos submetidos a paratireoidectomia, apesar da importante perda de seguimento em ambos os grupos ( 40\%).(63) Além disso, para se ter certeza de que uma perda adicional de função renal poderia ser prevenida pela paratireoidectomia, múltiplas aferições de creatinina pré-operatórias, com curva de queda da eGFR, deveriam ser mostradas previamente à cirurgia. Os estudos que defendem que a paratireoidectomia impediria a piora da função renal no HPTP não apresentam este dados, mostrando apenas um único valor de creatinina no pré-operatório.

A mesma análise, usando as faixas de eGFR pré-operatórias (KDIGO), foi realizada em nosso estudo, com algumas similaridades. Nos 392 pacientes DRC $G 1+G 2$, equivalentes ao grupo 1 do estudo de Tassone et al. (62), houve redução permanente na eGFR de $-5 \mathrm{~mL} / \mathrm{min} \times 1,73 \mathrm{~m}^{2}(p<0,0001)$, após 1 mês da cirurgia. No entanto, nos 102 indivíduos com eGFR <60mL/min x 1,73 $\mathrm{m}^{2}$, correspondente ao grupo 2 do estudo prévio (DRC G3+G4), a redução definitiva não foi significativa. Independentemente das diferenças na função renal crônica pós-operatória, ambos os grupos mostraram redução aguda da eGFR $(p<0,0001)$ em relação aos valores basais. Observou-se que o percentual de variação aguda do grupo com melhor função renal pré-operatória, foi, curiosamente menor que o grupo G3+G4 (-25 vs. $31,9 \% p=0,0079)$. De maneira inversa, o percentual de variação crônica da eGFR (basal vs. 12 meses) no grupo $\mathrm{G} 1+\mathrm{G} 2$ foi de $-5,1 \%$, enquanto que no outro grupo houve recuperação completa da eGFR $(p=0,042)$. Tais diferenças entre os grupos foram interessantes e podem ter sido influenciadas, em diversos graus, pelos outros fatores já correlacionados à variação aguda e crônica da eGFR no pós-operatório. Neste sentido, a condução de análise multivariada poderia ter sido útil em determinar qual a influência da reserva renal pré-operatória sobre a curva de eGFR, após o tratamento cirúrgico. 
Os resultados de função renal pós-operatória organizados por etiologia do HPTP e, consequentemente por extensão da cirurgia, repetiram o padrão de redução aguda da eGFR observado na análise geral $(p<0,0001)$. Indivíduos com NEM 1, mais jovens e com melhor função renal pré-operatória, mostraram curva de recuperação mais lenta da eGFR, após o insulto agudo. Com isso, foi possível observar maior diferença em 1 mês de pós-operatorio $(p=0,0426)$, nos pacientes com NEM1, quando comparados aos pacientes com adenoma da paratireóide (uniglandular). As curvas tenderam a se igualar após 12 meses de pós-operatório, quando já não havia diferença estatística entre os grupos. Foi possível inferir que o período de hipoparatireoidismo, observado com maior frequência após paratireoidectomia total com autoenxerto, poderia ter impacto na velocidade de recuperação da eGFR no pós-operatório.

Os mecanismos e o tipo de lesão renal causados pela paratireoidectomia não foram bem explicados e, não poderiam ser respondidos neste estudo. $O$ impacto agudo da paratireoidectomia sobre a filtração glomerular se mostrou desproporcional ao trauma cirúrgico e tempo operatório, como já demonstrados também no HPT terciário. (21)

A hipercalcemia crônica é uma causa bem estabelecida de insulto renal, cuja manutenção pode causar deterioração funcional e é uma das indicações para o tratamento cirúrgico do paciente com HPTP assintomático.(11) Além das alterações estruturais causadas por obstrução intratubular, pela inflamação intersticial peritubular e pela fibrose, há também um efeito vasoconstritor direto do cálcio sobre a arteríola aferente. $(64,65)$ No presente estudo, foram investigadas as curvas de cálcio até $72 \mathrm{~h}$ de pós-operatório e suas possíveis correlações com a variação aguda da eGFR. Nas primeiras $24 \mathrm{~h}$ houve redução mediana de $1,8 \mathrm{mg} / \mathrm{dL}$ no cálcio total, mais acentuada que nos demais dias. Os pacientes operados por NEM 1 mostraram curva de queda do cálcio até $3^{\circ} \mathrm{PO}$, diferentemente dos pacientes com adenoma. Foram observadas correlações fracas, porém significativas, entre a variação aguda da calcemia (\%) e a da função renal, em valores percentuais de eGFR.

Faltam, na literatura, estudos clínicos e experimentais com objetivo de esclarecer a influência do HPTP sobre a dinâmica renal, definir o modelo correto de injúria renal pós-operatória, assim como expor os papéis desempenhados pelo $\mathrm{PTH}$, 
cálcio, FGF-23 e o sistema renina-angiotensina-aldosterona na adaptação renal, após a paratireoidectomia. $(6,7,41,66,67)$ Além destes fatores, há evidência recente de que a deficiência de 25-OH vitamina D no HPTP está associada a doença mais severa, traduzida pelos marcadores ósseos e bioquímicos do HPT.(68) Nessa coorte, não houve correlação significativa entre a variação aguda de eGFR e os níveis de $250 H D$ pré-operatórios ( $r=0,0668 / p=0,1613$ ). Entre os 440 indivíduos com dados disponíveis, havia $235(53,4 \%)$ considerados deficientes pelo critério adotado ( $<20 \mathrm{ng} / \mathrm{mL}$ ). A mediana pré-operatória foi de $19 \mathrm{ng} / \mathrm{mL}$, considerada inferior à outras coortes de pacientes com HPTP, fato que poderia representar impacto negativo na recuperação renal tardia após insulto agudo, como já demonstrado experimentalmente em ratos, utilizando modelo de isquemia e reperfusão. $(69,70) \mathrm{A}$ notória diferença na amplitude de recuperação definitiva da eGFR, encontrada nos pacientes com níveis de $250 \mathrm{HD}$ iguais ou superiores a 20 e $30 \mathrm{ng} / \mathrm{mL}$, destacou o possível papel protetor da 250HD e, futuramente, poderá motivar investigação sobre o tema. Historicamente, existe preocupação em realizar suplementação de vitamina D nos pacientes com HPTP, pela suposto risco de piora da hipercalcemia préexistente. Essa suplementação pré-operatória poderia ser encorajada, pois estudos recentes mostraram que, quando foi realizada, não houve elevação subtancial do cálcio sérico. $(71,72)$

A identificação dos fatores de risco e do mecanismo de lesão renal, nos pacientes submetidos a paratireoidectomia, poderia ajudar a reduzir o risco de IRA, diminuindo consequentemente as chances de perda funcional definitiva. Estas informações seriam úteis também nos cuidados pré e pós-operatórios dos pacientes transplantados renais, com indicação de paratireoidectomia por HPT persistente (terciário).

Cabe ressaltar algumas limitações importantes do presente estudo, cujo caráter retrospectivo pode ter sido mitigado, parcialmente, pela disciplinada rotina assistencial. Outro fator foi a falta de informações clínicas e a falta de parâmetros de débito urinário, que complementam a estratificação de IRA pelos critérios KDIGO.(25) A creatinina sérica, biomarcador da função renal disponível neste estudo, possui elevada especificidade, porém baixa sensibilidade para detecção de injúria renal.(73, 74) Neste sentido, outros biomarcadores de lesão tubular, como a 
Neutrophil Gelatinase-Associated Lipocalin (NGAL) e a Kidney Injury Molecule 1 (KIM-1), poderiam detectar alterações mais precoces, numa parcela ainda maior de pacientes.(75) A utilização da taxa de filtração glomerular estimada (eGFR), calculada pela equação CKD-EPI, como indicador mais preciso da função renal, tem validação na literatura, apesar de apresentar imperfeições em situações em que há variação aguda da filtração glomerular. (51) Outro viés consistiu no desconhecimento do perfil de comorbidades dos pacientes, pois se sabe que a presença de doenças específicas poderiam afetar a risco de IRA no pós-operatório de outros tipos de cirurgias.(76) Dados sobre uso de drogas potencialmente nefrotóxicas e a ocorrência de hipotensão durante as cirurgias não foram controlados, tampouco o registro da duração dos procedimentos e do volume de perda sanguínea. Durante a internação pós-operatória, não foram controlados os fatores de hidratação endovenosa, as medicações recebidas, as doses de reposição de cálcio, assim como o uso eventual de anti-inflamatórios (AINEs), apesar destes não fazerem parte da rotina de prescrição destes pacientes na Instituição.

A injúria renal representa um problema de saúde pública, com repercussões sobre a qualidade de vida e consequente aumento de mortalidade, à medida que expõem os indivíduos ao risco de progressão para doença renal crônica. $(77,78)$ Recentemente, a Sociedade Internacional de Nefrologia e a Federação Internacional das Fundações do Rim (International Society of Nephrology and International Federation of Kidney Foundations) emitiram alerta com fortes recomendações de vigilância dos pacientes em risco de desenvolverem IRA.(79) Os resultados do presente estudo corroboram para uma política de monitorização da função renal antes e após as paratireoidectomias, assim como a de evitar drogas nefrotóxicas e a desidratação no peri-operatório. Não há, no entanto, nos guidelines atuais de tratamento do HPTP, recomendações neste sentido.(16)

O presente estudo representa, na literatura, uma casuística expressiva de pacientes submetidos a paratireoidectomia por HPTP, que talvez forneça a evidência mais contundente sobre as variações agudas da função renal e sua evolução tardia. A preocupação com o tema se justifica pelos inúmeros benefícios da paratireoidectomia, indicada para o tratamento definitivo do HPTP, procedimento 
cujo trauma cirúrgico - usualmente pequeno - inspira pouca vigilância clínica e laboratorial no período agudo. $(80,81)$ Dados de um estudo recente mostraram que o tempo médio de internação pós-operatória por HPTP nos EUA foi inferior a 24 horas $(0,9 \pm 2,7$ dias $)$. (55)

Como objetivo futuro, pode-se propor estudo prospectivo envolvendo pacientes com HPTP sintomáticos, com controle dos fatores clínicos e cirúrgicos. Poderiam ser utilizados, além da creatinina sérica, outros biomarcadores de injúria renal aguda no pós-operatório, capazes de identificar alterações ainda mais sutis e de maneira mais precoce. $(37,75)$ 


\section{CONCLUSÕES}

A cirurgia de paratireoidectomia em pacientes com hiperpatireoidismo primário causaram algum grau de disfunção renal aguda em $92.7 \%$ dos pacientes, sendo que mais da metade destes preencheram critérios de Injúria Renal Aguda (IRA).

A disfunção renal aguda tendeu a apresentar melhora evolutiva, porém cerca de $60 \%$ dos pacientes tiveram algum grau de perda definitiva da filtração glomerular, quando comparada ao pré-operatório. A presença e o estágio da IRA, pelos critérios KDIGO, se correlacionaram com o percentual de perda definitiva de função renal.

A intensidade da variação renal aguda se correlaciona com idade, valores de $\mathrm{PTH}$, cálcio e fósforo no pré-operatório, utilizando análise univariada.

O ponto de corte, em todas as análises, para indicar o prognóstico da função renal tardia foi a creatinina e taxa de filtração glomerular após 1 mês de pósoperatório. Após este período, não houve mudanças significativas. 


\section{REFERÊNCIAS BIBLIOGRÁFICAS}

1. Bilezikian JP, Cusano NE, Khan AA, Liu JM, Marcocci C, Bandeira F. Primary hyperparathyroidism. Nat Rev Dis Primers. 2016;2:16033.

2. Pallan $\mathrm{S}$, Rahman MO, Khan AA. Diagnosis and management of primary hyperparathyroidism. BMJ. 2012;344:e1013.

3. Heath H, 3rd, Hodgson SF, Kennedy MA. Primary hyperparathyroidism. Incidence, morbidity, and potential economic impact in a community. $\mathrm{N}$ Engl $\mathrm{J}$ Med. 1980;302(4):189-93.

4. Yeh MW, Ituarte PH, Zhou HC, Nishimoto S, Liu IL, Harari A, et al. Incidence and prevalence of primary hyperparathyroidism in a racially mixed population. $J$ Clin Endocrinol Metab. 2013;98(3):1122-9.

5. Press DM, Siperstein AE, Berber E, Shin JJ, Metzger R, Jin J, et al. The prevalence of undiagnosed and unrecognized primary hyperparathyroidism: A population-based analysis from the electronic medical record. Surgery. 2013;154(6):1232-8.

6. Khundmiri SJ, Murray RD, Lederer E. PTH and Vitamin D. Compr Physiol. 2016;6(2):561-601.

7. Verdelli C, Corbetta S. MECHANISMS IN ENDOCRINOLOGY: Kidney involvement in patients with primary hyperparathyroidism: an update on clinical and molecular aspects. Eur J Endocrinol. 2017;176(1):R39-R52. 
8. Ruda JM, Hollenbeak CS, Stack BC, Jr. A systematic review of the diagnosis and treatment of primary hyperparathyroidism from 1995 to 2003. Otolaryngol Head Neck Surg. 2005;132(3):359-72.

9. Bartsch D, Nies C, Hasse C, Willuhn J, Rothmund M. Clinical and surgical aspects of double adenoma in patients with primary hyperparathyroidism. $\mathrm{Br} \mathrm{J}$ Surg. 1995;82(7):926-9.

10. Lee PK, Jarosek SL, Virnig BA, Evasovich M, Tuttle TM. Trends in the incidence and treatment of parathyroid cancer in the United States. Cancer. 2007;109(9):1736-41.

11. Bilezikian JP, Brandi ML, Eastell R, Silverberg SJ, Udelsman R, Marcocci C, et al. Guidelines for the management of asymptomatic primary hyperparathyroidism: summary statement from the Fourth International Workshop. J Clin Endocrinol Metab. 2014;99(10):3561-9.

12. Evans LM, Owens D, Scott-Coombes DM, Stechman MJ. A decade of change in the uptake of parathyroidectomy in England and Wales. Ann R Coll Surg Engl. 2014;96(5):339-42.

13. Marcocci C, Bollerslev J, Khan AA, Shoback DM. Medical management of primary hyperparathyroidism: proceedings of the fourth International Workshop on the Management of Asymptomatic Primary Hyperparathyroidism. J Clin Endocrinol Metab. 2014;99(10):3607-18.

14. Peacock M, Bilezikian JP, Klassen PS, Guo MD, Turner SA, Shoback D. Cinacalcet hydrochloride maintains long-term normocalcemia in patients with primary hyperparathyroidism. J Clin Endocrinol Metab. 2005;90(1):135-41.

15. Peacock M, Bolognese MA, Borofsky M, Scumpia S, Sterling LR, Cheng S, et al. Cinacalcet treatment of primary hyperparathyroidism: biochemical and bone 
densitometric outcomes in a five-year study. J Clin Endocrinol Metab. 2009;94(12):4860-7.

16. Udelsman R, Akerstrom G, Biagini C, Duh QY, Miccoli P, Niederle B, et al. The surgical management of asymptomatic primary hyperparathyroidism: proceedings of the Fourth International Workshop. J Clin Endocrinol Metab. 2014;99(10):3595-606.

17. Udelsman $R$, Lin Z, Donovan P. The superiority of minimally invasive parathyroidectomy based on 1650 consecutive patients with primary hyperparathyroidism. Ann Surg. 2011;253(3):585-91.

18. Kluijfhout WP, Beninato T, Drake FT, Vriens MR, Gosnell J, Shen WT, et al. Unilateral Clearance for Primary Hyperparathyroidism in Selected Patients with Multiple Endocrine Neoplasia Type 1. World J Surg. 2016.

19. Witteveen JE, van Thiel S, Romijn JA, Hamdy NA. Hungry bone syndrome: still a challenge in the post-operative management of primary hyperparathyroidism: a systematic review of the literature. Eur J Endocrinol. 2013;168(3):R45-53.

20. Montenegro F, Ferreira G, lanhez L. Surgical treatment of tertiary hyperparathyroidism: the choice of procedure matters! World J Surg. 2008;32(8):1892-3; author reply 5-6.

21. Ferreira GF, Montenegro FL, Machado DJ, lanhez LE, Nahas WC, David-Neto E. Parathyroidectomy after kidney transplantation: short-and long-term impact on renal function. Clinics (Sao Paulo). 2011;66(3):431-5.

22. Schlosser K, Endres N, Celik I, Fendrich V, Rothmund M, Fernandez ED. Surgical treatment of tertiary hyperparathyroidism: the choice of procedure matters! World J Surg. 2007;31(10):1947-53. 
23. Jager MD, Kaaden S, Emmanouilidis N, Luck R, Beckmann JH, Guner Z, et al. Effect of incomplete parathyroidectomy preserving entire parathyroid glands on renal graft function. Arch Surg. 2011;146(6):704-10.

24. Kellum JA, Lameire N, Group KAGW. Diagnosis, evaluation, and management of acute kidney injury: a KDIGO summary (Part 1). Crit Care. 2013;17(1):204.

25. Kidney Disease: Improving Global Outcomes (KDIGO) Acute Kidney Injury Work Group. KDIGO Clinical Practice Guideline for Acute Kidney Injury. Kidney Int Suppl [Internet]. 2012; 2

:[1-138 pp.].

26. Ricci Z, Cruz D, Ronco C. The RIFLE criteria and mortality in acute kidney injury: A systematic review. Kidney Int. 2008;73(5):538-46.

27. Hoste EA, Clermont G, Kersten A, Venkataraman R, Angus DC, De Bacquer D, et al. RIFLE criteria for acute kidney injury are associated with hospital mortality in critically ill patients: a cohort analysis. Crit Care. 2006;10(3):R73.

28. Hoste EA, Bagshaw SM, Bellomo R, Cely CM, Colman R, Cruz DN, et al. Epidemiology of acute kidney injury in critically ill patients: the multinational AKIEPI study. Intensive Care Med. 2015;41(8):1411-23.

29. Kheterpal S, Tremper KK, Heung M, Rosenberg AL, Englesbe M, Shanks AM, et al. Development and validation of an acute kidney injury risk index for patients undergoing general surgery: results from a national data set. Anesthesiology. 2009;110(3):505-15.

30. Thakar CV, Arrigain S, Worley S, Yared JP, Paganini EP. A clinical score to predict acute renal failure after cardiac surgery. J Am Soc Nephrol. 2005;16(1):162-8. 
31. Brown JR, Cochran RP, MacKenzie TA, Furnary AP, Kunzelman KS, Ross CS, et al. Long-term survival after cardiac surgery is predicted by estimated glomerular filtration rate. Ann Thorac Surg. 2008;86(1):4-11.

32. O'Connor ME, Kirwan CJ, Pearse RM, Prowle JR. Incidence and associations of acute kidney injury after major abdominal surgery. Intensive Care Med. 2016;42(4):521-30.

33. Bucaloiu ID, Kirchner HL, Norfolk ER, Hartle JE, 2nd, Perkins RM. Increased risk of death and de novo chronic kidney disease following reversible acute kidney injury. Kidney Int. 2012;81(5):477-85.

34. D'Hoore E, Neirynck N, Schepers E, Vanholder R, Verbeke F, Van Thielen M, et al. Chronic kidney disease progression is mainly associated with non-recovery of acute kidney injury. J Nephrol. 2015;28(6):709-16.

35. Peacock M. Calcium metabolism in health and disease. Clin J Am Soc Nephrol. 2010;5 Suppl 1:S23-30.

36. Feng MG, Navar LG. Angiotensin II-mediated constriction of afferent and efferent arterioles involves T-type Ca2+ channel activation. Am J Nephrol. 2004;24(6):641-8.

37. Ermetici F, Filopanti M, Verga U, Passeri E, Dito G, Malavazos AE, et al. Estimated glomerular filtration rate by serum cystatin $\mathrm{C}$ correlates with cardiometabolic parameters in patients with primary hyperparathyroidism. Eur J Endocrinol. 2015;173(4):441-6.

38. Gil FZ, Silva VL, Cavanal MF, Malnic G. Effects of parathyroid hormone and calcium and their interrelationship on urinary acidification in the rat. Clin Sci (Lond). 1992;83(6):711-5. 
39. Zaladek Gil F, Nascimento Gomes G, Cavanal MF, Cesar KR, Magaldi AJ. Influence of parathyroidectomy and calcium on rat renal function. Nephron. 1999;83(1):59-65.

40. Massfelder T, Parekh N, Endlich K, Saussine C, Steinhausen M, Helwig JJ. Effect of intrarenally infused parathyroid hormone-related protein on renal blood flow and glomerular filtration rate in the anaesthetized rat. $\mathrm{Br} \mathrm{J}$ Pharmacol. 1996;118(8):1995-2000.

41. Verheyen N, Fahrleitner-Pammer A, Pieske B, Meinitzer A, Belyavskiy E, Wetzel J, et al. Parathyroid hormone, aldosterone-to-renin ratio and fibroblast growth factor-23 as determinants of nocturnal blood pressure in primary hyperparathyroidism: the eplerenone in primary hyperparathyroidism trial. $\mathrm{J}$ Hypertens. 2016.

42. Montenegro FM, Brandao LG, Ferreira GF, Lourenco DM, Jr., Martin RM, Cunha-Neto MB, et al. Transitory increase in creatinine levels after parathyroidectomy: evidence of another action of the parathyroid glands? Arq Bras Endocrinol Metabol. 2011;55(4):249-55.

43. Schluter H, Quante C, Buchholz B, Dietl KH, Spieker C, Karas M, et al. A vasopressor factor partially purified from human parathyroid glands. Biochem Biophys Res Commun. 1992;188(1):323-9.

44. Takenaka $T$, Inoue $T$, Watanabe $Y$. How the kidney hyperfiltrates in diabetes: From molecules to hemodynamics. World J Diabetes. 2015;6(4):576-82.

45. de Paula RP, Nascimento AF, Sousa SM, Bastos PR, Barbosa AA. Glomerular filtration rate is altered in children with sickle cell disease: a comparison between Hb SS and Hb SC. Rev Bras Hematol Hemoter. 2013;35(5):349-51. 
46. Lins LE. Renal function in hypercalcemia. A clinical and experimental study. Acta Med Scand Suppl. 1979;632:1-46.

47. Schwarz A, Rustien G, Merkel S, Radermacher J, Haller H. Decreased renal transplant function after parathyroidectomy. Nephrol Dial Transplant. 2007;22(2):584-91.

48. Montenegro F, Martin R, Lourenco DM, Jr. The parathyroids and the kidney: Fuller Albright revisited. World J Surg. 2009;33(2):246-7.

49. Peacock M. Primary hyperparathyroidism and the kidney: biochemical and clinical spectrum. J Bone Miner Res. 2002;17 Suppl 2:N87-94.

50. Egan RJ, Dewi F, Arkell R, Ansell J, Zouwail S, Scott-Coombes D, et al. Does elective parathyroidectomy for primary hyperparathyroidism affect renal function? A prospective cohort study. Int J Surg. 2016;27:138-41.

51. Levey AS, Stevens LA, Schmid CH, Zhang YL, Castro AF, 3rd, Feldman HI, et al. A new equation to estimate glomerular filtration rate. Ann Intern Med. 2009;150(9):604-12.

52. Kidney Disease: Improving Global Outcomes (KDIGO) CKD Work GroupKDIGO clinical practice guideline for the evaluation and management of chronic kidney disease. [Internet]. 2013.

53. Grams ME, Sang Y, Coresh J, Ballew S, Matsushita K, Molnar MZ, et al. Acute Kidney Injury After Major Surgery: A Retrospective Analysis of Veterans Health Administration Data. Am J Kidney Dis. 2016;67(6):872-80.

54. Wu HC, Lee LC, Wang WJ. Incidence and mortality of postoperative acute kidney injury in non-dialysis patients: comparison between the AKIN and KDIGO criteria. Ren Fail. 2016;38(2):330-9. 
55. Tang JA, Salapatas AM, Bonzelaar LB, Friedman M. Parathyroidectomy for the treatment of hyperparathyroidism: Thirty-day morbidity and mortality. Laryngoscope. 2018;128(2):528-33.

56. Kravietz AM, Buicko JL, Parreco JP, Lopez MA, Kozol RA. Thirty-day readmissions following parathyroidectomy: Evidence from the National Readmissions Database, 2013-2014. Am J Otolaryngol. 2018.

57. Evenepoel P, Claes K, Kuypers DR, Debruyne F, Vanrenterghem Y. Parathyroidectomy after successful kidney transplantation: a single centre study. Nephrol Dial Transplant. 2007;22(6):1730-7.

58. Montenegro FLdM. Paratireoidectomia total com autotransplante no tratamento do hiperparatireoidismo após transplante renal [Livre-docência]: Faculdade de Medicina da Universidade de São Paulo; 2014.

59. Tseng PY, Yang WC, Yang CY, Tarng DC. Long-term Outcomes of Parathyroidectomy in Kidney Transplant Recipients with Persistent Hyperparathyroidism. Kidney Blood Press Res. 2015;40(4):386-94.

60. Kristoffersson A, Backman C, Granqvist K, Jarhult J. Pre- and postoperative evaluation of renal function with five different tests in patients with primary hyperparathyroidism. J Intern Med. 1990;227(5):317-24.

61. Falkheden $T$, Ohlsson L, Sjogren B. Renal function in primary hyperparathyroidism. A follow-up study two to eleven years after surgery comprising 139 patients. Scand J Urol Nephrol. 1980;14(2):167-75.

62. Tassone F, Guarnieri A, Castellano E, Baffoni C, Attanasio R, Borretta G. Parathyroidectomy Halts the Deterioration of Renal Function in Primary Hyperparathyroidism. J Clin Endocrinol Metab. 2015;100(8):3069-73. 
63. Bollerslev J, Jansson S, Mollerup CL, Nordenstrom J, Lundgren E, Torring O, et al. Medical observation, compared with parathyroidectomy, for asymptomatic primary hyperparathyroidism: a prospective, randomized trial. J Clin Endocrinol Metab. 2007;92(5):1687-92.

64. Evan AE, Lingeman JE, Coe FL, Miller NL, Bledsoe SB, Sommer AJ, et al. Histopathology and surgical anatomy of patients with primary hyperparathyroidism and calcium phosphate stones. Kidney Int. 2008;74(2):223-9.

65. Levi M, Ellis MA, Berl T. Control of renal hemodynamics and glomerular filtration rate in chronic hypercalcemia. Role of prostaglandins, reninangiotensin system, and calcium. J Clin Invest. 1983;71(6):1624-32.

66. Pilz S, Kienreich K, Drechsler C, Ritz E, Fahrleitner-Pammer A, Gaksch M, et al. Hyperparathyroidism in patients with primary aldosteronism: cross-sectional and interventional data from the GECOH study. J Clin Endocrinol Metab. 2012;97(1):E75-9.

67. Kawata T, Imanishi Y, Kobayashi K, Miki T, Arnold A, Inaba M, et al. Parathyroid hormone regulates fibroblast growth factor-23 in a mouse model of primary hyperparathyroidism. J Am Soc Nephrol. 2007;18(10):2683-8.

68. Walker MD, Cong E, Lee JA, Kepley A, Zhang C, McMahon DJ, et al. Vitamin D in Primary Hyperparathyroidism: Effects on Clinical, Biochemical, and Densitometric Presentation. J Clin Endocrinol Metab. 2015;100(9):3443-51.

69. de Braganca AC, Volpini RA, Mehrotra P, Andrade L, Basile DP. Vitamin D deficiency contributes to vascular damage in sustained ischemic acute kidney injury. Physiol Rep. 2016;4(13). 
70. Goncalves JG, de Braganca AC, Canale D, Shimizu MH, Sanches TR, Moyses $\mathrm{RM}$, et al. Vitamin $\mathrm{D}$ deficiency aggravates chronic kidney disease progression after ischemic acute kidney injury. PLoS One. 2014;9(9):e107228.

71. Rolighed L, Rejnmark L, Sikjaer T, Heickendorff L, Vestergaard P, Mosekilde L, et al. Vitamin $D$ treatment in primary hyperparathyroidism: a randomized placebo controlled trial. J Clin Endocrinol Metab. 2014;99(3):1072-80.

72. Tucci JR. Vitamin $D$ therapy in patients with primary hyperparathyroidism and hypovitaminosis D. Eur J Endocrinol. 2009;161(1):189-93.

73. Moledina DG, Hall IE, Thiessen-Philbrook H, Reese PP, Weng FL, Schroppel B, et al. Performance of Serum Creatinine and Kidney Injury Biomarkers for Diagnosing Histologic Acute Tubular Injury. Am J Kidney Dis. 2017;70(6):80716.

74. Vaidya VS, Ozer JS, Dieterle F, Collings FB, Ramirez V, Troth S, et al. Kidney injury molecule-1 outperforms traditional biomarkers of kidney injury in preclinical biomarker qualification studies. Nat Biotechnol. 2010;28(5):478-85.

75. Klein SJ, Brandtner AK, Lehner GF, Ulmer H, Bagshaw SM, Wiedermann CJ, et al. Biomarkers for prediction of renal replacement therapy in acute kidney injury: a systematic review and meta-analysis. Intensive Care Med. 2018;44(3):323-36.

76. Huen SC, Parikh CR. Predicting acute kidney injury after cardiac surgery: a systematic review. Ann Thorac Surg. 2012;93(1):337-47.

77. Weiner DE. Public health consequences of chronic kidney disease. Clin Pharmacol Ther. 2009;86(5):566-9. 
78. Lameire NH, Bagga A, Cruz D, De Maeseneer J, Endre Z, Kellum JA, et al. Acute kidney injury: an increasing global concern. Lancet. 2013;382(9887):1709.

79. Li PK, Burdmann EA, Mehta RL, World Kidney Day Steering C. Acute kidney injury: global health alert. Kidney Int. 2013;83(3):372-6.

80. Silverberg SJ, Shane E, Jacobs TP, Siris E, Bilezikian JP. A 10-year prospective study of primary hyperparathyroidism with or without parathyroid surgery. N Engl J Med. 1999;341(17):1249-55.

81. Cheng SP, Lee JJ, Liu TP, Yang PS, Liu SC, Hsu YC, et al. Quality of Life After Surgery or Surveillance for Asymptomatic Primary Hyperparathyroidism: A Meta-Analysis of Randomized Controlled Trials. Medicine (Baltimore). 2015;94(23):e931. 


\section{APÊNDICES}

\section{Hospital das Clínicas da FMUSP}

Comissão de Ética para Análise de Projetos de Pesquisa - CAPPesq

\section{PROJETO DE PESQUISA}

Título: VARIAÇÕES DA FUNÇÃO RENAL APÓS PARATIREOIDECTOMIAS POR HIPERPARATIREOIDISMO PRIMÁRIO - RECADASTRAMENTO DE ACORDO COM EXIGÊNCIAS DO HCFMUSP

Pesquisador Responsável: Fabio Luiz de Menezes

Versão: 1

Montenegro

Pesquisador Executante: Marcelo Belli

CAAE: 03532612.4 .0000 .0068

Co-autores: Regina Matsunaga Martin, Giovanna Perantoni, Sergio Samir Arap, Climério Pereira do Nascimento Jr., Gilberto de Britto e Silva Filho, Ledo Mazzei Massoni, Lenine Garcia Brandão.

Finalidade Acadêmica: Não envolve obtenção de título acadêmico Instituição: HCFMUSP

Departamento: CIRURGIA - DISCIPLINA CIRURGIA DE CABEÇA E PESCOÇO

\section{PARECER CONSUBSTANCIADO DO CEP}

Número do Parecer: 53784

Data da Relatoria: 18/07/2012

Apresentação do Projeto: Trata-se de projeto que visa estudar de maneira retrospectiva as variações da função renal após paratireoidectomias por hiperparatireoidismo primário

Objetivo da Pesquisa: Estudar retrospectivamente a variação da função renal após as cirurgias para hiperparatireoidismo primário e suas relações clínico-laboratoriais, a fim de determinar fatores de risco para queda transitória e permanente da taxa de filtração glomerular de creatinina sérica

\section{Avaliação dos Riscos e Benefícios: A relação risco-benefício é positiva}

Comentários e Considerações sobre a Pesquisa: Trata-se de estudo retrospectivo sobre tema relevante, utilizando dados de prontuário hospitalar

Considerações sobre os Termos de apresentação obrigatória: Não há necessidade de Termo de Consentimento Livre e Esclarecido

Recomendações: Aprovar

Conclusões ou Pendências e Lista de Inadequações: Nenhuma

Situação do Parecer: APROVADO

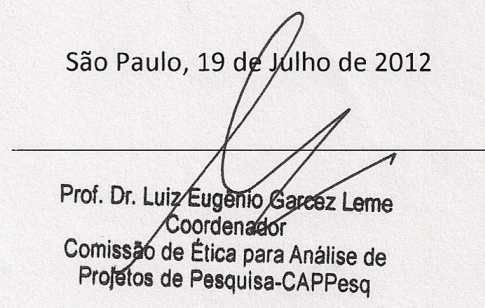

Rua Dr. Ovídio Pires de Campos, 225 - Prédio da Administração - 5o andar CEP 05403-010 - São Paulo - SP.

5511 2661-6442 ramais: 16, 17, 18 e 20 | cappesq@hcnet.usp.br 


\section{APÊNDICES}

\section{HOSPITAL DAS CLÍNICAS DA \\ FACULDADE DE MEDICINA DA Plotoforma USP - HCFMUSP}

\section{PARECER CONSUBSTANCIADO DO CEP}

\section{DADOS DO PROJETO DE PESQUISA}

Título da Pesquisa: VARIAÇÕES DA FUNÇÃO RENAL APÓS PARATIREOIDECTOMIAS POR HIPERPARATIREOIDISMO PRIMÁRIO- RECADRASTAMENTO DE ACORDO COM EXIGÊNCIAS DO HCFMUSP

Pesquisador: Fábio Luiz de Menezes Montenegro

Área Temática:

Versão: 1

CAAE: 03532612.4 .0000 .0068

Instituição Proponente: Hospital das Clínicas da Faculdade de Medicina da USP

Patrocinador Principal: Financiamento Próprio

\section{DADOS DA NOTIFICAÇÃO}

Tipo de Notificação: Outros

Detalhe: mUD

Justificativa: Mudança de Finalidade Acadêmica. O médico Marcelo Belli deseja realizar Doutorado

Data do Envio: 22/11/2013

Situação da Notificação: Parecer Consubstanciado Emitido

\section{DADOS DO PARECER}

Número do Parecer: 469.905

Data da Relatoria: 27/11/2013

Apresentação da Notificação:

O projeto será objeto de tese de doutorado.

Objetivo da Notificação:

O projeto será objeto de tese de doutorado do dr. Marcelo Belli sob orientação do pesquisador responsável.

\section{Avaliação dos Riscos e Benefícios:}

A notificação não implica modificação nas relações de risco.

Comentários e Considerações sobre a Notificação:

Não há comentários adicionais a respeito da notificação.

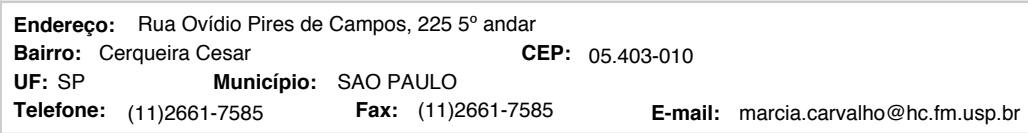

